Andrews University

Digital Commons @ Andrews University

\title{
Towards a Biblical and Missiological Model of Cross-Cultural Contextualization among Chinese Immigrants in "Barrio Chino" Duarte of Santo Domingo, Dominican Republic
}

Samuel Telemaque

Andrews Universeity, telemaque@andrews.edu

Follow this and additional works at: https://digitalcommons.andrews.edu/dmiss

Part of the Missions and World Christianity Commons

\section{Recommended Citation}

Telemaque, Samuel, "Towards a Biblical and Missiological Model of Cross-Cultural Contextualization among Chinese Immigrants in "Barrio Chino" Duarte of Santo Domingo, Dominican Republic" (2020). Dissertations DMiss. 1.

https://digitalcommons.andrews.edu/dmiss/1

This Dissertation is brought to you for free and open access by the Graduate Research at Digital Commons @ Andrews University. It has been accepted for inclusion in Dissertations DMiss by an authorized administrator of Digital Commons @ Andrews University. For more information, please contact repository@andrews.edu. 


\section{ABSTRACT}

TOWARDS A BIBLICAL AND MISSIOLOGICAL MODEL OF CROSS-CULTURAL CONTEXTUALIZATION AMONG CHINESE IMMIGRANTS IN "BARRIO CHINO” DUARTE OF SANTO DOMINGO, DOMINICAN REPUBLIC

by

Samuel Telemaque

Adviser: Bruce Bauer 


\title{
ABSTRACT OF GRADUATE STUDENT RESEARCH
}

\author{
Dissertation
}

\author{
Andrews University
}

Seventh-day Adventist Theological Seminary

\section{Title: TOWARDS A BIBLICAL AND MISSIOLOGICAL MODEL OF CROSS-CULTURAL CONTEXTUALIZATION AMONG CHINESE IMMIGRANTS IN "BARRIO CHINO” DUARTE OF SANTO DOMINGO, DOMINICAN REPUBLIC}

Name of researcher: Samuel Telemaque

Name and degree of faculty adviser: Bruce L. Bauer, DMiss

Date completed: May 2020

This study examines the challenge of contextualizing the gospel to Chinese immigrants in the Dominican Republic. Chinese people have been migrating to the Dominican Republic, mainly from Guangdong and Fujian, since the early 1960s. The immigrant population grew to appropriately 50,000 in the 1990s. In spite of this steady growth in population, Adventist leaders have not been able to influence Chinese immigrants to appreciate the gospel and to make decisions to begin a journey toward Christ. This study examines this missiological challenge. The purpose of this study is to develop a model of contextualization for presenting the gospel to Chinese immigrants that is biblically faithful and culturally relevant. The model is based on data obtained 
from interviews and participant observations I conducted in Duarte, known as Barrio Chino, in the city of Santo Domingo in the Dominican Republic. The data were gathered from 24 respondents consisting of six Chinese immigrants, six Dominican-born Chinese, six leaders from other denominations, and six Adventist church leaders. The data were analyzed for reoccurring themes, discrepancies, and nuances. After three cycles of analysis, eight reoccurring themes emerged from the data. These themes or findings are crisis, language, storytelling, social needs, pragmatism, hard work, values, and availability. Jackson Wu's theories of biblical exegesis and cultural contextualization were used to discuss the findings. The findings were framed within biblical and cultural themes. The cultural themes are relationship, fortune, and identity. On the other hand, the biblical themes are creation, covenant, and eschatology. The biblical and cultural themes were integrated to evoke responses of appreciation, acceptance, and decision for the gospel of Christ. The theories of conflict-competence-theory and critical realism were used to explain the inter-relationships between biblical and cultural themes in creating a model of contextualization that is biblically faithful and culturally sensitive. This study is relevant to church administrators, mission practitioners, students of mission, and teachers of mission. It exposes readers to theoretical and practical insights for engaging in contextualization that is biblically faithful and culturally appropriate to the Chinese immigrants' view of reality in the Dominican Republic. The study has the potential of helping Chinese immigrants develop a new appreciation of the gospel and to evaluate carefully biblical beliefs, values, teaching and practices in their journey toward Christ. 
Andrews University

Seventh-day Adventist Theological Seminary

TOWARDS A BIBLICAL AND MISSIOLOGICAL MODEL OF CROSS-CULTURAL CONTEXTUALIZATION AMONG CHINESE IMMIGRANTS IN "BARRIO

CHINO” DUARTE OF SANTO DOMINGO, DOMINICAN REPUBLIC

\author{
A Dissertation \\ Presented in Partial Fulfillment \\ of the Requirements for the Degree \\ Doctor of Missiology
}

by

Samuel Telemaque

May 2020 
(C) Copyright by Samuel Telemaque 2020

All Rights Reserved 


\title{
TOWARDS A BIBLICAL AND MISSIOLOGICAL MODEL OF CROSS-CULTURAL CONTEXTUALIZATION AMONG CHINESE IMMIGRANTS IN "BARRIO CHINO" DUARTE OF SANTO DOMINGO, DOMINICAN REPUBLIC
}

\author{
A dissertation \\ presented in partial fulfillment \\ of the requirements for the degree \\ Doctor of Missiology
}

by

Samuel Telemaque

APPROVAL BY THE COMMITTEE:

Adviser,

Bruce L. Bauer

Robert Folkenberg

Petr Cincala

Boubakar Sanou

Jim Park
Director, DMiss Program

Petr Cincala

Dean, SDA Theological Seminary

Jiří Moskala

Date approved 


\section{TABLE OF CONTENTS}

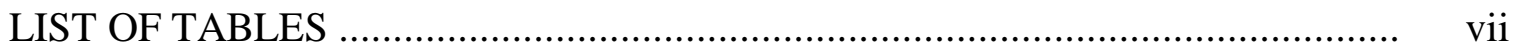

ACKNOWLEDGMENTS ………….................................................... ix

Chapter

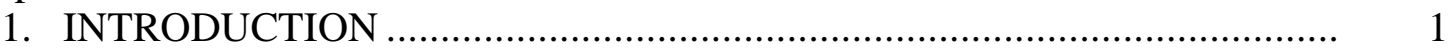

Background to the Problem ................................................................... 4

Problem Statement …………………………………………....... 9

Purpose Statement ........................................................................... 10

Research Questions ...................................................................... 10

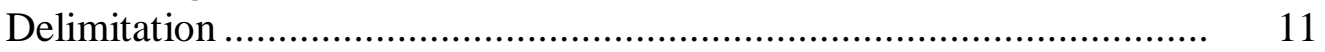

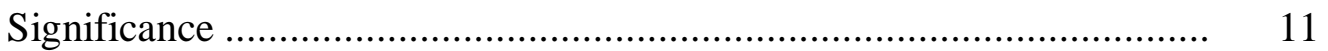

Missional Assumptions .................................................................... 11

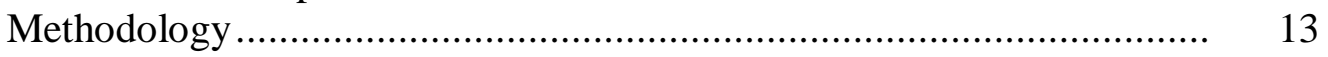

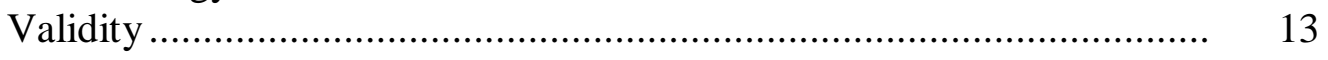

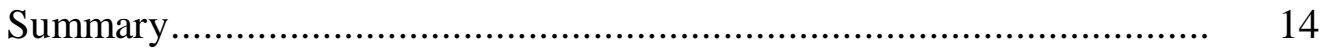

2. THE BIBLICAL FOUNDATIONS OF CONTEXTUALIZATION................ 15

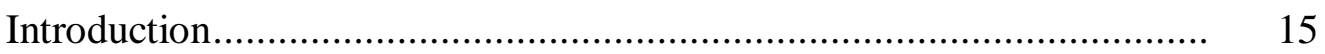

Definitions of Contextualization........................................................ 15

Historical Overview of Contextualization ............................................. 18

Biblical and Theological Foundation of Contextualization...................... $\quad 20$

Old Testament Models of Contextualization ..................................... 20

God's Earliest Attempts at Contextualization............................. 21

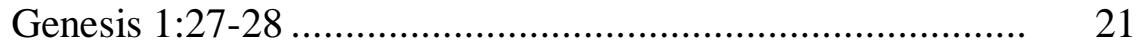

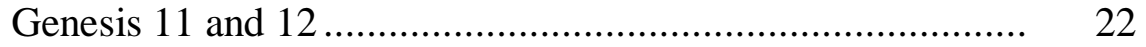

Sacrificial System .............................................................. 23

Animal Sacrifice …….................................................... 23

Human Sacrifice …….................................................. 23

Examples of Contextualization in the New Testament ...................... 24

Mark and Contextualization ..................................................... 25

Matthew and Contextualization................................................. 26

Luke and Contextualization .................................................... 27

John and Contextualization ....................................................... 29

Jesus and Contextualization .................................................... 30

Jerusalem Council and Contextualization .................................... 31 
Paul and Contextualization ...................................................... 33

Conclusion

3. THE THEOREICAL FRAMEORK, CONTEXT OF CHINESE IMMIGRANTS: ITS MISSIOLOGICAL SIGNIFICANCE FOR THE ADVENTIST CHURCH

Theoretical Framework

The Context of Immigrations: Its Missiological Significance for the

Adventist Church

Issues Confronting Chinese Immigrants

Educational Challenges

Cultural Challenges .....

Economic Challenges ................................................................ 49

Cultural Values ....................................................................... 52

Wealth Acquisition .................................................................... 52

Harmony ......................................................................... 53

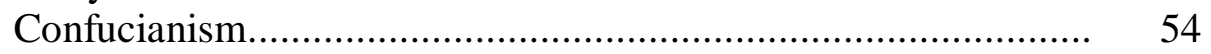

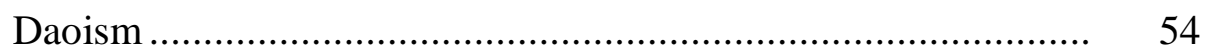

Buddhism ......................................................................... 55

Veneration of the Deceased ..................................................... 58

Missional Challenges Facing the Adventist Church ............................... 60

Missional Opportunities for the Church ................................................ 63

Acts of Kindness ..................................................................... 63

Consultation with Chinese Businesspersons..................................... 65

Language Classes ................................................................... 65

Collaboration with Persons with Dual Identities ............................. 66

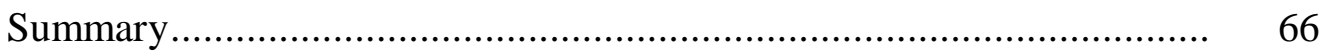

4. THE FIELD RESEARCH: ANALYSIS AND FINDINGS ........................... 68

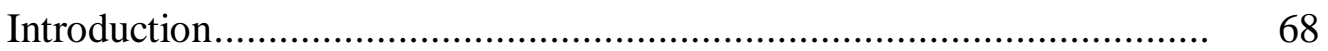

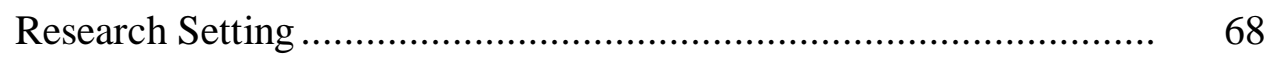

Data Collection and Analysis...................................................... 69

Research Findings ............................................................................ 69

Demographic Description of the Sample ......................................... $\quad 70$

Research Question 1: Influencing Factors ........................................ 73

Finding 1: Cognitive Dissonance .............................................. 73

Summary of Findings for Question 1 ...................................... 76

Research Question 2: Chinese Cultural Values ................................. 77

Finding 2: Meanings within Culture...........................................

Hard Work .................................................................... 77

Harmony .................................................................... 78

Respect ................................................................ 79

Dual Identity ….......................................................... 81

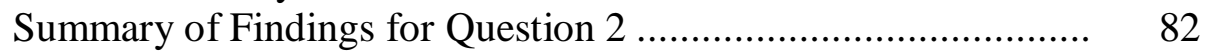


Research Question 3: Methods for Presenting the Adventist

Message.

Finding 3: Culturally-Sensitive Teaching and Ministry

Methods

Summary of Findings for Question 3

Based on Question 3: Findings 4-7 Relate to Chinese Immigrants'

Responses and Decisions .....

Finding 4: Language and the Deeper Experience.......

Summary of Finding 4

Finding 5: Pragmatism.

Summary of Finding 5

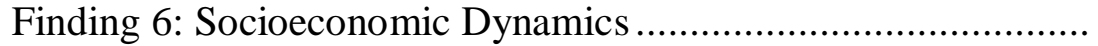

Summary of Finding 6

Finding 7: Saving Face and Preserving Harmony

Summary of Finding 7

Based on Question 3: Finding 8 Relates to Church Leaders'

Attitudes to Chinese Immigrants' Lack of Response to Adventist

Message.

Finding 8: The Unknown Factors.

Summary of Finding 8

Integration of Findings with Conflict-Competence-Based Theory.

\section{TOWARDS THE DEVELOPMENT OF A BIBLICAL AND MISSIOLOGICAL MODEL OF CONTEXTUALIZATION FOR} CHINESE IMMIGRANTS

Introduction.

Discussion of the Findings

Finding 1: Cognitive Dissonance

Finding 2: Meanings within Culture.

Hard Work.

Care and Respect ........................................................... 104

Harmony....

Dual Identity

Finding 3: Culturally-Sensitive Teaching and Ministry Methods...

Finding 4: Language and the Deeper Experience

Finding 5: Pragmatism. 
6. RECOMMENDATIONS FOR INSTITUTIONS, AND SUGGESTIONS

FOR FUTURE RESEARCH

Conclusions.

126

Recommendations for Institutions …………………....................... 129

Suggestions for Future Research........................................................ 134

Appendix

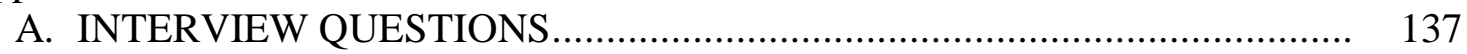

B. GOVERNMENT INFORMATION FORM............................................... 140

C. ANDREWS UNIVERSITY IRB APPROVAL_.......................................... 143

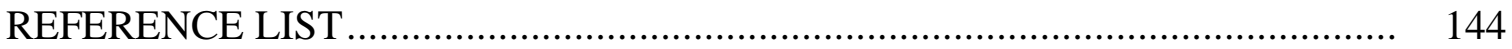

VITA 


\section{LIST OF TABLES}

1. Breakdown of 24 Informants by Language Proficiency ............................. 81

2. Average Age Range by Category ......................................................... 81

3. Participants' Gender Affiliation by Category .......................................... 82

4. Participants' Religious Affiliation or Ideology ......................................... 83 


\section{DEDICATION}

This dissertation is dedicated to my mother Merlin Mary Telemaque. She inspired me to pursue excellence with implicit faith in God; and to my father Jonathan Telemaque who instilled in me the value of perseverance, diligence, and a quiet pursuit of nobility. I especially dedicate this dissertation to my wife, Elvetha, and my two sons, Shemaiah and Kemuel, who unflinching supported me during my academic journey. 


\section{ACKNOWLEDGMENTS}

This dissertation reflects my implicit faith in God. I depended on Him to write this dissertation. To God be the glory who has been with me from the beginning to the end of this journey. I give the rest of my life to the expansion of the mission of God to all peoples_-including the Chinese Diasporas in Latin America.

My family supported me during my academic journey. Thanks to my wife, Dr. Elvetha Telemaque, for her patience, love, and tolerance during my long hours of study. Shemaiah, thank you son for sharing your apartment with me on four consecutive summers. Your dedication to your profession inspired me to press to the finish line. Kemuel, my son, you were truly an inspiration to me as I watched you pursue your doctoral degree in medicine with diligence and perseverance. Thank you, son.

I also acknowledge the moral support of my siblings. They include my two brothers Graham and Trevor, and three sisters Joyce, Vernel, and Verdan. I thank you sincerely for your moral support.

Many persons assisted me to gather the data for this study. I thank the administrators from the Dominican Republic Union Conference for giving me the permission to conduct the study in that Union. The administrators of Central Conference also assigned pastors to assist me with translation and ground transportation during my field research. Special thanks to Pastor Ernesto Cespedes, Chinese missionaries, and volunteers who assisted me to coordinate the field research.

Dr. Bruce Bauer, my committee chair, has given unprecedented guidance in designing and editing the dissertation. He also inspired me to pursue graduate studies in 
mission. Thank you, Dr. Bauer for your guidance, inspiration, and tolerance. Special thanks to Linda Bauer for assisting with the final editing of the dissertation.

Dr. Petr Cincala, my methodologist, assisted me with unique insights in areas of the structure and philosophical assumptions undergirding the study. Thank you, Dr. Cincala.

During my four years of study in the School of Intercultural studies at Andrews University, many teachers facilitated my learning experiences. Special thanks to Dr.Wagner Kuhn, Dr. Gorden Doss, Dr. John Matthews, Dr. Boubakar Sanou, Dr. Rick McEdward, Dr. Lester Merklin and Dr. Rudi Maier. These professors assisted me to think missiologically. They made my learning experiences memorable, spiritual, and doable. Teachers, you helped to make the journey possible. Thank you.

Special thanks to my editors for being so diligent in editing my work. My editors included Charissa Boyd, Camille Kurtz-Clayton and Averil Kurtz. Thank you for your patience with me.

This study program would not been possible without the financial support of the Inter American Division. The administrators of the Inter American Division, Dr. Israel Leito, Dr. Elie Henry and Dr. Filberto Verduzco, gave unflinching support to my study program. I thank these administrators for investing in my academic growth. To one and all I say thank you. 


\section{CHAPTER 1}

\section{INTRODUCTION}

Chinese people have been migrating to the Dominican Republic since the early 1960s. From that time, the Seventh-day Adventist Church in the Dominican Republic has not developed an appropriate model of contextualization to Chinese immigrants. There are no established Seventh-day Adventist churches among the Chinese people in the country. This phenomenon poses a missiological challenge for the Adventist Church in the Dominican Republic.

The seminal works of Randy Ki-Kwan and Yeow Beng Mah help to explain further the problem of contextualizing the gospel to Chinese immigrants. Yeow Beng Mah (2004), in Critical Contextualization of Chinese Folk Beliefs and Practices: Feng Shui as a Case Study, and Randy Ki-Kwan (1992), in A Cross-Cultural Study of the Collectivism and Individualism Paradigm: The Influence of Confucian Values on Conflict-Handling Behaviors of Male Graduate Business Students in Hong Kong and the United States explore this missiological challenge from different perspectives. Ki-Kwan argued that cultural differences determine how American and Chinese resolve conflicts. He indicated further that the Confucius values of harmony, hierarchy, and honor or face also influence Chinese approaches to conflict management. Thus, cultural differences between Chinese and American's influence approaches to conflict resolutions. 
Yeow Beng Mah (2004), on the other hand, contended that Singapore Christians are dubious of approaches for contextualizing their faith in Feng Shui. This is because Western missionaries taught the Singaporean Christians to view Chinese folk religions such as Feng Shui with suspicion and disdain. Christian ethnocentrism tends to be a deterrent to appropriate contextualization of the biblical text in cross-cultural contexts.

These seminal studies heighten the need for an effective and appropriate contextualization among migrant Chinese. However, none of these studies proposed a model for contextualizing in the literature the biblical message among Chinese in Hispanic communities. This is an area of deficiency. The literature focus is generally on differences between Chinese and Americans or Singaporeans (Hall 1976; Hofstede 1980; Hsu 1981; Ki-Kwan 1992; Mah 2004). However, very little is written on how to contextualize the biblical message culturally and appropriately to Chinese people in Hispanic communities.

Wen-Chu Chen (2008) in an ethnographic study entitled Dominican Attitudes toward Ethnic Chinese, the Minority's Efforts to Maintain Its Chinese Identity and Language Fluency, and the Unique Situation of Dominican explores relationships between Chinese and Hispanics in that country. This is the first serious attempt to examine Chinese identity and culture in the Dominican Republic. Wen-Chu Chen was primarily concerned about Hispanic attitudes towards Chinese and the Chinese people's struggles to maintain their identity in a Hispanic country. She contended that Dominicans consider Chinese to be like them in complexion and some eating habits. In the study she refers to a quote from an interviewee to illustrate the general perception Dominicans have of Chinese immigrants: "So you are like us, you [Chinese] eat plantanos (Plantain)" (23). 
Dominican views of the Chinese are not all positive. Chapter three of this study identifies some negative attitudes Adventist Church leaders have towards Chinese immigrants in the Dominican Republic. While negative views of Chinese immigrants can inhibit Adventist leaders' ability to evangelize Chinese immigrants, positive views such as the ones cited by Wen-Chu-Chen (2008) may help to facilitate contextualization. However, her seminal work fell short of addressing the question as to how to contextualize the biblical message to the Chinese people in Hispanic countries.

My study examined that challenge with a view to developing a suggested model of contextualization that is biblically faithful, culturally sensitive, and missiologically relevant.

The study consists of six chapters. Chapter 1 outlines the general trajectory of the study and consists of the problem and purpose statements, the significance of the study, its assumptions, its delimitation, and methods of data collection and analysis. The biblical foundation of contextualization is the focus of chapter 2. It explains how biblical writers used genres, symbols, metaphors, and prevailing cultural forms to illustrate biblical truth for specific audiences. Chapter 3 gives a detailed analysis of the issues confronting Chinese immigrants in the Dominican Republic and Latin America. It also explains the theoretic framework of the study. Chapter 4 identifies the results of the field research. These results or findings were discussed in chapter 5 .

A suggested model of contextualization emerges in chapter 5. The model integrates biblical themes with cultural themes to communicate the Adventist message appropriately to Chinese immigrants. Based on the discussions, recommendations, and suggestions for further studies are made in chapter 6. 
The appendices are the last section of the study. Information not found in the text is placed in the appendices for the readers' perusal. The information includes the research questionnaire, consent form, permission letter, documents related to Chinese missionaries, committee actions, and invitation documents. A brief background of the study helps to put the investigation into perspective in the next section

\section{Background to the Problem}

My interest in mission to the Chinese began in October 2011 when I was attending Inter-American Division meetings in Mexico. While riding in an elevator with Cesario Acevedo, president of the Dominican Union Conference, he said, "Samuel, I need help with the evangelization of the Chinese people in my Union!" I replied that I would give consideration to his request. It was from that moment that I began to reflect seriously on mission to the Chinese. I asked myself these questions: Where should I begin? What resources do I need? When should I begin the Chinese mission? Whom should I contact with reference to mission to immigrant Chinese in the Dominican Republic?

I began my quest for answers by contacting Rick McEdward, director of the Adventist Mission Study Centers at the General Conference, to inquire about possible approaches concerning mission to the Chinese people in the Dominican Republic. McEdward was very receptive to my inquiries and missional challenges and referred me to Samuel Wang for further consultation. At that time, Wang served as the General Conference Associate Mission Center Director for Asian Missions.

I made contact with Wang through email and explained my missional issues to him, asking for his guidance. He was willing to come to the Dominican Republic to assist 
with a missional framework to contextualize the gospel to migrant Chinese.

Before Wang's visit to the Dominican Republic, I invited him to speak at a Mission to the City Cross-Cultural Summit in April 2012 in Miami. Mission leaders from the Division's territories attended that Summit. At the Summit, Wang addressed delegates on the issue of a missional framework for sharing Christ with Chinese people. This presentation sparked further interest in a Chinese mission. Leaders with large Chinese immigrant communities also wanted to learn how to communicate the gospel to Chinese people. After the meeting, Wang consulted with leaders from Venezuela, Panama, Dominican Republic, Mexico, and Puerto Rico. This was the first consultation on Chinese mission in the Inter-American Division.

Wang visited the Dominican Republic in August 2013. While he was there, he assisted leaders in designing a missional framework for communicating the gospel to the Chinese migrant community. The missional framework included recruiting persons from China to work in the Chinese migrant community and in establishing a center of influence in the large Chinese community in Santo Domingo.

In January 2014, Sarah Kung arrived in the Dominican Republic from Guangdong, China. She worked among the Chinese immigrants to help bridge the gap between Adventists and the Chinese community. She also assisted Adventist leaders in establishing a Chinese Cultural Center in the city of Santo Domingo. However, this initial success in Chinese mission raised more questions than answers in my mind. I wanted to know more about the Chinese people. In 2014, I enrolled in the Doctor of Missiology program at Andrews University in order to continue my quest about how to address the problem of contextualizing the gospel for Chinese immigrant communities. I have since 
discovered some of the factors that triggered Chinese migration to the Dominican Republic.

The migration of Chinese people to the Dominican Republic began in the 19th century. According to studies by historians Jose Chez Checo and Mu Kien Adrina Sang (2009), Chinese migration to the Dominican Republic was part of a larger pattern of migration from China. The first Sino-Japanese war of 1894-1895 between the Qiny Dynasty of China and the Japanese Empire caused social and political upheavals in China. During this same period (1894-1895), there was a need for laborers in the industrial sectors in other countries. Thus, instability in China and the opportunities for economic growth in other countries were the primary causes for Chinese migration to the Dominican Republic. Chinese immigrants also viewed the Dominican Republic as a stopover on their way to the United States. However, many Chinese people settled in the Dominican Republic.

In 1950, Chinese immigrants began to establish small niches in the sector of Duarte in the city of Santo Domingo. However, there was a decline in Chinese migration to Duarte between 1960 and 1970. During this period of decline, many Chinese people became integrated into the culture of the Dominican Republic. By 1990, a new wave of Chinese immigrants to Duarte helped restore its culture and commercial vitality.

The Flora Rara Todos Foundation was organized on August 4, 2000 to promote Chinese education, culture, sports, and to honor the memory of Chinese ancestors. The Foundation envisions the development of new projects that include a theater, a museum of Chinese history, a Chinese language school, and a Chinese clinic dedicated to Eastern medicine. 
Chinese people in the Dominican Republic still view China as their home. One of the ways they remain connected to China is by honoring the memory of ancestors who migrated to the Dominican Republic. This aspect of the Chinese worldview continues among the Chinese people in the Dominican Republic. Other aspects of the Chinese worldview that have survived among Chinese immigrants include respect for the elderly, a strong family bond, and economic prudence. Worldview differences between Chinese immigrants and Dominican Hispanics provide a basis for perceiving the missiological problem.

There are differences in worldview between Chinese immigrants and Hispanics. Westerners view reality as either/or. Chinese view reality as holistic. The logic patterns are different. In addition, the Chinese consider time to be cyclical. This means that death is not a cessation of life, but rather, a continuity of life. On the other hand, Westerners view time as linear. This means that time moves forward. In addition, a person ceases to exist at death (Lakos 2010). Westerners and Chinese differ in their cognitive processes and perspectives of time. Another oblivious difference is language.

First generation immigrants coming from Guangdong Province speak Cantonese, while immigrants from Fujian Province and other areas of mainland China speak Mandarin. The differences between Cantonese or Mandarin and Spanish or Haitian Creole are the first difficulties encountered by Chinese immigrants upon their arrival in the Dominican Republic, where Spanish is the official language. However, because the Dominican Republic and Haiti are on the same land mass, Haitian Creole is also spoken in the Dominican Republic. Haitians are the largest immigrant population in the Dominican Republic and Haitian Creole account for $2 \%$ of the language spoken. The 
ratios of the other languages spoken in the Dominica Republic are Spanish 85\%, Chinese $.5 \%$, Japanese $.1 \%$, Italian .1\%, and others $11 \%$. These ratios illustrate the linguistic difficulty encountered by Chinese immigrants upon their arrival in the Dominican Republic. Research indicates that second and third generation Chinese immigrants tend to become frequent in Spanish. Chapter three in this research explores the issues of language differences and language acquisition (Misadi 2009).

Western culture tends to be built on Greco-Roman and Judeo-Christian ethical assumptions. Wan (2003a, 156) noted that the "Judeo-Christian value system and moral codes" have influenced the Western worldview of reality. Comparative anthropological studies of culture have observed that Western cultures (e.g., Spain, United Kingdom, Portugal) emphasize "guilt," but Eastern cultures (e.g., Chinese, Indians) emphasize "shame."

Westerners also process information differently from Easterners. Westerners tend to communicate the gospel with rationalistic arguments, lineal logic, and abstraction. Easterners are generally "relationally-oriented, co-relational thinking and pragmaticallyinclined" and express the gospel from this perspective (Wan 2003b, 8).

Easterners are conscious of the presence of evil forces and are often fearful of them. Many have witnessed manifestations of demonic activities, and some have been possessed by evil spirits. These spirit phenomena take place in an "excluded middle zone" (the region between the supernatural and the natural), which represents the habitation of demons and evil spirits. While Easterners are fearful of demons and evil spirits, Westerners often consider the existence of evil spirits to be "superstition" (Hiebert 2008, 144, 146). These differences in worldview affect how Hispanics present the gospel 
to Chinese immigrants. They also influence how Chinese immigrants respond to gospel presentations from Hispanics. Chinese immigrants appear to be responsive to a relational expression of the gospel, while Adventist Hispanic leaders tend to use rational arguments to share the gospel in the Chinese community. This incongruity between relational and rational expressions of the gospel is one of the issues affecting Chinese immigrants' acceptance of the Adventist message. The problem is fundamentally one of differences in worldview. These differences illuminate the research problem.

\section{Problem Statement}

There are differences in worldview assumptions between Chinese and Hispanics. Lakos (2010) and Wan (2013a) put these differences into perspective. The West (e.g., Hispanics, Americans, and Australians) believe in or value dualism, individualism, person choices, binary logic, propositional truth, clarity, and the correctness of the message. On the other hand, the Eastern (Chinese, Indians, etc.) worldview is characterized by integrated wholeness, fuzzy logic, holism, a cyclical notion of time, harmony, and naturalism (Lakos 2010). These differences in worldview impede the rate of evangelization of Chinese immigrants in the Dominican Republic. The Dominican Union Conference secretariat reports an average baptismal rate of 9,000 Hispanic persons every year over the last ten years by means of traditional evangelism. This form of evangelism is often held for one to three consecutive weeks. It emphasizes preaching, congregational singing, prayer, and public calls to repent and to follow Jesus by being baptized. This form of evangelism is not attractive to Chinese immigrants.

During the same ten-year period, the secretariat reports an average of eight Chinese baptisms in the Dominican Republic through traditional evangelistic approaches 
(Silvestre 2017). The Adventist traditional model of evangelizing Hispanics seems to be incongruent with the Chinese view of reality. The field research of this study indicates that a relevant model of evangelizing Chinese immigrants in the Dominican Republic should synchronize with their needs (e.g., language learning, orientation to local culture, and educational opportunities for their children, etc.), values, cognitive patterns, first language, and pragmatism. The traditional Adventist model of evangelization ignores the Chinese immigrants' view of reality.

\section{Purpose Statement}

The purpose of this dissertation is to develop a biblically faithful and culturally sensitive model of contextualization that synchronizes with the needs, cognitive patterns, relevant values and first or second language of Chinese immigrants to facilitate changes in their thinking, values, and decisions as they journey towards Christ and become incorporated into the Seventh day Adventist Church in the Dominican Republic.

\section{Research Questions}

1. What factors assist migrant Chinese to respond to the gospel and make decisions to follow Christ in other denominations in Duarte in the Dominican Republic?

2. What Chinese cultural values could facilitate Chinese understanding and acceptance of the gospel (e.g., following Jesus and incorporation into the Seventh day Adventist Church)?

3. How can the gospel be presented in culturally appropriate ways to Chinese immigrants in Duarte, Dominican Republic, in order to (a) facilitate their appreciation of that message and (b) foster decisions towards Christ? 


\section{Delimitation}

This study is confined to Chinese immigrants in Duarte in the city of Santo Domingo. Chinese born in the Dominican Republic are included in this study since they have a dual identity. The study focuses more on Chinese who migrated to the Dominican Republic during the last forty years. These immigrant Chinese tend to be more unresponsive to the Adventist message. On the other hand, Dominican-born Chinese tend to be more receptive to the Adventist message.

\section{Significance}

This study suggests a culturally- and biblically-sensitive model for contextualizing the Adventist message to Chinese immigrants in the Dominican Republic. This model of contextualization could be adapted to communicate the Adventist message to other people groups (e.g., Amerindians, Muslims, Mayas, and Aztecs) in Latin America. The principles, concepts, and theories undergirding this model of contextualization are relevant for equipping mission leaders in cross-cultural ministries. In addition, the knowledge from this study could be used to refocus church leaders' attention on migrant communities in their territory. For instance, the Chinese are the largest unreached migrant community in the territory of the Inter American Division. This study makes a significant contribution toward the evangelization of that migrant community. Finally, this study makes an invaluable contribution to Adventists' perennial dialogue on contextualization.

\section{Missional Assumptions}

I believe Jesus is the truth. He transcends all cultures. This means all cultures are 
judged by His values, principles, and teachings. In addition, Jesus modifies and changes cultures by teachings, principles, and values. I will not change or adapt the truth to cultural context.

Rather, I will use relevant cultural forms (genres, symbols, analogies) to explain the truth about Jesus from the perspectives of my audience (Schreiter 1985). The perspectives of the audience (Chinese immigrants) include their views of reality, languages, social, and emotional needs. The research of this study indicates that the Chinese view of reality and social needs should be considered in the development of a model of contextualization.

I believe sin exists in every culture. God reveals His attributes through nature, dreams, and cultural forms such as family, harmony, and symbols. These avenues of general revelation (nature, wealth, dreams, family, and harmony) can be used to facilitate the contextualization of objective truth (Jesus) to effect changes in the lives of Chinese immigrants and their cultures (Hesselgrave 1984; Hiebert 1984a; Hesselgrave and Rommen 2000; Bevans 2002; Moreau 2012; Wu 2015).

I define appropriate contextualization as a process of cultivating a context of trust, intimacy, and relational satisfaction through social, mental, and emotional ministries to expose Chinese immigrants in a culturally sensitive way to the deeds and words of Jesus in their journey toward Him and conversion to Him. The deeds of Jesus preceded His words in His ministry.

John Robb (1994) provided useful insights in the process of developing a strategy for the contextualization of people groups. He stated that after you have incarnated yourselves among people group to learn their beliefs, values, and needs, a strategy will emerge from the perceived needs of the people one 
wishes to come Christ. The worldview and needs of a people group should inform the strategy and ministry practices to that people group. There should be a skillful integration of Scripture, social actions, and power encounter in the implementation of a strategy to unreached people. (Robb 1994, 68)

\section{Methodology}

The convenience sample of my research consisted of 24 individuals within the age range of 18 to 65 . These individuals were comprised of six Chinese immigrants, six denominational leaders from others Christian religions, six Adventist Chinese members, and six Adventist administrators. These persons were selected for their potential insights into contextualization of the gospel to Chinese immigrants in Dominican Republic. Participants were invited to take part in this study by written invitations and personal contact via telephone (Plummer 1983). Interviews and observations were used to gather the data for this study.

The data was transcribed into approximately eighty pages of information. The analysis was carried out by coding the data for reoccurring themes, nuances, patterns, and differences. In the first cycle of coding, twenty-three themes emerged. However, in a second cycle of coding, the relevant themes were reduced from twenty-three to sixteen. In the final cycle of coding, the themes were reduced from sixteen to eight. These eight themes represent the research findings. The findings are discussed in the context of the theoretical frame of the study. Finally, the findings are displayed in tables, charts, diagrams, and figures (Creswell 2013).

\section{Validity}

In order to address translation issues during the interviews, the services of bilingual Chinese were employed to facilitate accurate transcription of the research 
questions from English to Mandarin. In addition, the services of bilingual Hispanics were used to transcribe questions from English to Spanish. During the semi-structured interviews, the Mandarin and Hispanic translators assisted me with the translation. I explained to the translators the intention of the questions and the need to communicate accurately to me the participants' responses to questions and follow-up probes (Creswell 2013).

Validity strategies were applied to negate any threats to the conclusion of the research. Four different groups of persons were interviewed to obtain multiple perspectives of reality.

In addition to the semi-structured interviews, there were unobstructed observations of models of contextualization to Chinese immigrants in other Christian congregations in the Dominican Republic. The participants were not aware of my personal observations. The data from my personal observations were used to make comparisons with data obtained from semi-structured interviews in order to triangulate the veracity of the findings (Creswell 2013).

\section{Summary}

This chapter explains the general trajectory of the study. First, it indicates the focus of each chapter in the study. Second, it describes the structural design, which includes the problem, purpose, assumptions, significance, delimitations, research questions, and the methodology of gathering and analyzing the data. These aspects of the study interact with each other to develop a culturally sensitive and biblically faithful model of contextualization to Chinese immigrants in the Dominican Republic. The next chapter provides a detailed analysis of the biblical foundation of contextualization. 


\section{CHAPTER 2}

\section{THE BIBLICAL FOUNDATIONS OF CONTEXTUALIZATION}

\section{Introduction}

God reveals Himself to people within prevailing cultural contexts. Throughout Scripture, many instances can be found on how God makes Himself known to people in meaningful and appropriate ways. He uses several means to contextualize His word within contemporary cultures in order to challenge old assumptions and transform people and their cultures. This chapter investigates principles, assumptions, and concepts of contextualization in the Bible.

This investigation provides answers to three questions: What are the biblical foundations of contextualization? How do Bible writers tailor their theological reflections to particular audiences so that the word is relevant in each specific context? How does the gospel challenge, change, or give new meanings to cultural themes? This last question is addressed in the third section.

The chapter is divided into three sections in order to answer these questions. Section one assesses definitions of contextualization, while section two gives a brief history of contextualization, and finally, section three focuses on the biblical foundations of contextualization.

\section{Definitions of Contextualization}

A theology of contextualization considers four critical variables. These variables 
are context, text, agent, and method. Context refers to the receptors' norms, rules, values, and customs. The text is the gospel—objective truth. The agents are persons who communicate the text in varied contexts. The final variable refers to the methods the agent uses to contextualize the text. All four variables interact with each other to formulate an appropriate definition of contextualization. The variable, which is given dominance, tends to define the meaning of contextualization (Moreau 2012, 183). Missiologists vary in the emphasis they give to specific variables in the contextualization process.

Missiologists define contextualization from different perspectives. For some, the context is of primary importance. Scott Moreau $(2012,36)$ defined contextualization as adapting the contents of the Christian message to make "it understandable to people of other cultural backgrounds." Moreau's definition gives priority to contextual analysis. The agent becomes immersed in the culture in order to understand cultural assumptions, values, beliefs, behaviors, and symbolic meanings. The agent's understanding of the context informs an appropriate method of contextualization.

On the other hand, David Hesselgrave and Edward Rommen (2000, 200) contended that "it attempts to communicate the works, Word and will of God that is faithful to His revelation." The Word takes priority over cultural context. Jackson Wu Chinese missiologist, also gave preeminence to the biblical text. He argued that exegetical contextualization allows missiologists to "locate the cultural context within the local biblical text. . . Contextualization via exegesis means listening for echoes of cultural [themes] within Scripture. Our goal is to exegete Scripture according to the author's original intent and at the same time to convey distinct emphases found within the 
contemporary setting" (Hesselgrave and Rommen 2015, 127).

Wu believed that the Bible has universal relevance to all cultural contexts (2015). While context may vary from place to place, human needs and concerns are generally the same in all cultural settings. Exegetical contextualization seeks to discover those cultural concerns or themes from within the biblical text.

Dean Flemming added a new dimension, that contextualization seeks to transform the culture by the Word. The Word critiques the culture in order to transform it. It is the prophetic voice within the culture. He says that contextualization refers to the "dynamic and comprehensive process by which the gospel is incarnated within a concrete, historical or cultural situation" $(2005,19)$.

In a seminar article, "Practical Contextualization: A Case Study of Evangelizing Contemporary Chinese," Wan defined contextualization from a more inclusive perspective. Contextualization is the "efforts of formulating, presenting and practicing the Christian faith in such a way that is relevant to the cultural context of the target group in terms of conceptualization, expression and application; yet maintaining theological coherence, biblical integrity and theoretical consistency" (2003b, 1). While Wan's definition tends to be inclusive of theories, culture, and biblical moorings, the contextualizers need to guard against syncretism.

Contextualizers should be careful not to impose cultural themes onto the biblical text. One must allow cultural themes to emerge from the biblical text. Wu's definitions of contextualization can lead to eisegesis or syncretism. Syncretism occurs when "what is drawn from local sources retains its original religious meaning, and is merely amalgamated with Christian elements" (Neil, Anderson, and Goodwin 1972, 580). 
Bruce Bauer (2005, 23), in a seminal article titled "Avoiding Syncretism by Doing Critical Contextualization," warned that over-contextualization or undercontextualization can result in syncretism. If the local culture is imposed upon the text, the communicator may be in danger of blending truth with error. Rather, Bauer and Flemming suggested that the text should critique cultural values and assumptions with a view to modifying, enhancing, or changing those cultural norms.

In this chapter, I define contextualization as an integrative process of using biblical themes (e.g., creation, covenant, and eschatology) to interpret cultural themes (e.g., relationships, work, fortunes, and dual identify) and to change, reinforce, or o give new meaning to those cultural themes in ways that are biblical and culturally sensitive to Chinese immigrants' needs, values, logic and patterns of decision making. I do this to facilitate their trust, intimacy, and relational satisfaction with the contextualizers and the gospel. Such a process can encourage the conversion of Chinese immigrant to Christ and their incorporation into the Seventh day Adventist Church. An integrative process of contextualization incorporates context, agent, methods, and Scripture. While Scripture takes preeminence, the other variables contribute to making the Scripture meaningful and pertinent.

\section{Historical Overview of Contextualization}

Western missionaries from the seventeenth to the twentieth centuries attempted three models of contextualization. The earliest missionaries, Catholic Jesuits (such as Mathew Ricci [1663] in China and Robert Nobili [1656] in South India), were sensitive to the cultural beliefs, practices, and values of native people. They advocated for accommodation and retention of cultural practices for new converts. In China, converts 
retained their worship of ancestors. This was considered an act of respect, rather than an act of worship. Likewise, converts in Indian retained their caste status since it was considered to have only social significance, not religious meaning. The accommodation model assumes that culture is inherently good. This approach to contextualization by the Jesuits can be described as uncritical.

By the 1800 s, the Franciscan view of contextualization became more prominent. The Franciscans argued that accommodation fostered "semi-pagan Christianity" (Neill 1964, 163). Francis of Assisi (1226) was the founder of the Franciscan Order. The Franciscans were advocates for a non-contextualized approach. They believed that Western cultures and values took precedence over local cultures.

Western missionaries viewed their cultures as superior to other peoples' cultures. This feeling of superiority led to an intolerance and rejection of the beliefs and the practices of Africans, Indians, Chinese, and others. In order to become Christians, natives were required to reject their cultures and accept Western culture. This non-contextualized model assumes the native culture is evil and that Western culture is good, which ultimately creates a distorted view of the gospel. Native people viewed Christianity as a foreign religion, irrelevant to their context. A more critical approach was required.

Paul Hiebert (1984b) proposed a critical contextualization model as an alternative to the models of accommodation and non-contextualization. Critical contextualization assumes that multitude realities are necessary in order to arrive at objective truth. These multiple realities can be uncovered through four steps: (1) an exegesis of the culture; (2) an exegesis of Scripture to uncover biblical perspectives related to the cultural issues being studied; (3) an evaluation of beliefs, values, and practices in the light of Scripture; 
and (4) the creation of new symbols to express Christian beliefs and values.

Critical contextualization gives preeminence to Scripture as the objective reality. However, this model also considers the relevancy of some elements of culture that may illuminate or illustrate objective truth. In addition, critical contextualization gives credence to the work of the Holy Spirit in human conversion and discipleship. This transformation takes place within hermeneutic communities, alongside fellow Christians who can contribute to one's understanding of Scripture. According to the philosophy of critical realism, multiple realities, exegesis of culture, Scripture, human responses, and hermeneutic communities contribute to our understanding of objective truth.

However, critical realism is based on Western assumptions. Ram Roy Bhaskar (2010) an advocate of this philosophy, held the view that reality cannot be known with any degree of certainty. It means, therefore, that critical realism is insufficient to explain contextualization from a biblical perspective. This chapter assumes that objective reality can be known from biblical perspectives. The rest of this chapter seeks to answer the question: What are the theological foundations of contextualization?

\section{Biblical and Theological Foundation of Contextualization}

The Old and New Testaments are accounts of how God contextualized the message of salvation for diverse cultures over more than sixteen hundred years. Bible writers used various genres, literary styles, idioms, and languages to communicate the gospel narrative within their specific contexts.

\section{Old Testament Models of Contextualization}

The Old Testament gives many examples of contextualization. For instance, God 
uses family metaphors, animal sacrifices, and languages to contextualize the story of redemption to His people.

\section{God's Earliest Attempts at Contextualization}

Genesis 1:27-28

From the very beginning, God sought to reveal Himself to His creation in ways that they could understand. Hesselgrave and Rommen $(2002,27)$ cited God's command in Gen 1:27-28 to be fruitful and fill the whole earth as an example of contextualization:

In a real sense, contextualization, culture and theology all have a simultaneous beginning. Along with the shafts of light that broke through the foliage of Eden on the first morning of human life, the silence was broken by voice of God. . . . Since that morning men and women have wrestled not just with the problems of knowing God and subduing the earth, but also with communicating what they have learned about divine will and their own environment.

God conveyed the message of universal blessing in a perfect culture. He created a culture of collaboration, multiplication, and universalization. In such a culture, He used the human reproductive organs as a metaphor to contextualize His message of universal blessing. The first human beings understood and obeyed the command to "be fruitful, and multiply, and replenish the earth" (v. 28). God tailored His message to the cultural context of multiplication, collaboration, and universalization. However, sin disturbed this perfect culture.

That disruption created resistance and distortion within God's redemptive story (Gen 3, 6). However, God continued to use analogy, metaphors, literary forms, and cultural norms to contextualize the redemptive story for people in different cultures. In the Old Testament, God revealed the plan of salvation through prevailing cultural forms 
such as fig leaves, offerings, languages, families, animals, the ark, sacrifices, and attempted human sacrifice.

Genesis 11 and 12

Genesis 11 and 12 portray the fact that God makes Himself known to all people in multiple languages. Genesis 11 describes the mono-linguistic culture of early civilization. Humankind wanted to congregate around one culture, one language, one city, and one reference point as one people. This monoculture was contrary to God's personal quality of multiplicity. God created language and cultural diversity to reveal multiple facets of Himself. Marvin J. Newell $(2016,32)$ put it tersely in his book Crossing Cultures in Scripture: "The grandeur of God can't be captured adequately in one cultural expression. Through the many and various cultural expressions, we begin to grasp and more deeply appreciate the character, awesomeness and multifaceted nature of God." Through diversity in cultures and languages, God conveyed that He wanted to be known to all people, in all languages, and in all places. He is the God of all families.

The mishpakhap formed the nucleus of Hebraic society. Walter Elwell (1996, 243) observed that "every individual found his/her place in society through the family and its extensions." The needs of family took precedence over the needs of individuals. The Hebraic people viewed families as sources of strength, wisdom, security, and blessings (Jer 2:3-4; Judg 6:15, 9:1; 1 Sam 16:5).

The author of Genesis used mishpakhap to convey the idea that God's redemptive plan includes every clan, family, people, and ethnicity in every geographic area. The family then and now is still the smallest unit in a society. Newell $(2016,36)$ captured the relevance of the family metaphor: "God who created humankind, endowed it 
with culture and then instituted cultural diversity, planned to bring blessing to the varied and numerous ethnicities."

\section{Sacrificial System}

The most contextualized example of the Old Testament is probably that of the sacrificial system. Human and animal sacrifices were common features of the Canaanite religion. The blood and organs of animals were offered to the god Baal.

Animal sacrifice

Canaanite religious practices influenced Israelite religion. God rejected some of those practices such human sacrifice and prostitution. On the other hand, using relevant Canaanite religious practices, God "established and ordained Israelite religious practices" (Rogers 2004, 92). For example, the Israelites were familiar with animal sacrifices as early as Abel's sacrifice of animals to God (Gen 4:4). The Canaanites gave new meaning to animal sacrifices. The Canaanites shed the blood of animals and humans to appease their gods. In contrast, God instructed the Israelites to shed the blood of animals to illustrate the substitutionary death of the Messiah (Isa 53:1-10).

The context did not shape the message. Rather, God gave new meaning to prevailing cultural norms. The Canaanites' context facilitated a renewed understanding of the story of redemption.

\section{Human sacrifice}

God's command to Abraham to offer up his son Isaac as a sacrifice reflected the Canaanite cultural practice. In Mic 6:7, the prophet asked, "Shall I give my firstborn for my transgression?" The prophet Ezekiel gave credence to Micah's question. In Ezek 
20:25, the prophet indicated that the Israelites offered their firstborn as a sacrifice to pagan gods. Child sacrifices were a common practice among the Canaanites. Ezekiel argued that such practices were also common among the Israelites. However, in Lev 20:2-5, child sacrifices were forbidden. This prohibition is expressed in v. 2: "Any Israelite or any foreigner residing in Israel who sacrifices any of his children to Molek is to be put to death."

Accordingly, the angel stopped Abraham from killing his son. However, he understood the meaning of this action. He was acquainted with Canaanites' offering children to their gods. While he was familiar with the prevailing culture, he attached new meanings to his action.

In Gen 22, God used child sacrifice to illustrate the story of redemption. The illustration foreshadowed the death of the Messiah. However, at the same time, it forbade the practice of child sacrifice.

This illustration of contextualization could not communicate the full meaning of the story of salvation. It communicated the Father's love, as well as the importance of human faith and obedience to God, but it was inadequate to atone for or rescue the sinner from sin. A child sacrifice can save neither a parent nor a child from the penalty of sin. However, God used this cultural practice to communicate that by the death of His Son, people from all nations would have access to salvation.

Examples of Contextualization in the New Testament

The New Testament features many prominent agents of contextualization. Each agent differs in his or her approach to communicating the gospel to their audience. Jesus, one of the major agents, is the very essence of contextualization. The Gospel writers, as 
well as Paul, Peter, and James, emulated some of His methods of contextualization. This section examines the dynamic interactions of the context, text, agents, and methods in the process of contextualization in the New Testament.

New Testament writers contextualized the gospel for specific audiences. For instance, the four Gospels were written in the context of the Greco-Roman world. The writers used literary styles (bibliography, historiography, and drama) of the GrecoRoman world to reveal to the story of Jesus. However, the Gospel writers each communicated the story of Jesus in different ways for particular readers. Flemming $(2005,240)$ saw the four Gospels as "contextualized documents."

\section{Mark and Contextualization}

Mark's writing reflects his target audience. He wrote primarily to a Gentile audience in the Greco-Roman world. Flemming $(2005,44)$ noted that Mark "retells the story of Jesus in a Palestinian Jewish heritage" within a Greco-Roman context. At the time of Mark's writing, Jewish Christians experienced severe persecution and atrocities from both Roman and Jewish leaders. In the Greco-Roman world, there was also as a general fear of demons and evil spirits. There were miracle workers everywhere in the Roman world. Mark contextualized the story of Jesus for this unique audience.

Mark used Greco-Roman literary styles to contextualize the story of Jesus for his audience. He employed the bibliographical and historical writing styles of the Romans to present Jesus as "the powerful, divine Son of God, yet He is also the suffering Son of Man who must die, humiliated, abandon even by God Himself on a Roman cross" (Flemming 2005, 241). 
Mark's writing inspired Jewish and Gentile Christians to remain faithful to Jesus in spite of persecution and their feelings of rejection.

\section{Matthew and Contextualization}

Matthew, in contrast to Mark, wrote to a Jewish audience. Matthew's audience was comprised of Jewish Christians. They were in a state of transition from Judaism to Christianity. In this state of in-betweenness, Jewish Christians were concerned about their Jewish heritage and the inclusiveness of God's mission to the Gentiles. This new reality created a cognitive dissonance within the Jewish Christian community. Matthew wrote to put the Jewish heritage and God's mission in the context of this new reality (Flemming 2005).

While Mark told the story of Jesus' supernatural power and suffering, Matthew tailored his story of Jesus to address the concerns of his audience. He sought to convince the Jewish Christians that "Jesus is the Messiah who fulfills the promises of the sacred Scriptures" (Flemming 2005, 246). Matthew argued that Jesus was the Messiah through whom all families of earth would be blessed (Gen 12:3; Matt 1:5-6, 4:15, 12:18-21).

Matthew contextualized his message to his audience by employing Jewish language and culture. He began his writing with reference to the genealogy of Jesus. All the historical mentors of the Jews were included in Jesus' genealogy (Abraham, David, Jacob, and so forth). Matthew cited Jesus' genealogy to communicate to Jewish Christians that "the story of Jesus is a continuation of Israel history" (Flemming, 2005, 246). He argued that the birth, ministry, death, burial, and resurrection of Jesus were all fulfillments of Old Testament prophecies (Matt 1:22). Matthew was also careful to mention significant Gentile characters such as Rahab and Ruth in Jesus' genealogy (Matt 
1:1-5). He wanted his readers to know Jesus' mission also included the Gentiles.

Matthew's approach to contextualizing his story of Jesus was relevant and helpful to the Jewish Christians. They believed that Jesus was the promised Messiah. They were also better able to explain to their Jewish critics the significance of Jesus in Israel's history and tradition. Matthew's new hermeneutic of God's mission from particular to universal gave the Jewish Christians the rationale for sharing the story of Jesus to the Jews first, and then to the Gentiles (Matt 10:5-6, 28:18-19). This contextualized story of Jesus transformed the thinking, attitudes, and missional perspective of the Jewish Christians (Flemming 2005, 247).

\section{Luke and Contextualization}

Unlike Matthew, a Jew writing to Jews, Luke wrote to a Gentile audience in the Greco-Roman world. Luke's story of Jesus synchronized with the cultural, social, and economic norms of the Hellenistic context. The Greco-Roman world was known for its social distinctiveness (Luke 1:52, 71, 2:1-2). The society consisted of the elite and nonelite, patrons and clients (Luke 7:1-10, 22-25), the righteously pure and the unclean.

Luke used several literary forms and cultural norms to contextualize his story of Jesus for the Gentile Christians. He used a Hellenistic bibliographic style to narrate Jesus' birth and infancy. The prologue in his writing is patterned after the historiography of the Greco-Romans (Luke 1:1-4).

Luke began his genealogy from Adam, as compared to Matthew, who began his genealogy from Abraham. According to scholars, Matthew portrayed the legal genealogy of Jesus from Abraham to Joseph in accordance with Jewish custom. On the other hand, 
Luke traced the biological genealogy of Jesus from Adam to Mary to appeal to his Gentile audience.

Luke portrayed Jesus in Greco-Roman urban scenes that were more familiar to his audience (Luke 7:36-50, 14:1-21). In addition, he cited many references from the Septuagint, the Greek Bible, to highlight the universal nature of Jesus' mission.

Luke addressed the assumptions undergirding social structures. Luke engaged his readers with the inclusiveness of Jesus' mission. In Luke 14:12-14 and Luke 15:4-30, he used stories to illustrate how Jesus engaged the patron and client system to convey the inclusiveness of mission. He argued that Jesus provides salvation for all people. All are invited to repent and receive forgiveness. Luke contended that salvation was for the elite and non-elite, client and patron, rich and poor, man and woman. Jesus was not adapting his message of inclusiveness to the culture. Rather He used Scripture to give new meaning to prevailing cultural forms. Luke 14 and 15 illustrate how Jesus reinterpreted prevailing norms to communicate the biblical meaning of humility and salvation.

It was the cultural norm in the Roman Empire for exaltation to precede humility. He transformed old assumptions. Luke's writing portrayed the fact that humility comes before exaltation (Luke 14:10-11). Luke also portrayed salvation in reversal. The prodigal returned home, and a party was held in his honor. However, the son who had remained at home was furious that he had never been honored (Luke 15). This illustrated how all who are last can become first, and some who are first can become last (Luke 13:30).

Luke challenged his Greco-Roman Christians to new patterns of thinking. Flemming put it tersely: "Luke not only anticipated the universal mission of the church, 
but he called his audience to embody a gracious and inclusive fellowship that reaches beyond ethnic, religious and status quo [of the Greco-Roman world]" (2005, 253).

\section{John and Contextualization}

John wrote to Jewish and Gentile Christians. Marianne Meye Thompson (1992, 372-73) describes John's audience as a "new generation of Christians." They were not eyewitnesses to the signs and miracles of Jesus. They were fearful of persecution and anxious about the future of the Christian church and its mission in the Greco-Roman world (John 15:18-24, 16:1-4). These Christians needed a fresh glimpse of Jesus. John used Jewish and Gentile images to repackage his story of Jesus to a new and skeptical audience. He wrote to convince them that Jesus was the Christ, the Son of God, and by believing one would have eternal life in His name (John 20:30-31).

John made many references to Jewish themes (Moses, Abraham, the Passover, and other festivals) to appeal to his Jewish audience. He used symbols with deep Jewish roots and universal appeal to contextualize his story of Jesus. The symbols of the temple, the tabernacle, the bread, and the slain lamb were familiar to the Jewish people. He used these symbols to convince Jewish Christians of His identity. For example, Jesus said, "I am the Bread that came down heaven" (John 6:41).

Using a masterful technique, John introduced Jesus to his audience as the Word or Logos. This metaphor was full of meaning in the religious and philosophical culture at the time of John's writings. Greek Stoic philosophers understood Logos as "the principle of divine reason that stood behind the cosmos" (Flemming, 2005, 260). The Jews understood Logos to be the preexisting wisdom of God and was useful in conveying the preexisting nature of Jesus. John used the word Logos because it resonated with both 
Jewish and Hellenistic cultures. Flemming (2005) observed that "John draws from a wide range of symbols to enable him to communicate [his story of Jesus] to Jews and non-Jew alike" (261).

\section{Jesus and Contextualization}

Jesus used appropriate images to contextualize His message. John's writing cites many examples of Jesus' contextualized approaches. Jesus used water to theologize on the meaning of living water (John 4:4). In John 6:6, Jesus used bread to communicate that He Himself was the Living Bread. The healing of a blind man was an occasion for Jesus to proclaim Himself as the Light of world, in contrast to spiritual darkness (John 9:1-34). He used the image of the death and resurrection of Lazarus to communicate His message of eternal life (John 11:1-44). Jesus declared, "I am the resurrection, and the life" (John 11:25). Flemming $(2005,260)$ summarized this idea: "Jesus uses different approaches with different people. He tailors the particular language and imagery to communicate the offer of salvation to the occasion."

At the same time, Jesus gave evidence that His audience also consisted of Gentiles: "Other sheep I have, which are not this fold" (John 10:16; see also 11:52, 12:20-21). He used universal symbols such as life, light, darkness, water, birth, and the vine and branches to contextualize his story for Gentile Christians. These symbols were familiar to Gentile Christians and heathens.

Jesus was the complete self-revelation of God among us. He became human to contextualize His message of salvation. Jesus "was made flesh and dwelt among us" (John 1:14). He was called "Emmanuel, which being interpreted is, God with us" (Matt 1:23). In Phil 2:7, Paul refers to Jesus as being "made . . of no reputation, . . made in 
the likeness of men." These verses illustrate how Jesus incarnated Himself among people to communicate the story of redemption in relevant and appropriate ways.

Gorden Doss (2015) articulated a unique perspective of the incarnation of Jesus:

"The Creator became Jesus of Nazareth, who was not a generic human being but a member of a particular cultural group, living in a particular village, in a specific time period" (7). His lifestyle may have been different, but the incarnation would have remained the same.

Jesus became human to disclose that His Father was "full of grace and truth" (John 1:14). He became human to make His message relevant and appropriate for human beings. This is the foundation of contextualization. The Messiah took onto Himself the nature of His intended audience to identify with and transform His audience. This transformation led to the birth, growth, and global expansion of the Christian Church.

After the ascension of Jesus, the Holy Spirit guided the apostles' approaches to communicating the gospel to the Gentiles. The Jerusalem Council reflected the influence of the Holy Spirit on the process of contextualization.

\section{Jerusalem Council and Contextualization}

The Jerusalem Council addressed the means or agent of salvation. The Jews argued that circumcision was necessary to receive salvation. Therefore, they resisted the conversion of Gentiles to Christianity without circumcision. On the other hand, Paul contended that circumcision was not necessary for salvation. There arose a sharp contention between Paul and the Jews on the legitimate means of salvation. Paul brought this theological issue to the Jerusalem Council for analysis and resolution. 
The Jerusalem Council consisted of Jewish leaders. These leaders substituted the symbol of salvation for the means of salvation. The Holy Spirit revealed to them that "through the grace of the LORD Jesus Christ we shall be saved, even as they" (Acts $15: 11)$.

At the Council, Peter and James confessed their new understanding of the Agent of salvation. Both leaders came to a new understanding of salvation-God had given salvation to all people (Jews and Gentiles) without circumcision. God used symbols to communicate the story of salvation for all people.

Peter cited his experiences with Cornelius when God used a vision of unclean animals to convey to him the universal scope of salvation. The diverse composition of animals meant salvation was for "whosoever" and there is no "partiality" (John 3:16; Acts 10: 34-35) with God.

James cited God's universal perspective in the Old Testament (Amos 9:11). In the Old Testament, the symbol of "broken walls" conveyed restoration of God's plan of salvation to all people. Erich Sauer (1972), in the book From Eternity to Eternity, identified three critical issues in Amos 9:11-12. The issues relate to the meanings and significance of James' statement to resolve the debate at Jerusalem council. James' statement implies issues of content, extent, and time. James quoted from Amos to convey the fact that the content of the gospel remains the same from to Abraham to the early church and beyond (Gen 3:15, 9:27, 12:1-3; Rom 10:6-8). The gospel has always been by grace through faith in the coming Messiah. James affirmed this belief.

James also confirmed that salvation has always been for both Jews and Gentiles. The inclusiveness of God's kingdom, incorporating Jews and Gentiles, is imbedded in the 
stories of Melchizedek, Jethro, Zipporah, Balaam, Rahab, Ruth, and possibly the Gibeonites, the Rechabites, and Jonah. These stories illustrate the universal scope of God's mission.

God used symbols familiar to Peter and James to convey His original plan of salvation for all. The symbols helped them to grasp the scope and means of salvation.

This method of contextualization effected three significant changes. First, Peter and James gained a deeper understanding of salvation. They became advocates of God's universal story of redemption. Second, circumcision was not required to receive salvation. It was also a learning experience for Paul. He learned that God uses dreams and symbols to clarify leaders' understanding of the gospel. He may also have learned new ways of tailoring the gospel the Gentiles.

\section{Paul and Contextualization}

Paul tailored his theologizing to the worldview of the Greco-Romans. He was a Hellenistic Jew. At the time of his writings, most of the population in the Mediterranean world spoke Greek. Therefore, he wrote his letters in the literary styles and language of the Grecians. Glen Rogers $(2004,105)$ confirmed, "By utilizing Paul the way he did, God was meeting the cultural needs of believers in that time and place. . . The Jewish ways

of thinking were replaced with culturally appropriate ways of thinking, communicating and doing."

Paul used innovative means to communicate the gospel in the Greco-Roman world. Flemming $(2005,106)$ observed that Paul personalized "his interpretation of that atoning death [of Jesus] to fit the needs and circumstances of his audience." The Apostle Paul was always cognizant of the diversity of his audience. He expressed his philosophy 
of contextualization in these apt words: "To the weak became I as weak, that I might gain the weak. I am made all things to all men, that I might by all means save some" (1 Cor 19:22).

However, while Paul displayed great flexibility in his theologizing, he was always faithful to the "moorings" of the story of redemption. He used metaphors, genres, idioms, and cultural forms to make the story of redemption relevant to people within their cultural contexts. The listeners understood the story of redemption, and it transformed their lives and cultures (Flemming 2005, 117). The methods of contextualization may vary from context to context, but the story of redemption remains the same.

A famous example of Paul's adaptability took place during his visit to Athens. He observed that the city was full of idols. He also noted that the elite of the city, both Athenians and foreigners, devoted significant time to discussing new ideas. He studied his audience in the synagogue and in the marketplace. He walked through the city to observe its proverbs, statutes, and values. Paul examined all their objects of worship. One such monument contained the inscription, "To the Unknown God" (Acts 17: 23). Paul used the inscription to contextualize his message to the Areopagus council. This elite group of scholars and philosophers wanted to hear his "new teaching." He cited a literary line from an Athenian poet: "We are also his offspring" (v. 28), to contextualize the story of creation and redemption to his audience.

The message effected changes in some of the hearers. "When they heard of the resurrection of the dead, some mocked: and others said, 'We will hear thee again of this matter" (Acts 17:32). Some of the people became followers of Paul and believed. Among 
Paul's converts were Dionysius, a member of the Areopagus, and also "a woman named Damaris, and others with them" (v. 34).

\section{Conclusion}

The text is a critical variable in the process of contextualization. It is the objective reality which should not be changed or modified to facilitate a specific model of contextualization. The text changes agents' assumptions, and peoples' cultural norms, beliefs, values, and customs. Indeed, it changes their hearts.

However, other variables need to support the text in the process of contextualization. First, the context determines how the text is communicated to the intended audience. The agent needs to know relevant aspects of the audience's history, values, beliefs, traditions, and historical mentors. By understanding these pertinent aspects, the agents can use appropriate values, norms, and historical data from within the context to assist him/her to tailor the text in culturally appropriate ways in order to transform the audience and its culture. The method of contextualization emerges from an assessment of the context. This means that methods of contextualization vary from context to context. However, the contents of the text remain the same.

This chapter assessed the biblical views of contextualization in the Old and New Testaments. Throughout the Bible, the agents of contextualization demonstrate an understanding and appreciation for the audiences to whom they communicated the story of redemption. The next chapter gives an analysis of the context of Chinese immigrants in the Dominican Republic. It also assesses the missiological significance of those contextual issues for the Adventist Church in the Dominican Republic. 


\section{CHAPTER 3}

\section{THE THEORETICAL FRAMEWORK, CONTEXT OF CHINESE IMMIGRANTS: ITS MISSIOLOGICAL SIGNIFICANCE FOR THE ADVENTIST CHURCH}

\section{Theoretical Framework}

This chapter examines three issues: The theoretical framework of the study, issues affecting Chinese immigrants, and the missilogical significance of those issues. The process of moving to a new country affects Chinese immigrants in many ways. Immigrants often experience isolation, identity crisis, communication challenges, overwork, tension from financial struggles, intergenerational conflicts, insecurity, discrimination, and educational difficulties. The theoretical framework seeks to explain an appropriate and effective strategy for achieving relational satisfaction, trust, and competence with immigrants.

The theoretical framework of my study is based on the theories of critical realism, biblical and cultural exegesis, and conflict-competence-based theory. Daniel Canary and Brian Spitzbereg (1987) used a conflict-competence-based theory to explain appropriate modes of communication between Chinese and Americans. The authors found that the Chinese were receptive to American modes of communication that were appropriate to their view of reality. Conversely, the Americans responded favorably to effective patterns of communication from the Chinese. The authors explained their conflict-competencebased theory in an article entitled "Appropriateness and Effectiveness of Perceptions of 
Conflict Strategies. ” This article was first published in the Human Communication Research Journal.

The literature confirms that specific dialogue strategies enhance relational outcomes. Canary and Spitzberg $(1987,630-49)$ studied 140 students enrolled in a southeastern technological university to examine the influence of strategic dialogue on competence and relational outcomes. In conflict, individuals often choose from three dialogue strategies: avoidant, distributive, and integrative. Integrative dialogue promotes relational objectives. On the other hand, distributive tactics pursue individual goals to the exclusion of partners' goals. In contrast, avoidant tactics attempt to avert direct conflict.

The research reveals that integrative dialogue relates positively to perceptions of competence, but distributive and avoidance relate negatively to perceptions of competence. Canary and Spitzberg (633) found that competence is strongly and positively associated with evaluations of an appropriate and effective conflict strategy." If the conflict strategy, such as integrative dialogue, promotes trust, intimacy, and relational satisfactions then persons in a dialogue are perceived as competent.

Competence is more than a quality of the dialogue. According to Canary and Spitzberg $(1987,630,633)$, it is related to perceptions of effectiveness and appropriateness. Appropriate communication avoids "violation of relationally or situationally sanction rules." Conversely, effective communication "achieves valued objectives of interactants." Research confirms that competence is generally associated with the appropriateness and effectiveness of strategic tactics or dialogues. In other words, the use of an appropriate strategy to solve conflict is perceived as competence. A perception of competence has positive influence on relational outcomes. Relational 
outcomes include trust, mutual control, intimacy, and satisfaction.

These components interact with each other to facilitate wholesome relationships. Researchers argue that relationships are functional to the degree that partners trust each other, agree on who has the rightful power of influence, share knowledge about one another, like what they know about each other, and experience satisfaction with their partners. An integrative strategy leads to positive perceptions of competence, and positive perceptions lead to satisfactory relationships.

This conflict-competence-based theory has been used to explain how to contextualize American values for Chinese people in China. However, there is little evidence that this conflict-competence-based theory has been applied to the contextualization of the Adventist message for Chinese immigrants in Hispanic countries such as the Dominican Republic. I propose using this conflict-competence-based theory to explain a model of contextualization relevant to Chinese immigrants in a Hispanic context.

The conflict-competence-based theory will assist me in answering the overarching research question: How can the Adventist message be made culturally appropriate for Chinese people in Duarte, Santo Domingo, Dominican Republic, so that they may be receptive to the message, experience conversion, and come to faith in Christ? This question implies a context, an agent, and an objective truth. The theory explains the relationship between the agent and the context, but it does not explain the objectivity of the biblical text. The theory of critical realism explains the link among the objective truth, the context, and the agent.

Hiebert's (1984b) theory of critical realism explains that the Bible is objective 
truth. However, critical realism acknowledges that the agent or contextualizer cannot totally grasp ultimate truth as revealed in Scripture. Contextualizers seek new ways to amplify the truth. First, they attempt to understand the cultural context. Critical realism assumes that some truth (general revelation) exists in every culture. Second, contextualizers look for insights within the culture and the "hermeneutical community" that may help to amplify biblical truth.

Jackson $\mathrm{Wu}$ is a Chinese missiologist. He teaches theology and missiology for Chinese church leaders in Asia. Two of his seminal works are Saving God's Face: A Chinese Contextualization of Salvation through Honor and Shame and One Gospel for All Nations. In One Gospel for All Nations (2015), he cited two kinds of contextualization. First is exegetical contextualization. The contextualizer examines Scripture from the perspective of culture. This means locating cultural themes within Scripture. This kind of exegetical contextualization may do three things: (1) redefine cultural meanings, (2) reinforce existing meanings, and (3) reject existing meanings. In this type of contextualization, the agent does not superimpose culture themes onto the Bible. This would be eisegesis — a way of injecting foreign ideas into Scripture. In exegetical contextualization it means "seeing what is true of our cultural context within the Bible itself' (Wu 2015, 13). In other words, in this approach, one reads the Scripture from the viewpoint of one's culture. Persons in different cultures tend to identify or ignore different cultural themes. The Western reading of Scripture tends to focus on cultural themes of individualism, privacy, and guilt. On the other hand, Chinese people more readily notice and relate to portions of Scripture that emphasize shame, 
honor, family, and collectivism. A person's cultural orientation influences what he or she sees in Scripture.

Second, cultural contextualization can refer to an exegesis of culture from a biblical perspective. The contextualizer evaluates culture by the moral and ethical standards of Scripture in order to determine their similarities or differences with the biblical meaning of those themes (Wu 2015, 13).

Exegetical contextualization analyzes cultural themes in Scripture, but cultural contextualization examines biblical themes within the culture. Wu found that "a key distinction between exegetical and cultural contextualization is the use of lenses. The former uses culture as a lens to interpret the Bible. The latter uses the Bible to interpret or assess culture" $(2015,109)$. These two methods of contextualization assist the contextualizer in finding nexuses between culture and Scripture.

For instance, when the biblical meaning of a cultural theme synchronizes with the cultural meaning of that theme, the possibility for contextualization exists. Wu (2015) and Wan (2011), prominent Chinese missiologists, advocated a theoretical frame that may guide the design of a model of contextualization. The theoretical frame consists of biblical theology, cultural themes, and missional applications that effect transformation in human lives.

Wu made a distinction between systematic theology and biblical theology. According to him, systematic theology limits the holistic scope of the gospel. It tends to restrict the gospel to specific scriptural passages. Conversely, biblical theology frames the gospel within the grand narrative of Scripture. "By keeping in mind the grand 
narrative of Scripture, we can better discern and balance the various themes that belong more fully to the biblical gospel" (Wu 2015, 29).

These "various themes" are classified as firm and flexible themes. Firm and flexible themes give the gospel holistic and adaptable perspectives. Firm themes are consistent theological centers/pillars that frame the gospel. They redefine or reinforce cultural themes. Wu argued that three firm themes shape the grand narrative of the gospel. These are creation, covenant, and kingdom. They provide the theological framework for understanding the holistic dimension of the gospel.

Flexible themes are adaptable to various cultural contexts. These are themes such as curse/blessing, honor/shame, redemption, justification, adoption, sacrifice, eschatology, law, and grace. While flexible themes such as honor/shame are more comprehensible for Chinese immigrants, themes of curse/blessing may be more understandable to Hispanics.

Wu's books reflect evangelical theological assumptions. He advocated kingdom theology as one of the theological centers of Scripture. The role of the kingdom tends to supersede the role of the church. He put it this way: "The gospel proclaims, Christ is King. This announcement is relevant to every culture of the world. Christ is King over every context" (Wu 2015, xxi). While this is true, the role of the church in the process of contextualization needed greater prominence in his books.

Contextualization is the interconnection of biblical themes with appropriate cultural themes in order to facilitate a culturally sensitive and biblically faithful expression of the gospel. Wu proposed that appropriate cultural themes can be used "to faithfully frame and explain biblical presentation.... The goal is to interconnect the 
biblical text and the cultural text" $(2015,97)$. Scripture clarifies or determines the significance of a cultural theme as a means of illustrating biblical meanings, principles, and teachings. The Bible is the final authority.

Wu maintained that cultural themes may be assessed from the perspectives of covenant, creation, and kingdom. He found that relationship, the world, and authority are "framing ideas for contextualizing the gospel to Chinese" $(2015,99)$. They are major themes in Chinese culture. According to $\mathrm{Wu}$, the theme of relationship may relate to the covenant motif. Similarly, world can relate to creation, and authority may be related to kingdom.

Wu's theoretical model is useful to my discussion of a biblically and culturally sensitive model of contextualization for Chinese immigrants. It frames the gospel around major biblical themes. Wu identified and interpreted the gospel within the grand narrative of Scripture, thus giving a holistic view of the gospel. He then interconnected major biblical themes with dominant themes in Chinese culture. This interconnectedness allows for an assessment of culture in light of Scripture. Finally, he demonstrated how Scripture infers, clarifies, reinforces, and changes cultural themes to make them appropriate for illustrating biblical meaning.

The biblical message for Chinese immigrants in Latin America can be interpreted through three theological themes. In my discussion of the research findings, I propose to examine the results within the framework of creation, covenant, and eschatology. Instead of the Kingdom theme, I chose to use an eschatological theme. Eschatology tend to provide an appropriate framework to interpret dual identity among Chinese immigrants. In additional eschatology help to frame the identity of Adventists (Knight 2000:87). On 
the other hand, Evangelicals (e.g., Wu 2015) use the Kingdom motif to frame their religious identity. I believe the eschatological motif provides a better framework for interpreting the dual identify among Chinese immigrants.

These themes seem to synchronize with the Chinese immigrants' cultural themes of relationship, identity, and fortune. I used fortune instead of authority because hard work that is used as means to acquire wealth, is a more dominant cultural theme among Chinese immigrants in the Dominican Republic. My discussion integrates the biblical and cultural themes to give the church competence in its expression of the biblical message to Chinese immigrants in a way that is culturally appropriate and transformational.

\section{The Context of Chinese Immigrations: Its Missiological Significance for the Adventist Church}

Seventh-day Adventist church leaders have not been able to contextualize the biblical message to the Chinese in the Dominican Republic. A review of the literature and analysis of field research data show that church leaders are not very aware of the needs, values, rituals, and customs of the Chinese immigrants who live in the Dominican Republic. This chapter examines the needs and values of Chinese immigrants in Latin America and the Dominican Republic, and why those social issues pose a missional challenge to the Seventh-day Adventist Church. The chapter will also recommend missional strategies for church leaders to consider, including identifying relevant metaphors, redemptive analogies, and connectors that may be used to illustrate the gospel in culturally appropriate ways to Chinese. In addition, the chapter will examine how Chinese enclaves or Chinatowns help immigrants assimilate into their host countries.

Most immigrants feel a strong need for community. Immigration to a new country 
creates anxiety, uncertainty, and separation from a familiar community (Zinzius 2005).

Chinatowns provide safe environments for first-generation Chinese immigrants. Mary Cronin and William Huntzicker (2012) contended that Chinatowns provide recent immigrants with familiarity because there is continuity in language, food, values, religion, and culture. Ethnic enclaves protect the immigrants from hostility, discrimination, racism, and social injustice in the host country. Chinatowns also provide Chinese immigrants with jobs, community, and a sense of belonging (Zinzius 2005). These towns reinforce immigrants' beliefs, values, and customs. In the Dominican Republic, Chinese leaders give priority to the creation of safe zones or towns for Chinese immigrants.

Rosa Ng Báez (2016, 25), in her book El Barrio Chino de Santo Domingo, argued that she developed a Chinatown in the Dominican Republic "to honor memories of her father, and immigrants who died" in the Dominican Republic. Some Chinese still practice ancestor worship in the Dominican Republic. Ng Báez agreed with Zinzius that Chinatowns help to reinforce religious beliefs and values such as ancestor worship. Chinatowns also provide a safe environment for immigrants to assimilate into the host culture. After a few months, immigrants tend to feel safe enough to begin to engage in the culture, language, and challenges of their host countries.

\section{Issues Confronting Chinese Immigrants}

This section examines the educational, cultural, economic challenges facing Chinese immigrants. These issues are examined to determine opportunities for mission to the Chinese people. 


\section{Educational Challenges}

Immigration creates unique educational needs which center primarily on language learning, especially for first-generation immigrants. These immigrants seldom have the time to participate in formal learning environments. They are preoccupied with making money to provide their children with a formal education. For instance, first-generation Chinese learn just enough Spanish to conduct commercial activities with the local people. First-generation immigrants also tend to learn just enough language and culture to survive in their host countries.

Scott South, Jeremy Pais, and Kyle Crowder (2008) argued that foreign-born immigrants are likely to experience isolation, segregation, and alienation because of their linguistic deficiency. Immigrant children who are deficient in their host country language, experience alienation, anxiety, and marginalization among their friends. If immigrants are deficient in their second language, but efficient in their first language, their assimilation into the host culture is slowed severely because second language skills are "crucial for academic success, long-term social and economic well-being" (Bianchi 1984, 184).

The second generation of Chinese Dominicans have learning needs. The first generation is fluent in Mandarin, but deficient in Spanish, while the second generation is fluent in Spanish, but deficient in Mandarin. These Chinese Dominicans learned Spanish in formal settings, such as primary and secondary schools. However, many Dominicanborn Chinese also want to learn the language and culture of their parents, but their parents are too busy to teach them. In interviewing (2018) three prominent Chinese Dominican women they told me, "Our biggest regret is that our parents did not teach us Mandarin." 
Second-generation immigrants who are deficient in their first language may experience interpersonal conflict with first-generation immigrants. Wong Fillmore $(1991,323)$ stated, "When parents are unable to talk to their children, they cannot easily convey their values, beliefs, and understanding to them." This language deficiency can cause interpersonal conflicts, isolation, and identity crises.

First- and second-generation Chinese Dominicans need to be bilingual in order to survive in their host country and at the same time, remain connected to their ancestors' homeland. Learning to be bilingual minimizes interpersonal conflict. People who are bilingual can appreciate the emotions and values of the first generation. They also learn to appreciate their own culture. The first and second languages carry different "emotional valence" (Aragno and Schlachet 1996, 23). The first language, or "mother tongue" (23), encodes immigrants' first emotions. It is the language of the heart. The second language enables them to appreciate the culture, commerce, and opportunities of their new homeland. While the first language influences immigrants' internal worldview, second language acquisition gives them access to the opportunities of their host countries.

The field research tended to correlate with arguments in the literature with reference to the needs of Chinese immigrants in the Dominican Republic. In this study, the names of respondents are changed to protect their identities. Findings from a pilot study (2017) and the actual field research (2018) are cited to support arguments from the literature.

Second-generation Chinese approach language differently, and that generation does not want to make the same mistakes as their parents did. Thus, they encourage their children to be bilingual. For example, they may send their children to Mandarin classes 
on Saturday evenings or to China to live with relatives in order to learn Mandarin and the Chinese culture. Chinese parents speak to their children at home in their "mother tongue" and facilitate exposure to the second language at school. The home and school environments support maintenance of the first language and foster acquisition of the second language. Claudio Toppelberg and Brian Collins (2010, Educational Implications section) noted, "A supporting environment for the first and second languages in homes and schools may prove to be beneficial to immigrant children's linguistic, psychological and academic development."

However, first- and second-generation Chinese have other learning needs. Firstgeneration Chinese tend to be deficient in speaking the language of the host country. On the other hand, second-generation Chinese lament their shortcoming in speaking their mother tongue, such as Mandarin or Cantonese. This defect in language proficiency sometimes creates identity issues for second-generation Chinese.

\section{Cultural Challenges}

Chinese Dominicans also struggle with their cultural identity. They are fluent in Spanish and immersed in the Dominican culture. On the other hand, they are deficient in the Chinese culture and language. This state of liminality causes cultural dissonance. I asked three prominent Chinese women what it means to be a Chinese Dominican. It was a difficult question for them to answer; however, they each provided similar answers. Their fathers were Chinese, but their mothers were Dominicans. They consider themselves Dominicans culturally, but Chinese philosophically. These women struggle with their dual identities, especially since they did not learn their fathers' native language. This is one of their biggest regrets and frustrations as Chinese Dominicans. 
Chinese Dominicans usually feel accepted in their native country but alienated from their parents' culture and language. R. G. Rumbaut (1991) and LaFromboise et al. (1993), in particular, used bicultural and multicultural theories to explain the phenomena of cultural identity. Xie, Xia, and Zhou $(2014,216)$ assessed these theories and concluded that "contact with people from the same country reinforced one's sense of self and one's affinity to the heritage culture, whereas contact with people from the host culture facilitated the entry [into those cultures]. The absence of social support and familiarity often engendered feelings of loneliness, and bred anxiety and loss of security and control." While second-generation Chinese may feel alienated from their parents' culture, immigration laws in the Dominican Republic ascribe to them a White identity which facilitates acceptance into the Hispanic culture of the country.

Dominicans seem to have an affinity for whiteness. The Dominican racial ideology, la raza dominicana [The Dominican Race], espouses a preference for whiteness. La raza dominicana facilitates the immigration of Asians and Europeans into Dominican society and one factor to distinguish and distance Dominicans from Haitians (Lundius and Lundahl 2000, 575). Haitians are classified as Black, while Dominicans consider themselves to be White.

La raza dominicana enforced this distinction. The Trujillo government (19301938) encouraged the immigration of Chinese and Japanese people to the Dominican Republic, at least partially because Asians are similar in complexion to Hispanic Dominicans. Trujillo advocated for the legislation of la raza dominicana to facilitate Chinese integration into Dominican society. At the same time, the law inhibited the integration of Haitians into the Dominican Republic (Turits 2003, 145). The law rejected 
blackness, but fostered an acceptance of whiteness in Dominican society.

Dominicans consider Chinese to be White because they are not Black. Chen $(2008,25)$ argued that "while the Chinese are seen as phenotypically and culturally distinct from the 'typical Dominican', they are nevertheless regarded favorably, in large part because they are not Black." Chinese and Hispanic Dominicans enjoy a peaceful coexistence, and this pattern of racial tolerance between Chinese and Hispanics is also common in other Latin American countries.

Chinese usually feel comfortable in other Latin American countries where there are thousands of Chinese - Peru $(1,300,000)$, Venezuela $(450,000)$, Paraguay $(50,000)$, Brazil (300,000), Argentina $(200,000)$ Panama $(135,000)$, Costa Rica $(45,000)$, and the Dominican Republic (approximately 50,000). This racial tolerance throughout Latin America encourages Chinese to invest in business enterprises across the region (Wikipedia 2019).

While Dominican immigration laws give Chinese a pseudo-identity, Dominican Chinese continue to struggle with their dual identity. They feel accepted in the country; however, they still desire to learn the language and culture of their ancestors. This search for cultural identity may be usurped by the desire to acquire wealth. While cultural identify is important to the migrants, the desire to acquire money seems to be a greater priority for them.

\section{Economic Challenges}

Chinese are involved in a wide range of business enterprises. The first immigrants in the 1930s and early 1980s established restaurants. They earned a living by selling pica 
pollo or fried chicken flavored with unique Chinese seasonings. Local people relished Chinese food, while Chinese restaurants provided employment for Chinese immigrants.

However, since the 1990s, Chinese immigrants have come to the Dominican Republic to invest their wealth. In the Dominican Republic, first and second generations are involved in simple and complex business ventures. These businesses include restaurants, textiles, hotels, and private schools, among many others. However, Chinese residents also work as teachers, doctors, and other professionals in both the private and public sectors in their effort to acquire wealth.

The Chinese work approximately seventeen hours per day to pursue prosperity. The Chinese work ethic is a significant cultural value. In April of 2017 another Chinese immigrant reported, "Many Chinese work on an average of seventeen hours per day." Further, one interviewee remarked, "Chinese spend all their health making money. When they become sick, they spend all their money to regain their health."

In my interview with Zuni in November 2018 he explained, "We learn to work hard by imitating our parents. A good work ethic is instilled in us at early age."

Chinese work long hours for many reasons as Wi said, "We say we [work] long hours to make enough money to send our children to universities, to maintain our independence in the host countries, to repay relatives who bought our airline tickets to host countries. We also have to send remittances to family members in China." Long hours of work may be detrimental to their health, but it makes them astute businesspersons.

Many Chinese businesspersons share a common need. Kim, a Chinese businessperson said, "Because of the language barrier, we do not always understand 
government laws and policies with reference to our business. We are made to pay exorbitant taxes." Another common need of Chinese businesspersons is adherence to fair trade practices. What appears fair to Chinese businesspersons is viewed with suspicion by local Dominican businesspersons.

Conflicts have arisen between Chinese immigrants and native Dominicans in regard to business practices. Dominicans are sometimes suspicious of their commercial transactions with the Chinese. $\operatorname{Li}(2015,35,37)$ explained the perception of local people in the Dominican Republic: "The local population is of the impression that Chinese take advantage of loopholes in [the] legal system to avoid taxes. ... For instance, Chinese restaurants often do not accept [a] credit card but cash only.” The Chinese also tend to sell their goods cheaper than local businesses. In July 2013, Dominican vendors protested unfair Chinese trade practices. The vendors claimed that the Chinese imported textile products without paying proper taxes and tariffs. In addition, they claimed that Chinese merchants used cheap labor from Haiti to sell their textiles at unfairly low prices to force local vendors out of business ( $\mathrm{Li} 2015,14)$.

There is a shift in Chinese enterprise in the Dominican Republic. Chinese began arriving in the Dominican Republic as early 1865 . These immigrants came mainly from Guangdong, China. They were relatively poor immigrants. Therefore, they earned a living by establishing restaurants in their host countries. However, by the 1970s, a new wave of migrants began to arrive in the Dominican Republic from Fujian, China. These immigrants came with large sums of money. They established textile industries instead of restaurants in the Dominican Republic. This shift in business enterprise resulted in cheaper textiles on the market. 
In addition, the immigration of low-skilled Chinese to Latin America and the Caribbean also caused resentment from local skilled laborers. Local workers in the Bahamas, Venezuela, Suriname, and across Central America contend that they are denied employment because of a large influx of low-skilled Chinese laborers into their countries. Residents in Latin America tend to view the Chinese work ethic with resentment and suspicion. In spite of these negative feelings, the Chinese work ethic reflects the high value they place on the procurement of wealth.

\section{Cultural Values}

\section{Wealth Acquisition}

Chinese tend to give priority to wealth acquisition. It is an important cultural value. I interviewed Su King, a retired Chinese chief, on July 1-2, 2016, and he stated that "without money, it very difficult to live.... Money makes you an independent person. Money allows you to provide for your family." Su King believed that the Chinese existence is dependent on the acquisition of wealth. Kim, a young Chinese mother, said, "My husband came to the DR [Dominican Republic] to make money. Our lives depend on our business" (2017, interview). This was the motive for her migration.

The view that Chinese people come to the Dominican Republic to "make money" was echoed by many interviewees. Li gave his assessment of Chinese people in the country. He said that "money is more important than family. The Chinese work sixteen hours per day." He added, "Chinese youth spend all their health making money, but when they are old, they spent their money to regain their health." Yowee, a young Chinese mother, echoed the priority of the immigrant community: "Our greatest need is making money because we come from so far" (2017, interview). 
The acquisition of wealth has other significant meanings for the Chinese. It means daily survival in a foreign country. It also means intentional preparation for future obligations. These obligations may include their children's education, new business endeavors, or retirement. Yim contended that "making money gives one a bright future." Thus, Chinese people in the Dominican Republic believe that "making money" means survival now and preparation for the future.

These meanings also reflect the worldview of Chinese people in the Dominican Republic. The past, present, and the future combine to create the present reality. The Chinese work very hard in the present, but think more about the future. It is a type of interregnum. Ybarrola (2012) argued that immigrant communities are generally in a state of liminality. The theory of liminality explains the state of "in-betweenness" or interregnum in which immigrant people live (Van Gennep 1960; Turner 1967; Thommassen 2009; Ybarrola 2012). The innate desire of the Chinese to attain wealth may be an attempt to find harmony between the present and their hope for the future state of being.

\section{Harmony}

Chinese also strive for harmony in their relationships. Ge Gao and Ting-Toomey $(1998,7)$ put the value of harmony in sharp focus: "The ultimate goal of communication in Chinese culture is the preservation of harmony. Harmony is foundational to Chinese culture. The Chinese term he denotes harmony, peace, unity and kindness." Francis Hsu $(1981,475)$ argued that "the relational aspect of 'self' influences all facets of Chinese communication." He added, "Chinese communication is aimed at the preservation of harmonious relationships with families, others and the surrounding environment" (439). 
Gao and Ting-Toomey $(1998,7)$ supported Hsu's argument. They contended that

"Chinese are inspired to live in harmony with family members, to be on good terms with their neighbors and achieve unity with the environment."

Chinese view reality in triad relationships. Several assumptions help shape the Chinese understanding of reality. These assumptions originate from teachings of Daoism, Buddhism, and Confucianism. A brief review of the assumptions of the folk religions (Daoism, Buddhism, and Confucianism) in China is necessary.

\section{Confucianism}

Confucianism gives priority to relationships. David Noss argued that relationships are the basic assumptions of Confucianism. These relationships are between "humankind, the earth and heaven" $(2003,296)$. Julia Ching emphasized the "moral character" of these relationships $(1999,57)$. Analects 15:23 in the writings of Confucianism says "not to do to others what you would not have them do to you." Harmony with heaven is the assumption which undergirds Confucius' teachings on family and hieratical relationships.

\section{Daoism}

Daoism also influences the worldview of the Chinese people. This philosophy focuses on humankind's relationships to nature. Daoism assumes oneness between humans and nature. Ching defined "Daoism as striving for immortality of the whole person [through] contemplative practices" $(1999,86)$. Gan-Theow Ng observed that the "popular version of Daoism shaped the Chinese worldview by its affinity for geomancy, magic, and spirit worship" $(1991,74)$. 


\section{Buddhism}

Buddhism had a profound effect on the Chinese worldview. Its founder, Gautama Buddha, assumed that happiness could be achieved by spiritual self-discipline. Kung and Ching (1989, 200), Wolfgang Bauer (1976, 153-159), and Arthur Wright (1965, 33, 34) argued that Buddhism influenced the worldview of China through its emphasis on practices of monastic life, spiritual self-disciple, and rebirth. The authors noted that Buddhism interacted with the pragmatism of Confucianism and Taoism to shape the worldview of the Chinese. These folk religions influenced the practical out-workings of harmony in the daily lives of Chinese.

I observed the significance of harmony among Chinese. While standing in a Chinese store, I noticed how the storekeeper cared for her 89-year-old mother. The storekeeper informed me that her mother had cared for her; now it was her time to care for her mother. She understood harmony to mean respect for parents. She maintained harmony with her mother through care and respect. Yim, a retired secretary of the Chinese Cultural Organization, expressed that "harmony is the goal of communication in Chinese families." This value influences relationships within families.

However, if the value is ignored, it causes anxiety and conflict in families. Chinese youth sometimes ignore this value. While standing in the same store, another mother entered the store. Yangu, a Chinese missionary, asked her about her daughter. The mother responded angrily, "My daughter is very disrespectful to me." The daughter ignored the value of harmony between mother and daughter. Harmony is essential to human relationships at all levels of society.

Xinzhong Yao (2000:170-181) in his book An Introduction to Confucianism, 
articulates a comprehensive view of harmony. Confucian understanding of harmony is related to music. Yao believed music was essential for a good character and music could not only harmonize human sentiments but also bring order from chaos. To be in harmony with others requires something new-a virtuous character. It is believed that by cultivating harmony within people become virtuous. On the other hand, people spoil their character when they are involved in violence or disharmony.

To avoid disharmony, harmony must be cultivated at various levels. Confucius advocated for the cultivation of harmony between heaven and humans. He believed heaven and humans were comprised of the same nature-yin and yang. The theory of yin and yang explains the inseparable relation between heaven and humans, male and female, light and darkness, and parents and children. These forces work together to foster harmony between the heaven and humans.

In addition, one needs to cultivate harmony in one's family. Self-centeredness tends to create conflict and tension in families. However, according to Confucius, one can reduced family conflicts by cultivating "one's own character and then be in harmony with others by one extending one's virtue to others" (Yao 2000, 179). The family is the cornerstone of order and peace. Family relations in Confucian classics are threefold: parents and children, husband and wife, and between older and younger brothers. Of these three relationships, the one between parents and children is the most important. The responsibility for harmony is placed on the children. "The tension between different generations is reduced through the respect, reverence and service the younger provides to the older" (181). Thus, the cultivation of internal virtues of respect, reverence, and 
oneness with heaven tend to produce harmony in families, with the government, and in society.

The Chinese use the word guanxi to convey their understanding of harmony. Christy Chow (2013) defined guanxi as a web of relationships that binds people together and deepens their shared experiences in instrumental and affective ways. I asked interviewees to share with me what the word guanxi meant to them. The responses reflect a shared worldview.

Su King revealed, "It is about relationships. It means respect for one another." $\mathrm{He}$ added, "Guanxi also means a good relationship between two countries." Yim shared a similar view. She said that guanxi means a "peaceful relationship." Louis Sung provided a profound definition of guanxi. He described it as "a relationship that takes precedence over laws." Youwee confirmed Louis Sung's meaning. She contended that guanxi means harmony, unity, and love in families. These shared meanings of guanxi reflect the Chinese view of reality.

Yun, Secretary of the Chinese Cultural Club for twenty-eight years, explained the meaning of harmony with the environment. She said, "It is important for Chinese in DR to remember their culture [harmony] and maintain good relationships with the local people." She added, "Never fight with the local people."

Yun noted further in my interview with her in July 2016 that the reciprocal relationship exists between the Chinese and the government. She stated, "The government treats the Chinese with respect, and the Chinese help the government in times of disaster." She said that "the Chinese people obey the law. They cause no trouble to the local people." 
Yun gave an example of how harmony or disharmony may affect relationships with native Dominicans or Chinese relatives. She said that she preferred to employ nationals, rather than Chinese people. This is because she pays a lower a salary to the nationals. The locals tend to accept lower salaries. However, if she should pay the same salary to a Chinese relative, this would foster animosity between the relative and herself. She sought to maintain harmony with her relatives by giving them a higher salary. While one may question the ethics of her employment dealings, she does what is necessary to maintain harmony with locals and relatives.

Chinese also seek to avoid confrontation with locals or relatives. Micheal Bond noted, "Chinese communication serves both affective and relational purposes. Therefore, a confrontational mode of communication is avoided at all costs" $(1992,7)$. $\mathrm{He} \mathrm{Yu}$, a retired businessperson, put it tersely: "Saving of face is more important than conflict [shame]" (2017, interview). Chinese minimize conflicts to avoid shame. In addition, Chinese tend to be receptive to modes of communication that foster honor, reverence, and respect for the sages, parents, governments, local people, and ancestors.

\section{Veneration of the Deceased}

The belief in survival after death has a profound influence on the worldview of the Chinese people. Noss indicated that "family solidarity and the belief in survival after death are closely interrelated" $(2003,261)$. The family includes living descendants, as well as those who have died. The dead members of the family depend on the living for food. However, the living members of the family depend on their ancestors for prosperity and protection. This interdependence between the living and the dead gives longevity to ancestor worship practices in China and the Chinese diasporas in Latin America. 
Immigrant and Dominican-born Chinese have retained their ancestor worship practices. The Chinese believe it is their obligation to worship the dead. The Chinese assume that the deceased have physical needs. I interviewed Chinese immigrants in the Dominican Republic to assess the meanings they attached to ancestor worship. They shared different interpretations. Su King said, "It means we remember the things our ancestors did for us." He added, "We make money available to our ancestors by burning paper money. Our ancestors need money." Youwise agreed with Su King. She contended that "ancestor worship is an act of respect" to parents or relatives. Once a year, she gives fruits, chicken, and cakes to her ancestors. Another respondent said that ancestor worship means "protection and a better business." She offers food to her ancestors daily to invoke their blessings and protection.

Chinese tradition advocates an inseparable bond between the living and the dead. de Bary $(1999,4)$ contended that "the fate of the living is tied to the dead. ... Status in this life continues into the next." Ancestral worship remains a sacred religious practice for the majority of Chinese who live in the Dominican Republic and have their roots in ancient Chinese civilization.

During the Shang dynasty (1045/1040 BCE), the king believed success or failure came from a high god, nature, and the ancestors. The ancestors needed the king's divinations. Conversely, the king needed the blessings and protection of the ancestors. This "inseparable bond between religion and kin" continues to shape the worldview of the Chinese people (de Bary 1999, 4).

The Chinese view of death is contrary to the biblical view. The Bible teaches that there is discontinuity of life at death. Conversely, the Chinese believe life continues after 
death. This cyclical view of life is incongruent with the biblical view of life. The Bible teaches a linear view of human existence. However, Buddhism teaches a cyclical view of human existence. This incongruity in worldviews is a critical problem confronting church leaders in the Dominican Republic. The purpose of this research is to address this and other critical issues.

An appropriate model of contextualization for the Chinese cannot ignore the Chinese view of death. Rather, the contextualizer should acknowledge this incongruence and seek to build bridges between the two worldviews.

\section{Missional Challenges Facing the Adventist Church}

In the Dominican Republic immigrant Chinese are joining other Christian denominations; however, they do not respond to typical Adventist evangelistic methods. As a result, the rate of Chinese conversions to Adventism is extremely low. At the same time, thousands of Hispanics are accepting the Adventist message. The Secretariat of the Dominican Union Conference reports an average baptismal rate of 9,000 Hispanics every year over the last ten years through traditional evangelism. Traditional evangelism refers to an established pattern of presenting the gospel to Hispanics. This form of evangelism is conducted in local churches, in large tents or community centers, and in small groups for the duration of one to four weeks. It features singing, preaching, and public invitations to be baptized. During the period of 2000 to 2010, approximating 90,000 Hispanics were baptized by means of traditional evangelism (Silvestre 2017).

During the same ten-year period, the secretariat reported that there were no Chinese baptisms in the Dominican Republic through traditional evangelistic approaches (Silvestre 2017). Church leaders seem satisfied with the high receptivity and conversion 
of Hispanics, but these leaders are still searching for a new model of presenting the Adventist message to the 50,000 immigrant Chinese in the Dominican Republic.

As the church searches for ways to contextualize the gospel for the Chinese in the Dominican Republic, certain aspects of the culture need to be taken into account. The Chinese perspective of reality should determine the mode of communication. At present, church leaders communicate with Chinese people from Western perspectives of reality. There is a need for a paradigm shift in the modes of communication with the Chinese in the Dominican Republic. This shift can only occur when Seventh-day Adventist church leaders are exposed to a deeper understanding of the worldview held by the Chinese people in the country.

In November 2018, I traveled to the Dominican Republic to interview church leaders about the missional challenges of Chinese immigration. I selected two groups. The first group consisted of ten church administrators. The second group was comprised of five young professionals. These professionals have been interacting with the Chinese every Sabbath for the past five years. I wanted to compare and contrast their perspectives with those of church administrators with reference to the challenges of mission work among Chinese immigrants. Each interview lasted for one hour. I conducted the interviews in offices, homes, and at centers of influence.

In the interview, the church administrators described strategies for evangelizing Hispanics. However, when I asked about the evangelization of Chinese, the leaders shared their fears, anxieties, and apprehension.

The leaders shared vast ranges of perspectives in an interview with them in November 2018: 
- "I do not know the Chinese people."

- "The Chinese people are secretive."

- "I can't speak Mandarin."

- "We never consider the Chinese for salvation." [This means we do not know how to reach them. Therefore, we have not intentionally attempted to share the gospel with Chinese immigrants.]

- "We know how to evangelize Hispanic people, but we do not know how to evangelize Chinese."

- "I do not know the Chinese culture."

- "We need Chinese pastors."

- "The Chinese are only concerned about work and money."

These are just some of the perspectives the first group shared with me.

The young professionals shared different perspectives.

- "The Chinese are human. ... They experience pain, grief, and fear."

- "The Chinese respond to our kindness."

- "As we became friends with the Chinese, they began to trust us."

- "We want to speak Mandarin to improve our ministry."

The second group who were working with the Chinese showed a willingness to minister to their social and spiritual needs. They volunteered to teach Spanish or serve as mentors at camps for Chinese children, and they interacted with the Chinese on Sabbath. The first group, on the other hand, revealed their ethnocentric beliefs. They were Dominicans. The Chinese were foreigners. One leader remarked, "We never consider them for salvation," implying that "we are saved but they are lost."

The first group was effective in evangelizing Hispanics, while the second group was learning to provide an incarnational ministry to the Chinese by meeting their social needs. The first group made little attempt to bridge the cultural distance and was satisfied with its success in traditional evangelism. The second group was learning to cross cultures to serve others.

Language was another problem. Neither the first nor the second group spoke Mandarin. The first group considered language to be the number one issue. One leader 
remarked, "I am too old to learn Mandarin." The second group had a different attitude. They taught the Chinese Spanish to facilitate communication. However, the second group was not oblivious to their need to learn Mandarin.

Both groups lacked cross-cultural training. The first group did not know how to minister to the Chinese people. "We do not know the Chinese culture!" they argued. The second group was willing to learn. They learned about the culture through observation and participation in the Chinese community. After four years of interaction with the Chinese, the second group said, "The Chinese are people. They experience pain and suffering."

Chinese social needs pose enormous challenges to the church in the Dominican Republic. The first group was daunted by those challenges. However, the second group demonstrated that those challenges were not insurmountable.

\section{Missional Opportunities for the Church}

Church leaders can gain access to the hearts of Chinese immigrants through kindness and compassion. However, church leaders need to come closer to the migrant Chinese in order to do this. They can get closer to the Chinese through acts of kindness, economic ventures, language learning opportunities, and employment of people with dual Chinese and Hispanic cultural ties. Through these avenues and others, church leaders may discover the felt needs of the migrant Chinese.

\section{Acts of Kindness}

Chinese immigrants are amenable to acts of kindness, and this is evident among Chinese people living in the Dominican Republic. Church leaders may use acts of 
kindness to lead the Chinese to Christ. Wang told me how a church leader led him to Christ. Wang was in a state of depression after the sudden death of his father. His mother said to him, "Son, you look terrible. Please go to the barber to cut your hair." While at the barbershop, a church leader showed kindness to him. He was invited to the church member's home for a meal. The family gave him meaningful emotional support. The family also invited Wang to church. He was the first Chinese to attend that local church. The members showed him love and gave him spiritual counsel. The kind ness of the members helped him cope with his grief. After one year of attending church, Wang gave his life to Jesus in baptism, making him the first Chinese to be baptized in that local church. Wang is now preparing to become the first Chinese pastor in the Inter-American Division.

I interviewed Bon and Pi in November 2018. They are Chinese missionaries in a Chinatown in Latin America. In a semi-structured interview, these missionaries confirmed that "acts of kindness to Chinese children give the missionaries access to the parents of the children." The parents said to the missionaries, "We like the changes your acts of kindness and teachings are making in our children. We see the changes in their lives. Our children are available to you whenever you need them.”

Chinese missionaries and church leaders conducted a ten-day camp for Chinese children. At the camp, the children participated in sports, music, swimming, reading, worship, and language learning. When the children returned home after the end of camp, the parents noticed changes in their children's values and behaviors. The children's appetites for video games diminished, and their attention to academic work increased. The children were also eager to attend church services on Sabbath and Bible study on 
Tuesdays. The ten-day camp not only changed the trajectory of the lives of these Chinese children, but also changed the thinking of their parents.

\section{Consultation with Chinese Businesspersons}

Adventist businesspersons may consider consultation seminars for Chinese businesspersons. A church leader shared with me (2018) that "he would like to convene a business forum between Seventh-day Adventist businesspersons and Chinese businesspersons to dialogue on best practices in business in the Dominican Republic." Such dialogue is relevant and appropriate to the felt needs of the Chinese business community. Chinese business owners would welcome such a dialogue, perceiving it as a welcoming gesture. It may also provide Chinese business professionals with opportunities to engage in joint ventures with Seventh-day Adventists. In addition, church leaders may gain greater insights into the Chinese culture and worldview, as well as any challenges they face. These insights can be the gateway to new relationships and opportunities to share Christ with the Chinese people.

\section{Language Classes}

Church leaders can explore the missional relevance of bilingual competence, that is, pastors with proficiency in both languages. Mr. Zuia, a layperson in the Chinese Baptist Church, told me in 2018 that there is a need for Mandarin/Spanish-speaking pastors in Latin America. "English/Mandarin pastors are easy to find, but it is difficult to find Mandarin/Spanish pastors,” said Mr. Zuia. For example, “Our Chinese pastor died five years ago, and we have not found a Chinese Mandarin/Spanish pastor to replace him." 
Chinese Dominican people like $\mathrm{Zu}$ and her children can assist church leaders in bridging the language barriers between the two communities. Zu's children are secondgeneration Chinese Dominican. They are competent in Spanish and Mandarin. They are also active members of the Seventh-day Adventist Church in the Dominican Republic (2018, participant observation, interview).

\section{Collaboration with Persons of Dual Identities}

Church leaders can identify persons of peace. These people need to have roots in both Chinese and Dominican cultures. For example, $\mathrm{Zu}$ is a Chinese Dominican. Her father was Chinese, but her mother was Dominican. In 1986, she became a Seventh-day Adventist. She is self-employed but also works part-time in Chinatown in Santo Domingo. She can assist church leaders in bridging cultural barriers in their effort to share Christ with the immigrant Chinese in the Dominican Republic.

\section{Summary}

This study examined the effects of immigration on first- and second-generation Chinese in the Dominican Republic and Latin America. The study is limited to the period from 1937 through the 1990s. During this period, Chinese immigration to the Dominican Republic changed the immigrants' social, economic, educational, and cultural trajectories. The first generation worked for long hours to achieve economic success; however, they were deficient in Spanish and struggled to acculturate to their host countries. Therefore, many immigrant Chinese lived in ethnic enclaves to help them cope with feelings of insecurity, loneliness, and fear of the local culture. In contrast, the second generation spoke Spanish fluently, which enabled them to assimilate into the culture of 
the Dominican Republic. However, the second generation of Chinese immigrants also experienced the effects of immigration, including a deficiency in the mother tongue of their parents. Overall, second-generation immigrants experience a crisis of cultural identity. They struggle with being Dominican and Chinese at the same time. What an opportunity for the church.

The values of the Chinese in Latin America provide excellent opportunities for contextualization. In another chapter, the research will explore bridges or connectors in Chinese values of harmony, wealth acquisition, and respect that are culturally appropriate to contextualization of the gospel to that people group.

Chinese immigrants struggle with many issues in their host countries. In the Dominican Republic, the Chinese are faced with issues involving language, cultural identity, and resistance from local businesspersons. These issues can become bridges for a culturally appropriate contextualization of the gospel to the Chinese; however, church leaders need to be cognizant of these issues. Church administrators, such as presidents and pastors, are largely ignorant of the issues confronting the Chinese in the Dominican Republic. On the other hand, some lay leaders are taking the time to understand the challenges faced by Chinese immigrants. While these leaders are not always aware of worldview differences between themselves and the Chinese, they are beginning to appreciate the social, economic, and cultural issues faced by Chinese immigrants. These issues are investigated in the next chapter through qualitative research to determine the validity and relevance of these issues to a model of biblical and culturally appropriate contextualization. 


\section{CHAPTER 4}

\section{THE FIELD RESEARCH: ANALYSIS AND FINDINGS}

\section{Introduction}

This chapter only presents findings from the data analysis. The next chapter discusses the findings. Rather, it describes the findings and other aspects related to them, which includes reviewing methods of data collection, an analysis, and demographics. I review these aspects to remind readers of the phenomenon of the study. In addition, charts are inserted into the text instead of in the appendix to give readers easy access to the data of the study.

Several themes emerged from the data analysis. Out of an initial twenty-three themes, eight major themes eventually emerged. Each theme answered one or more of the research questions with data from the interviews and participant observations obtained in the Dominican Republic.

\section{Research Setting}

The Chinese commercial center provided the setting for the field research. In Santo Domingo, the capital of the Dominican Republic, there is a Chinese commerce center known as "Barrio Chino." This town has many Chinese businesses, such as restaurants, fabric stores, supermarkets, and street markets. Chinese people travel to this commercial center to work, eat, celebrate, and carry out various forms of commercial 
activities. It was an appropriate setting for my field research.

I arrived in "Barrio Chino" on November 12, 2018, to begin my field research among the Chinese. The fieldwork ended on December 2, 2018. Each day, I interviewed two or three respondents. Some informants spoke Cantonese, others spoke Mandarin, and others spoke Spanish. I also interviewed respondents who were bilingual. Bilingual interpreters assisted me in the interviews.

\section{Data Collection and Analysis}

To achieve this aim, data was collected by means of interviews and observations. The data was transcribed into approximately eighty pages of information. The analysis was carried out by coding the data for reoccurring themes, nuances, patterns, and differences. In the first cycle of coding, twenty-three themes emerged. However, in a second cycle of coding the relevant themes were reduced from twenty-three to sixteen. In the final cycle of coding, the themes were reduced from sixteen to eight. These eight themes represent the research findings.

\section{Research Findings}

A thematic pattern is used to describe the findings. Each finding is described and supported by data from the semi-structured interviews, observations, and literature. The findings are described in relation to the research questions. In addition, identifies of respondents have been concealed. During the field research, I indicated to the respondents that their actual names would be concealed. In this study, pseudo names are given to respondents. Finally, a summary is given for each finding. The research demographics contribute to the validity of these findings. 


\section{Demographic Description of the Sample}

In the following descriptions, category 1 is made up of Chinese participants from other denominations. They shared their expertise regarding the ways Chinese respond to and make decisions to follow Jesus. These experiences related to Research Question 1. Participants in category 2 are Chinese immigrants who have been living in the Dominican Republic for periods ranging from 11 to 40 years. They responded to Research Question 2 on the issue of the values of immigrant Chinese in the Dominican Republic.

Participants in category 3 are Chinese Seventh-day Adventists who live in the Dominican Republic. Five of the six participants were baptized recently. They had been members for a minimum of one month and a maximum of three years. The Chinese Adventists responded to Research Question 3, addressing appropriate methods for presenting the gospel to Chinese immigrants in the Dominican Republic. The responses from the Chinese Adventists were compared with responses from participants in category 4 who are Adventist church leaders. These leaders also responded to Question 3 on the issue of appropriate methods for presenting the gospel to immigrant Chinese. In addition, participants in category 4 shared insights on barriers to sharing Christ with Chinese people in the Dominican Republic. They were also candid about their methods of sharing the gospel with Hispanics.

Table 1 provides a breakdown of the languages of the respondents according to the categories of participants interviewed. 
Table 1. Breakdown of 24 informants by language proficiency

\begin{tabular}{|c|c|c|c|c|}
\hline Language Proficiency & Mandarin & Spanish & English & Bilingual \\
\hline Category $1 \& 2$ & 11 & & & \\
\hline Category 2 & & 1 & & 1 \\
\hline Category 3 & 2 & & & \\
\hline Category 4 & & & 6 & \\
\hline Totals & 13 & 1 & 6 & 1 \\
\hline
\end{tabular}

More than $50 \%$ of the informants were proficient in Mandarin, $47 \%$ were proficient in Spanish. The other 3\% either spoke English (1\%) or were bilingual (2\%).

In terms of age, participants fell within the range of 25-60 years of age, even though the research was open to those as young as 18 . The majority of the participants were between the ages of 30 and 60 years. This age range accounts for $99 \%$ of the participants. Just one participant was below the age of 30 . Table 2 reveals the dominant age ranges according to the categories of participants interviewed.

Table 2. Average age range by category

\begin{tabular}{|c|c|c|c|c|}
\hline \multirow[b]{2}{*}{$\begin{array}{l}\text { Age } \\
\text { Range }\end{array}$} & \multicolumn{4}{|c|}{ Category } \\
\hline & $\begin{array}{l}\text { Chinese, } \\
\text { Other } \\
\text { Denominations }\end{array}$ & Immigrant Chinese & Chinese Converts & $\begin{array}{l}\text { SDA Church } \\
\text { Leaders }\end{array}$ \\
\hline $30-55$ & 6 & & & \\
\hline $40-60$ & & 6 & & \\
\hline $25-40$ & & & 6 & \\
\hline $50-60$ & & & & 6 \\
\hline Totals & 6 & 6 & 6 & 6 \\
\hline
\end{tabular}


The dominant age range indicates the maturity of the respondents. The respondents in category 1 and 2 were knowledgeable of the needs, struggles, values, and aspirations of Chinese immigrants in the Dominican Republic.

Participants were nearly equally divided between genders. Table 3 displays the balance between males and females according to the categories of participants interviewed.

Table 3. Participants' gender affiliation by category

\begin{tabular}{lllll}
\hline \multirow{2}{*}{ Gender } & \multicolumn{4}{c}{ Category } \\
\cline { 2 - 5 } & $\begin{array}{l}\text { Chinese, } \\
\text { Other } \\
\text { Denominations }\end{array}$ & $\begin{array}{l}\text { Immigrant } \\
\text { Chinese }\end{array}$ & $\begin{array}{l}\text { Chinese } \\
\text { Converts }\end{array}$ & $\begin{array}{l}\text { SDA Church } \\
\text { Leaders }\end{array}$ \\
\hline Male & 3 & 2 & 3 & 5 \\
Female & 3 & 4 & 3 & 1 \\
\hline Totals & 6 & 6 & 6 & 6 \\
\hline
\end{tabular}

While males and females were fairly evenly distributed in categories 1 to 3 , there was a noticeable difference in category 4 , which was due to a disparity in gender among church leaders in administrative positions. The female in category 4 is a leader in a local church. In comparison, the five males in category 4 are leaders at the higher levels of the Seventh-day Adventist Church in the Dominican Republic.

Table 4 reveals that $49 \%$ of the participants are Chinese Christians from a Buddhist background. Conversely, 25\% of the participants are Buddhists. The other 25\% of participants are Hispanic Christians. Chinese insights are significant to this research; however, the views of Hispanics offer unique perspectives on the phenomenon under investigation. 
Table 4. Participants' religious affiliation or ideology

\begin{tabular}{lllll}
\hline \multirow{2}{*}{$\begin{array}{l}\text { Religious } \\
\text { Affiliations }\end{array}$} & $\begin{array}{l}\text { Chinese, } \\
\text { Other } \\
\text { Denominations }\end{array}$ & $\begin{array}{l}\text { Immigrant } \\
\text { Chinese }\end{array}$ & $\begin{array}{l}\text { SDA Chinese } \\
\text { Converts }\end{array}$ & $\begin{array}{l}\text { SDA Hispanic } \\
\text { Church Leaders }\end{array}$ \\
\hline $\begin{array}{l}\text { Baptist } \\
\text { Chinese }\end{array}$ & 1 & & \\
Alliance & 1 & & & \\
Chinese & & & & \\
Banner & 3 & 6 & 6 & \\
Chinese & & & & \\
Buddhists & & & & \\
Chinese & & & & \\
Adventist & & & & \\
Hispanic & & & & \\
Adventist & & & & \\
\hline
\end{tabular}

\section{Research Question 1: Influencing Factors}

\section{Finding 1: Cognitive Dissonance}

This finding is in response to Question 1: What factors lead Chinese immigrants to respond to the gospel and make decisions to follow Christ in other denominations in Duarte, Santo Domingo, Dominican Republic? Five out of six respondents in category 3 identified crisis events as major factors in their decision to follow Jesus. The data from the November 2018 interviews indicate that more than $90 \%$ of category 3 participants (Chinese converts) considered that a crisis event influenced their decision to follow Christ. The respondents' crisis factors included "death of my father," "divorce," "loss of my job," "the drowning of my son," and "surgery." One respondent told God before having major surgery, "God, if you wake me up after my surgery, I will never eat pork again." The individual did wake up and has abstained from eating pork since that surgery took place.

In times of personal crisis, participants tended to be receptive to ideas or persons 
capable of restoring harmony in their lives. When participants experienced cognitive dissonance, they tended to gravitate to things or persons with solutions that would alleviate that dissonance. For instance, one participant turned to a friend, another sought support from missionaries, and still another found solace in a church or with a pastor. However, conversion must include cognitive and affective changes.

God's faithfulness is closely associated with participants' vulnerability. Some participants noted that during crisis events in their lives, God demonstrated his faithfulness by bringing them in contact with "a pastor," "a member," "a church," and "missionaries." Participants felt the need for emotional support in times of vulnerability. The data from November 2018 interviews with Chinese converts show 4 out of 6 participants consider mentors to be significant to their decision making and observation.

The analysis of data based on Question 1 elicits other subthemes. The data from participants in category 1 and observations from Chinese churches identify several emotive factors affecting Chinese responses to the gospel and decisions to follow Christ.

Chinese are sensitive to indebtedness. The concept of quanxi, reciprocal relationships among Chinese, instills in Chinese an attitude of indebtedness to each other. Chinese tend to reciprocate because of favors shown them. This act of reciprocity fosters healthy relationships in families and with local people. It appears that quanxi is a possible basis for favorable Chinese responses to the "substitutionary death of Jesus." A participant in category 1 , a leader of a Chinese church, noted that Chinese respond favorably to the "substitutionary death of Jesus," the "assurance of God's love," and “God's protection."

Chinese immigrants live in constant fear. Chinese immigrants seek protection for 
their families and business. The data from category 2 indicate that four out of six respondents depend on "ancestor altars" and "guangon statues," an ancient Chinese general, for protection. The "ancestor altars" are located in homes to protect family members. Guangon statues are generally located in businesses to protect workers and commodities from evil spirits and criminal activities.

A prominent respondent noted, "Chinese immigrants in the Dominican Republic feel insecure because criminals enter into homes and businesses of the Chinese to steal and to kill" (shared in November 2018 interview). Chinese immigrants tend to depend on their ancestors, Guangon, and sometimes the services of paid security guards for protection.

Appropriate Christian liturgy appears to help Chinese immigrants cope with crises, fear, and indebtedness. The data from personal observations in two Chinese congregations suggested that prayer, singing, soft music, voice intonation, and humor have a positive effect on Chinese responses to the gospel and their ability to cope with crises.

The social theory as espoused by Anthony Wallace (1956), Leon Festinger (1957), Alan Tippet (1987), and Charles Kraft (1996) argues that the introduction of new ideas or events into a stable state create cognitive dissonance.

Such dissonance may be in the form of stress or crisis. The factors causing the stress may come from within a person's mind or from external factors. If there is persistent stress, a "reservoir of tension" (Kraft 1996, 437) is created within the mind or stable state.

This tension is resolved in two different ways. People may retain their core 
worldview. However, they may also make some dramatic changes to their behaviors. Old assumptions are submerged, and minor changes are made in order to achieve stability.

The tension can also be resolved by radical changes to one's entire worldview. If such radical changes occur, there would be an extinction of the old assumptions or restructuring of previous ideas to accomplish a new stable state of being. Whenever peoples' view of reality is disturbed by new information or events, there is an urgent search for ways to create a stable state or worldview.

Hiebert $(2008,10)$ used the social science theory to explain the holistic nature of worldview change. Worldview change needs to be holistic in scope. For example, cognitive transformation is a critical aspect of conversion. The disciple needs to learn to think critically about truth in relation to error or deception.

However, conversion must also include experiential or affective transformation. The affective dimension of worship such as singing, greeting, and fellowship tends to provide the "initial impulse" to conversion. Ellen G. White (1990, 323) stated, "He who beholds the Savior's matchless love will be elevated in thought and purify in heart."

Hiebert put it tersely: "Feelings are caught not taught." Discipleship emphasizes feelings as well as knowledge to foster spiritual transformation $(2008,313)$.

\section{Summary of Findings for Question 1}

In response to Question 1, the research confirmed that crisis events elicit cognitive and emotional responses from the Chinese. According to the literature that supports finding 1, a crisis event creates cognitive dissonance in a person's mind. At such times, the person becomes open to guidance, emotional support, and spiritual disciplines such as prayer, singing, and Bible reading. Emotional support tends to comfort the person 
in his or her state of cognitive dissonance. The data from category 3 indicates that 90 percent of respondents (Chinese immigrants) who experienced a major crisis in their lives responded positively to the Adventist message.

\section{Research Question 2: Chinese Cultural Values}

\section{Finding 2: Meanings within Culture}

This finding identifies and describes four Chinese cultural values that may be culturally appropriate to illuminate the meaning of the Adventist message to Chinese. This second finding is based on the question: What Chinese cultural values could facilitate Chinese understanding and acceptance of the gospel? The cultural values are the independent variables: hard work, harmony, respect, and dual identity. These values may serve as bridges to assist the Chinese in comprehending and accepting the gospel. Chinese comprehension and acceptance are the dependent variables. This means that cultural values tend to influence how the Chinese perceive the gospel.

\section{Hard work}

Analysis of the data from category 2 indicated that 95 percent of the respondents considered "hard work" to be an important value. It is "instilled in us at an early age," said one respondent. The data indicate that immigrant Chinese spend 12-15 hours per day at work. A respondent noted, "Chinese spend many hours to make money, but when they are sick, they spend all their money to regain their health.” Jokingly, a respondent remarked, "Business is good when the boss is not working." He meant that others are working for him.

Hard work carries a range of meanings: "security for a good life," "honesty," "an 
act of honor," "avoiding shame," "wellness of the family, and "a better life." These meanings reflect the Chinese immigrants' view of reality in the Dominican Republic. A better life means health and happiness for themselves and their children in the Dominican Republic.

\section{Harmony}

Chinese tend to strive for harmony with family members, nature, and the local people. Four out of six respondents in category 2 considered harmony a significant value. The other two respondents did not negate its importance; they simply did not mention the word "harmony." One mentioned "obligation to children's education" while the other mentioned "belonging." However, $66 \%$ of respondents mentioned the word "harmony" in relation to local people, their families, ancestors, and governments.

One respondent indicated that harmony is "not causing trouble with local people." Other respondents gave more succinct meanings: "law abiding," "peace," "fidelity in marriage," and "solidarity." Chinese immigrants in the Dominican Republic endeavor to live in solidarity with the government and the local people. One respondent put harmony into perspective. There are "no immigrant Chinese in the Dominican Republic penitentiary." This means Chinese tend to avoid shame or embarrassment. This desire to "save face" undergirds their desire for harmony with others so that they may achieve success, honor, and integrity among the local people. Harmony is an act of honor and prestige for Chinese families.

Another respondent was interviewed in 2018, a Chinese immigrant. She related her experience with harmony in the Dominican Republic. She has not "always practiced harmony." When asked why, she noted that she treated the local people kindly, but they 
responded to her with "harsh words and deeds." The Dominican people "ridiculed me," "called me nicknames," and "threw rocks at me." She then abandoned the term "harmony" to defend herself and her children. However, she considers harmony to mean "not fighting or talking back to others."

Harmony is foundational to Chinese culture. Gao and Ting-Toomey put the value of harmony into sharp focus: "The ultimate goal of communication in Chinese culture is the preservation of harmony" $(1998,7)$. The Chinese term he denotes harmony, peace, unity, and kindness. Hsu argued that "the relational aspect of 'self' influences all facets of Chinese communication" $(1981,475)$. He added, "Chinese communication is aimed at the preservation of harmonious relationships with families, others and the surrounding environment" (439). Gao and Ting-Toomey supported Hsu's argument. They contended that "Chinese are inspired to live in harmony with family members, to be on good terms with their neighbors and achieve unity with the environment" $(1998,7)$.

\section{Respect}

Respect is another critical value in Chinese culture. The data from category 2 revealed that $66 \%$ of the respondents cited "respect" for family members as a critical value. The word "respect" was mentioned by 4 of the six respondents in relation to immediate families, deceased family members, the government, and local people. In relation to local people, one respondent was asked, "Why is your fabric store so neat?" He noted that "it reflects my respect for my customers." Another respondent cited respect in relation to the "forefathers." Respect is also a factor in sending "remittances" to family members living in mainland China. A respondent also remarked, "Chinese send money back to China to remember their ancestors." 
The respondents consistently cited two Chinese festivals related to family togetherness or fidelity. The first was the Mid-Autumn Festival. An article on the Internet under the caption "Mid-Autumn Festival in China 2019," states:

Ancient Chinese emperors worshiped the moon in autumn to thank it for the harvest. The ordinary people took Mid-Autumn Festival as a celebration of their hard work and harvest. Today, people mainly celebrate the moon festival as a time for family reunions. Mid-Autumn Festival is the second most important festival in China after Chinese New Year. To the Chinese, the festival means family reunion and harmony. It is celebrated when the moon is full, and Chinese people believe a full moon is a symbol of reunion, harmony, and happiness. (emphasis added)

The second holiday commonly mentioned was the Chinese New Year. The Oxford Lexico Dictionary states, "The Chinese festival marks the start of the New Year, beginning on the second new moon after the winter solstice and ending on the full moon fifteen days later. It is marked by visits to family and friends, special meals, fireworks, and gift giving."

The Chinese New Year signifies renewal. In response to the question, "What does the Chinese New Year mean to you?" one respondent remarked, "It means the end of old things and the beginning of new things. It means good luck, new hope, and good fortune." The other respondents echoed these salient meanings associated with the Chinese New Year. One such meaning is respect for ancestors. During the Chinese New Year, Chinese travel to China to show respect to their ancestors. If they are not able to travel, immigrants convene special events to show respect to their ancestors. The values of respect and fidelity of the Chinese are aligned closely with ancestor rituals.

For instance, ancestor worship communicates continuity between the living and the deceased. This ritual fosters a cyclical view of time; it reinforces the values of respect, harmony, reciprocity, and wealth acquisition in families. Ancestor worship 
maintains harmony between the living and the deceased. This ritual communicates the Chinese worldview of integrated wholeness (Lakos 2010, 45).

\section{Dual identity}

Dual identity emerged as a significant value. The data from interviews in category 2 indicate that $40 \%$ of the female respondents had concerns about their dual identity. They were born in the Dominican Republic. These Dominican-born Chinese females are troubled by their inability to speak Mandarin. It robs them of their Chinese identity. This state of liminality — a state of being between two nationalities — denies these women of their full potential as Dominican Chinese.

Dominican Chinese want to be proficient in the Chinese culture and languages. They want to be able to visit China to enjoy its culture and appreciate its history. In my interview (2018) all four females remarked, “Our biggest regret is that our parents did not teach us Mandarin.” One respondent noted, "Culturally, I am Dominican, but philosophically, I am Chinese.” Three factors resulted in their deficiency in Mandarin. Two females cited parental neglect; one female noted the "American war in 1965," and one said, "mental difficulties."

One interesting issue related to dual identity emerged from the data. Mandarin/Spanish-speaking pastors are rare in Latin America. The data from observations at four Chinese Christian churches revealed that none of the churches had a full-time Mandarin/Spanish-speaking pastor. A lay leader from one of the Chinese Christian churches contended, "It is difficult to find a Mandarin/Spanish speaking pastor throughout Latin America."

Literature also shows that being bilingual is an integral part of cultural identity. 
Rumbaut (1991) and LaFromboise, Coleman, and Gerton (1993), in particular, used bicultural and multicultural theories to explain the phenomenon of cultural identity. Xie, Xia, and Zhou $(2014,216)$ concluded that "contact with people from the same country reinforced one's sense of self and one's affinity to the heritage culture, whereas contact with people from the host culture facilitated the entry" into those cultures.

\section{Summary of Findings for Question 2}

This finding describes four Chinese cultural values that may illuminate the Adventist message to Chinese people in the Dominican Republic. These cultural values are hard work, harmony, respect, and cultural identify. The meanings of these values tend to intersect with meanings associated with the Adventist message. These intersections will be discussed in chapter five and may become bridges to contextualize the Adventist message to Chinese immigrants in the Dominican Republic.

Kraft in Anthropology for Christian Witness, contended, "God's message is a message of meaning not a message of form" $(1996,140)$. Finding 2 is a description of the meanings that Chinese collectively give to certain forms within their culture. These

meanings seem appropriate for illustrating the meaning of the Adventist message in ways the Chinese will comprehend and accept.

\section{Research Question 3: Methods for Presenting the Adventist Message}

This section describes the results of the analysis of data from interviews and observations based on Question 3. The question focused on culturally appropriate methods: How can the Adventist message be presented in culturally appropriate ways to Chinese immigrants in Duarte, Santo Domingo, Dominican Republic to (a) facilitate 
their appreciation of that message and (b) foster decisions toward Christ? The findings verify whether or not culturally appropriate methods have significant effects on how Chinese appreciate the gospel and their readiness to make a decision to follow Jesus.

\section{Finding 3: Culturally-Sensitive Teaching and Ministry Methods}

In response to the question, What helps Chinese listen to your message? the respondents tended to cite, among other methods, storytelling. In an interview (November 2018) with two Mandarin teachers and a businessperson, the Mandarin teachers mentioned storytelling as a method for getting Chinese students to listen. This resonated with the businessperson. He exclaimed, "As a child, storytelling caused me to day dream." He used his imagination to acquire new knowledge. Another respondent agreed: "In teaching the substitutionary death of Jesus, I allow the Chinese to imagine a father giving his only son." Chinese Adventist respondents also remarked that storytelling from Chinese missionaries facilitated their appreciation of the message.

In Chinese tradition, students give deference to sages. The sages were often great storytellers. Hesselgrave (1991, 267, 268), in Communicating Christ Cross-Culturally, viewed Christian communicators as "bibliographers." He added, "Chinese have a good appreciation for stories - especially when valuable lessons can be learned from them." Storytelling tends to facilitate a new appreciation for the gospel.

Sixty-six percent of the respondents from category 3 indicated that the Chinese responded favorably to needs-based ministries. The data indicates that Chinese listen to messages related to their health, social, and cultural needs. Mary, a Chinese religious teacher, related how she facilitates Chinese appreciation of the gospel and fosters 
decisions toward Christ. Mary begins her dialogue with Chinese by first listening to their needs:

I listen to find out their needs. When they trust me, they will listen to me. For example, I help the Chinese mothers with children. I also visit them in the hospitals. The Chinese respond to such acts of kindness. Sometimes they cry. These acts of kindness make Chinese want to listen to me. I speak with them in relation to their social needs. Then at an appropriate time in the conversation, I transition to speaking about how Jesus solves our problems.

Mary's needs-based methods led two Chinese women to appreciate the gospel.

Pica, a Chinese migrant, is one of those women. In an interview, she related the influence of Mary's needs-based ministry in her response to the Adventist message. Mary "stayed at my home to assist me in caring for my baby. She also stayed with me in the hospital." This type of social support was meaningful to her because it was during the time of her surgery. She needed someone to assist with her baby. Mary's kindness helped the respondent to appreciate Christianity. Christianity has "changed my thinking. Before my baptism, I was concerned about what people thought about me. If friends disappointed me, I would be angry, but now if they do, I am not angry anymore. When you want to gain something, you need to lose some things. This testimony from the 2018 interview illustrates the influence of needs-based methods on Chinese immigrants' responses and appreciation for the Adventist message in the Dominican Republic.

White's (1905) statement is aligned with this finding: “Christ's method alone will give true success in reaching the people. The Saviour mingled with men as one who desired their good. He showed His sympathy for them, ministered to their needs, and won their confidence. Then He bade them, "Follow Me" (143). However, the statement needs to be adapted to differences in cultures. For instance, how I mingle with Chinese women 
would be different from how I mingle with Moslem women. The need-based method resonates with the Chinese worldview.

The Chinese worldview tends to be humanistic. Both Laotzu and Confucius espoused the goodness of humanity. Xinzhong Yao in his Introduction to Confucianism, cited two main perspectives of Confucius. "First, human goodness can be taught and learned. Second, society can only be in harmony and peace under guidance of wisdom" (2000:26). The Confucian doctrine of humanness (ru) emphasizes the Way (dao), rituals/propriety (li), humanness (ren), and virtue (de). These aspects of Confucian doctrine extol the ability of human beings to make themselves good. Confucius' humanistic teachings continue to inform Chinese perspectives of reality. The data demonstrate that Chinese immigrants do not want to be considered "sinners." They consider themselves "to be good people" with social needs. A needs-based method synchronizes with this Chinese view of humanity (2018 interview).

\section{Summary of Findings for Question 3}

This finding described the effects of culturally-sensitive teaching on Chinese perceptions and decisions. Storytelling tends to change Chinese perceptions by activating their imaginations. They perceive moral lessons in stories and make decisions related to perceived benefits. In addition, Chinese interest in the gospel tends to emerge from their social and cultural needs.

Teaching methods tend to be appropriate if they emerge from prevailing needs. These may include social needs, cognitive patterns, and processes of learning. For instance, teaching methods should foster and facilitate Chinese cognitive patterns to consider multiple alternatives. Methods of teaching should also foster the Chinese 
cognitive mindset for wholeness. Within the literature, William Gudykunst (2003) and Ting-Toomey (1999) showed that the Chinese prefer consensus rather than individual opinion. Methods of contextualizing the Adventist message needs to be synchronized with the Chinese worldview and social needs.

\section{Based on Question 3: Findings 4-7 Relate to Chinese Immigrants' Responses and Decisions}

\section{Finding 4: Language and the Deeper Experience}

Language is also linked to Chinese formative experiences. Chinese immigrants respond favorably to ministries or methods delivered in their mother tongue. Data from participant observations at two Chinese churches confirm the significance of language to first-, second- and third-generation Chinese. This finding examines the effects of language on Chinese immigrants' responses to the gospel in two Chinese churches.

I arrived at the church about 10:00 a.m. on Sunday morning, November 18, 2108. The elder greeted me warmly at the gate. After explaining the purpose of my visit, I was escorted into the worship service. I sat quietly and waited for the service to begin. The program began with singing songs in Mandarin as displayed on a screen. The words of the songs were also in Spanish and English. However, Mandarin was the official language of worship. After the singing, the offering was collected, followed by the announcements and prayer. Then it was time for the sermon.

A visiting pastor delivered the sermon in Spanish. However, a lay leader translated the sermon into Mandarin. The Spanish pastor was spontaneous in his delivery of the sermon, but the Chinese leader read the sermon verbatim. He used intonation to punctuate important points. In contrast, the Spanish pastor emphasized salient points with 
his hands. These cultural differences between the men were conspicuous.

The Chinese leader spoke in Mandarin to facilitate his congregation's appreciation of message. Mandarin was the mother tongue for the first-generation Chinese. On the other hand, Spanish was the mother tongue for the second and third generations of Chinese. As noted before, Mandarin was the official language of the church worship service. The church leaders wanted the Chinese members to appreciate the gospel within the context of their cultural heritage and language.

Data from another observation give insight into how other methods can incorporate language to influence appreciation and decisions for the gospel. At the Banner Chinese Church in Santo Domingo, Dominican Republic, I observed how the church leader and his wife utilized the congregant's first language to facilitate appreciation for and acceptance of their message. It was Thanksgiving in the United States of America. The leader and wife used the occasion to encourage immigrant Chinese to be thankful to God while living in a foreign country.

The worship service began with happy and meditative songs. The words of the songs were in Mandarin and Spanish on a white screen. However, the songs were sung in Mandarin. The message from the leader and his wife was in Mandarin. They used a variety of methods to present the message of encouragement. The methods included images on the screen, questions for interactive learning, role-play, and case study.

The wife read the case study in soft tones. It expressed the sentiments of a son who was not able to be with his parents for Thanksgiving. Many immigrants likely identified with the sentiments of the son. The leader's wife then asked the congregation to describe their feelings by writing them on a slip of paper. After ten minutes, she called 
their attention to a picture on the screen. It showed people forming a circle around a red heart - a clear message of love and unity in spite of separation from love ones. She then divided the members into groups of two. She asked the members to tell stories of encouragement to each other. Finally, she gave members colored cards on which to write brief testimonies of thanksgiving to God. The members joyfully wrote their testimonies. She used appropriate methods to present her message in the languages of the Chinese members (observation in November 2018 interview).

However, not everyone appreciated her message. I interviewed a respondent who had attended the worship service at the Banner Chinese Church. The respondent did not understand everything that was spoken during the worship because she did not speak Mandarin. She was a Dominican-born Chinese. She remarked, "I depended on the members' facial expressions, interactions, laughs, intonations, and application exercises to get insights. My deficiency in Mandarin limited my appreciation of the message." Proficiency in Mandarin appeared to be a critical variable in facilitating an appreciation of the gospel and fostering decisions toward Christ.

Although some later generations of Chinese in the Dominican Republic have not gained fluency in Mandarin, it is a priority for prominent Chinese leaders in the Dominican Republic. For instance, Jack and Jones arrived in the Dominican Republic in 1963 and 1965 respectively. They argued:

Mandarin is not an issue for second and third generations of Chinese in the Dominican Republic. Parents teach their children Mandarin at an early age. They enrolled them in local schools during the week but Saturdays and Sundays, the parents send their children to Mandarin classes. Children go to local schools in order to work and live in the Dominican Republic but they learned Mandarin to maintain their culture and do business with mainland China.

Another respondent echoed similar perspectives on language. She contended: 
Language is vital to immigrant cultural identity. The first-generation Chinese were deficient in the Spanish. However, second and third generations seek to acquire both languages. For example, I ensure that my children speak fluent Spanish and Mandarin. It is necessary to be bilingual to do business in the Dominican Republic and with mainland China.

The Mandarin language facilitates a deeper appreciation for the gospel. First and second languages carry different "emotional valence" (Aragno and Schlachet 1996, 23). The first language, or "mother tongue" (23), encodes immigrants" primary emotions. It is the language of the heart. The second language enables them to appreciate the culture, commerce, and opportunities of their new homeland. While the first language influences immigrants' internal worldviews, second language acquisition gives them access to the opportunities of their host countries.

\section{Summary of Finding 4}

Communicating in Mandarin is a culturally appropriate method for facilitating Chinese immigrants' appreciation of the Adventist message. However, Mandarin is not an end in itself. Immigrants who are bilingual tend to be more effective in their ability to contextualize their messages to first-, second-, and third-generation Chinese.

\section{Finding 5: Pragmatism}

This finding indicates that ministries to Chinese immigrants need to offer tangible and short-term outcomes. The respondents used words such as "benefits," "values," and "practicality" in answering the question, "What motivates you to make a decision?" One respondent, a Chinese teacher, put it tersely: "Chinese are practical people. They want to see and feel the message. The message needs to have benefits to encourage them to listen." The Chinese are concerned with the benefits or the practicality of the message to 
themselves or their children. For instance, a Chinese mother observed changes in her son after he attended a ten-day Christian camp. She allowed her son to continue attending Bible study. It appears that short-term and tangible benefits assist Chinese in making a decision for Christ. Another respondent cited many instances of God's answers to her prayers for her children as practical evidences of divine intervention in the affairs of her family. These evidences may have influenced her husband to make his decision to be baptized. I was in their home when she encouraged her husband to make such a decision. He did not hesitate. He had witnessed firsthand God's answers to his wife's fervent prayers for their children.

This finding reflects the Chinese worldview. Confucius gave preeminence to pragmatism over the supernatural. He urged his disciples to do what must be "rightly done for the people," and at the same time, "keep a distance from spiritual beings" (Legge 1861, Analects 6:20). He was not against spiritual beings. He simply preferred to give attention to practical issues such as harmony and morality in families. Confucius was concerned with "serving human beings" before "serving spiritual beings" (Legge 1861, Analects 6:20). The finding reflects the influence of pragmatism on the Chinese decision-making process.

Buddhism had a profound effect on the Chinese worldview. Its founder, Gautama Buddha, assumed that happiness can be achieved by spiritual self-discipline. Kung and Ching (1989, 200); Bauer (1976, 153-159); Wright (1965, 33, 34) argued that Buddhism influenced the worldview of China through its emphasis on the practices of monastic life, spiritual self-disciple, and rebirth. The authors noted that Buddhism interacted with the pragmatism of Confucianism and Daoism to shape the worldview of the Chinese. 


\section{Summary of Finding 5}

Chinese people tend to prefer practical endeavors. The data reveal that Chinese immigrants respond favorably to messages, ministries, and events that offer short-term benefits. Pragmatism takes precedence over idealism. Mission to Chinese immigrants needs to be contextualized to offer practical benefits to foster the social, spiritual, and economic aspirations of Chinese immigrants in the Dominican Republic.

\section{Finding 6: Socioeconomic Dynamics}

The Chinese invest their time in profitable endeavors. The data reveal that immigrant Chinese spend an average of 12-16 hours per day pursuing commercial enterprises. One respondent shared, "An inch of time is an inch of gold.” This Chinese proverb links profitability with a wise use of time. Chinese tend to associate time with profit. Edward Hall (1983) explained that Chinese tend to engage in multitasking. This means that the Chinese are likely to perform many tasks at the same time. A Chinese mother may be caring for her child in a fabric store while attending to customers. Chinese tend, therefore, to have very little free time to listen to abstract ideas or doctrines.

Chinese also tend to be available only at specific times. Data gathered indicate that Chinese with restaurants are likely to be available between 3:00 and 5:00 in the afternoon, whereas Chinese with fabric stores tend to be available in the mornings. These times reflect slow periods at restaurants and fabric stores. During such slow periods, the Chinese may attend special events said the one being interviewed.

Chinese immigrants do attend religious events. The data indicates that Chinese accept invitations to attend activities such as musical and Mother's Day events, and Thanksgiving, Chinese New Year, and Christmas festivals. The Chinese are likely to 
close their businesses on Christmas and New Year's Eve. Chinese children are often available during the summer and for Christmas events since they want to know the meaning of Christmas. These special occasions provide positive opportunities for Chinese families to attend profitable and practical spiritual events.

\section{Summary of Finding 6}

Chinese immigrants tend to invest more time in economic endeavors than in social interactions. However, they do take time off to engage in profitable and practical social events. These data reveal insights concerning Chinese availability for religious gatherings. Mission leaders may use the Chinese immigrants' time schedule to engage them in culturally appropriate dialogues.

\section{Finding 7: Saving Face and Preserving Harmony}

This finding is related to question 3. It describes the influence of honor and harmony on the Chinese immigrants' decision to follow Christ. A Chinese respondent described his indirect process of guiding other Chinese toward decisions for baptism:

I give examples of persons who were baptized. I then indicate there are persons who are contemplating baptism at a certain time and place. In this way, I indirectly suggest the time and place of the baptism to potential prospects. I invite the prospects to witness the baptism of other Chinese persons. Those who accept the invitation are likely to be baptized with the other Chinese people.

Indirect dialogue facilitates critical thinking without undue influence from religious teachers.

The literature considers the Chinese to be collectivists. In a collectivist culture, Ting-Toomey found that people tend to emphasize "the preferential use of indirect talk, status-oriented verbal communication, verbal self-effacement and silence" $(1999,103)$. 
The author noted further that indirect dialogue promotes "saving of face and harmonious interaction" $(1999,103)$. The literature and the data illustrate that the Chinese preserve harmony through indirect dialogue.

Second, although the Chinese prefer communal-type spaces for eating, chatting, and other forms of interaction, the data reveals that they prefer private spaces, such as their homes, to make personal decisions, including decisions related to the gospel. It seems that privacy gives the Chinese flexibility to change their minds about a decision without losing face with many people. They have a tendency to avoid shame or public attention. Privacy allows the Chinese to contemplate their decisions in a secure and relaxed environment.

\section{Summary of Finding 7}

Chinese tend to learn new idea within the setting of the family. This means small group arenas can be appropriate to disciple the Chinese toward a biblical worldview. Small groups facilitate trust, harmony, and interpersonal relationships and are safe environments for Chinese to experience honor as they evaluate new ideas.

\section{Based on Question 3: Finding 8 Relates to Church Leaders' Attitudes to Chinese Immigrants' Lack of \\ Response to Adventist Message}

\section{Finding 8: The Unknown Factors}

This finding describes Adventist leaders' feelings regarding the Chinese in the Dominican Republic. The data in category 4 reveals that Adventist leaders expressed uncertainty, anxieties, and ethnocentrism towards Chinese immigrants in the Dominican Republic. Notice some of their responses from the interview of November 2018: 
- "I do not know the Chinese people."

- "The Chinese people are secretive."

- "I can't speak Mandarin."

- "We never consider the Chinese for salvation." [This means we do not know how to reach them. Therefore, we have not intentionally attempted to share the gospel with Chinese immigrants.]

- "We know how to evangelize Hispanic people, but we do not know how to evangelize Chinese."

- "I do not know the Chinese culture."

- "We need Chinese pastors."

- "The Chinese are only concerned about work and money."

These perspectives illuminate the research problem. Church leaders seem satisfied with the high receptivity and conversion of Hispanic people, but are still searching for a new model for contextualizing the Adventist message for the 50,000 Chinese immigrants in the Dominican Republic.

\section{Summary of Finding 8}

The leaders' anxieties and uncertainties are legitimate. These feelings are the result of their ignorance of Chinese values, history, and culture. This ignorance produces "discomfort" among the leaders due to "unpredictability." Mission to the Chinese can be intimidating. The discussion of the findings in chapter 5 may give leaders new skills and knowledge to minimize their uncertainty and anxieties.

\section{Integration of Findings with Conflict- Competence-Based Theory}

The literature confirms the fact that specific dialogue strategies enhance relational outcomes. The data from this research demonstrates that culturally-sensitive teaching promotes a consensus of ideas. It appears from the data that a consensus of ideas increases Chinese perceptions of the competence of religious teachers. Such perceptions promote harmony between the Chinese and their teachers. It appears from the data that 
culturally sensitive teaching synchronizes with Chinese patterns of thinking. This method of teaching promotes a synthesis of alternative views to arrive at a consensus. Chinese cognitive processes value wholeness, instead of the part. Culturally-sensitive teaching, such as storytelling, interactive learning, and rote learning, relates positively to harmony and satisfactory outcomes. In addition, social ministries (referred to as ministry methods) promote the satisfaction of the basic needs of Chinese immigrants. This satisfaction evokes a reciprocal response from Chinese immigrants who are beneficiaries of social ministries from church leaders. Social ministries facilitate a harmonious relationship between church leaders and Chinese immigrants. Social ministries and culturallysensitive teaching not only foster consensus, satisfaction, harmony, and relational outcomes, but also convey a perception of the teachers' competence.

The data also demonstrate that six of the findings are related to the perception of competence. Canary and Spitzberg defined competence as a "molar assessment of the quality of interaction" or a "general impression that results, in part, from evaluations of an interactants' conversational behavior" $(1987,631)$. Church leaders who assist Chinese immigrants to resolve their cognitive dissonance are perceived as competent. Immigrants tend to value the support and guidance of a church leader during crisis. Chinese tend to be solution-oriented. Persons who help them resolve a crisis are perceived as competent. Messengers need to demonstrate competence in other areas. A person who illustrates he or she knows the meanings ascribed to components within Chinese culture may enhance Chinese perceptions. Competent messengers use meanings within culture to illustrate their messages. They also communicate in the mother tongue of the listeners. They use the mother tongue to facilitate a deeper experience for the listeners. Such 
persons can further enhance their perception of competence through practical and illustrative religious instructions. Chinese immigrants tend to perceive others to be competent: (1) if the messages are in their mother tongue, (2) the messages offer practical benefits to family members, and (3) Chinese cultural forms and meanings are used to illustrate the messages. Chinese immigrants are inclined to amass large fortunes for themselves and their relatives. Teachers may be perceived as competent if their instructions facilitate acquisition of wealth, prestige, harmony, and honor. The data demonstrate that Chinese immigrants tend to perceive others to be competent when they use appropriate supportive strategies to help Chinese cope with crisis.

Harmony and face saving promote relational outcomes. According to Canary and Spitzberg relational outcomes refer to "trust, control, intimacy and satisfaction" (1987, 633). The data indicate that Chinese immigrants' work ethic is linked to a desire for honor and harmony in families and with the local people. A prominent respondent summarized the immigrants' desire for honor and harmony. "There are no Chinese immigrants in the Dominican Republic penitentiary." This statement echoes the immigrants' desire for honor, to avoid shame, and to achieve family harmony. Harmony and honor also foster appropriate relational outcomes between Chinese immigrants and Dominicans.

For instance, indirect dialogue in an appropriate place can be used to encourage the Chinese to make or postpone decisions without losing face in front of others. Chinese tend to have a positive view of indirect dialogue. By not losing face, Chinese are able to maintain harmony with their teachers, local people, family members, and government officials. 
Canary's and Spitzberg's (1987) Conflict-Competence-based Theory puts seven

of these research findings into perspective. These findings foster integrative relationships that relate positively to perceptions of competence. A competent person is likely to use appropriate communication strategies, such as integrative dialogue, to evoke and sustain trust, satisfaction, harmony, appreciation, and acceptance of his or her message.

\section{Summary}

This chapter described seven findings that provide valid answers to three research questions. Finding 1, cognitive dissonance, related to Question 1 regarding factors affecting Chinese responses to and decisions about the gospel. Finding 2, meanings within culture, is linked to Question 2, which investigated the meaning of four Chinese cultural values: hard work, respect, harmony and cultural identify. Findings 3, 4, 5, 6, and 7 (culturally sensitive teaching and ministry methods, language, and the deeper experience, pragmatism, socioeconomic dynamics, saving face and preserving harmony) responded to Question 3's inquiry into appropriate methods for presenting the Adventist message.

These findings are valid. They emerged from the data derived from interviews and observations, while the literature triangulated the findings to confirm their validity. In addition, the findings were integrated into a theoretical framework to give additional validity and reliability.

The Scripture determines the relevance of the findings in creating a model of contextualization. The next chapter discusses the findings in the context of biblical themes to reinterpret, clarify, change, or reinforce the meaning of the findings. The theories of biblical exegesis and cultural contextualization help to facilitate the 
development of a new model of contextualization of the Adventist message to Chinese immigrants in Latin America. 


\section{CHAPTER 5}

\section{TOWARDS THE DEVELOPMENT OF A BIBLICAL AND MISSIOLOGICAL MODEL OF CONTEXTUALIZATION FOR CHINESE IMMIGRANTS}

\section{Introduction}

This chapter discusses the field research findings. The purpose of the discussion is to develop a biblical, cultural, and missiological model for presenting Christ to Chinese immigrants in the Dominican Republic. This model will facilitate the Chinese immigrants' journey toward Christ. The journey refers to immigrants' gradual decisions to follow Jesus. The decision to follow Jesus is a dependent variable. Other dependent variables include Chinese responses to and appreciation of the gospel. The independent variables are biblical exegesis, cultural contextualization, interrogative methodology, and conflict competence theory. These independent variables tend to influence how Chinese immigrants respond to, appreciate, and make decisions about Christ.

The chapter examines cultural themes in light of biblical theology to determine their cultural and missiological significance and proposes a biblical and culturally sensitive model for presenting Christ to Chinese immigrants in the Dominican Republic.

In my discussion of the research findings, I proposed examining the results within the framework of creation, covenant, and eschatology. These themes seemed to synchronize with the Chinese immigrants' cultural themes of relationship, identity, and fortune. 


\section{Discussion of the Findings}

Finding 1: Cognitive Dissonance

Finding one indicates that crisis events positively affect Chinese immigrants' decisions to accept Jesus and the Adventist message. Five out of six respondents in category 3 (Chinese converts) identified crisis events as major factors in their decisions to follow Jesus. The data from the interviews indicate that more than $50 \%$ of category 3 participants considered a crisis event to have influenced their decision to follow Christ. During these crises, the respondents sensed the need for relationship, protection, emotional support, and reciprocal responses, and they expressed appreciation for God's faithfulness.

The Bible cites numerous examples of crisis events. The first crisis event (Gen 3:6-7) was an act dishonoring the God of heaven. This act of dishonor caused a broken relationship, fear, anxiety, and loss of face in the first family (Gen 3:9-10). In Gen 3:15, the God of heaven made a covenant to restore harmony, honor, and fidelity in families. In this covenant, God would send His only Son to defeat sin and the dragon (Gen 12:3; John 3:16). This act of deliverance would restore families' relationships with their Creator.

The Bible indicates that God also created crises in the minds of heathen kings. The crisis events took different forms, but the goal was the same-conversion and accessibility. In some crisis events, God issued severe warnings (Gen 20:3); in others, sudden death (Exod 13:29); in still others, disturbing dreams (Gen 41:8; Dan 2:1, 4:5), mysterious writings (Dan 5:6), a bright light from the heaven (Acts 9:3-4), and visions (Acts 10:3). These events created cognitive dissonance in the minds of Abimelech, Pharaoh, Nebuchadnezzar, Belshazzar, Paul, and Cornelius. God disturbed the minds of 
these leaders with words, dreams, death, visions, and light. The Bible indicates that these leaders needed God's servants to resolve the cognitive dissonance in their minds.

God revealed to His servants how to support heathens in their crises. For instance, Abraham prayed that God would heal Abimelech (Gen 20:17). Moses appeared to be sympathetic and tolerant of Pharaoh during his times of crisis (Exod 10:27-29). Daniel revealed to Nebuchadnezzar his dream and its interpretation (Dan 2:31-41). He also interpreted the handwriting on the wall for Belshazzar (5:24-28). In the New Testament, Ananias visited Saul, laid his hands on him, and baptized him (Acts 9:17-18). In addition, Peter visited Cornelius to learn about his encounter with God and to reveal to him that Gentiles were also included in the plan of salvation (10:34-36). These crises provided opportunities for God's servants to give moral support and to communicate His message to secular leaders.

Even heathen kings responded to God's message. For example, Abimelech gave gifts to Abraham and restored his wife, Sarah, to him (Gen 20:16). Pharaoh made Joseph the ruler over his house and his people $(41: 39,40)$. Later, Pharaoh allowed the Israelites to leave Egypt to serve their God (Exod 12:13). Nebuchadnezzar also responded. He "fell on his face" to offer praise to God, and he promoted Daniel and gave him many gifts (Dan 2:46-48). Belshazzar also gave gifts to Daniel and promoted him to be third in command of the kingdom (5:29).

A pattern emerges from an assessment of the theology of crisis events. A crisis tends to be followed by a desire for relationship and support. Human support helps to restore a balanced state of mind. This return to equilibrium inspires gratitude to God and others for their support and insights during the crisis event. 
The Bible gives new meaning to human crises. It appears that a crisis creates a need for new insights and additional support. When new insights and support help resolve a crisis, the person tends to change his or her attitude toward God and others. The life of such a person is characterized by humility and reciprocal overtures. As seen in the biblical passages, the heathen kings bore witness to God's power to resolve crises, reveal mysteries, and give new direction. God works through human crises to restore families into relationship with Him and bring families into contact with His servants.

A review of Scripture reveals that God sometimes caused crises in the minds of heathen kings to give His servants access to those kings. In addition, God worked with His servants to reveal the plan of salvation to those kings. The kings responded with humility, gratitude, and honor to God and His servants.

Within the context of covenant and relationship, the Adventist message can bring new meaning to crisis events. Jesus restores us into relationship with Him in times of crisis. In a seminal article entitled "Jesus Christ for the Chinese: A Contextual Reflection," Wan argued, "In contrast to the rationalistic and forensic presentation of Jesus Christ, Sino-theology is highly relational. This method of relational theologizing is most adaptable to the primarily agricultural mind-set of people from the two-thirds-world (i.e., Asia, Africa, and Latin America) where [a] strong personal relationship is of supreme importance" (2003a 7, 8). According to Wan, Sino-theology presents Jesus to Chinese as “fu-he-zhe 復和者 Redeemer—one who reconciles us unto God" $(7,8)$.

Jesus should be contextualized to Chinese immigrants in the Dominican Republic as One who restores harmony in families. God created the first family to live in 
relationship with Him. He created them with honor and glory. Scripture says that God made the first family with the capacity to love and to live in harmony with their Creator and each other (Gen 1:27-29). In spite of the Creator's fidelity to the first family, the family chose to dishonor Him. The family disregarded the law of harmony established by God (Gen 2:16-17). The family dishonored God and brought shame to all families. This was the first human crisis, and it created disharmony between the Creator and the first family. They hid themselves from the Creator. However, God came looking for the first family because He wanted to restore their relationship with Him.

In Gen 3:15, 12:3, and Matt 1:21, the Creator announced His plan to restore relationship with "the families of the earth." God sent Jesus to bear our shame. He died a shameful death on a Roman cross. His own people humiliated him by spitting in His face (Matt 27:27-31; Phil 2:5-11). Jesus redeemed us from the curse of the law by becoming the curse for us (2 Cor 5:21; Gal 3:13). He bore our shame and curse to give us honor and glory and to reconcile us unto Himself. Emphasizing what God has done to give honor and glory to families may evoke reciprocal responses from Chinese immigrants.

All families are indebted to Jesus. He died so that all families may be reconciled to God through the death of His son. Therefore, we owe God our love, loyalty, and lives. The biblical theme of covenant gives new meaning to the Chinese cultural themes of relationship and reciprocity. The faithfulness of God, in spite of humanity's dishonoring Him, requires reciprocal responses from every family.

The crisis event began the process of conversion for some of those kings. The research data and Scripture suggest that crisis events create a need to regain cognitive equilibrium. This need is satisfied through human support, new insights, and a renewal of 
relationship with God and family members. God appears to allow or create crises in the minds of Chinese immigrants in order to reconcile them unto Himself and give His church opportunities for ministry. The church may frame its message to Chinese immigrants in crisis by integrating biblical themes of creation, covenant, and eschatology with cultural themes of honor, shame, and relationship. In this way, its message to Chinese immigrants in Latin America will be more biblically authentic and culturally sensitive.

\section{Finding 2: Meanings within Culture}

Cultural values have specific meanings. People within the culture ascribe meanings to their values. The data indicated that Chinese immigrants consider hard work, respect, harmony, and dual identity to be significant values. Each of these values has specific meaning to the immigrants. However, Scripture also reinterprets the meanings of these values.

The four values are discussed within the framework of creation, covenant, and eschatology. Each value is framed by one or two biblical themes. The covenant motif frames respect and harmony. The eschatology motif frames dual identity. Hard work is framed in the context of creation. This framework will assist me in discovering the biblical meaning and missiological relevance of the values.

\section{Hard Work}

Chinese immigrants in the Dominican Republic interpret hard work to mean several things: security, honesty, honor, avoidance of shame, wellness for the family, and the pursuit of a better life. These understandings of hard work find new meaning in Scripture. 
Scripture maintains that work began with God. In the beginning, God created the heavens and earth. He created it in six literal days (Gen 1:31). On the sixth day, $\mathrm{He}$ created the first family as the crowning act of His work (v. 31). On the seventh day, He ceased from His work to give the family an opportunity to ascribe honor and glory to their Creator (2:1). Even before the first family began to exercise dominion over God's creation, they found their significance/security in giving glory to Him for who He is and what He had done for them. God gave honor to His work. In other words, work derived its honor from its Creator. The Creator shared His honor with the first family. He gave them the task of naming the animals and caring for His creation (Gen 1:28; 2:20). This was an act of honor. The first family did not receive honor based on their work. Rather, God honored them by giving them dominion over His creation.

The first family dishonored God. They transferred their right to rule over His creation to an evil being. The family lost the honor God had bestowed on them and they attempted to restore their honor through work. They made themselves clothing from "fig leaves" (Gen 3:7), a symbol of honor through work. Work, rather than God, became the source of their honor and glory. God honored the first family with work. After they dishonored Him by transferring their right to rule over His creation to an evil being, God redefined the meaning of work for the first family. Work functioned as a means of discipline to lead them to ascribe glory and honor to God. A better life and the wellness of the family were not achieved through the discipline of work, but were derived from their relationship with their Creator.

The New Testament also puts work in its right perspective. In Rom 3:20-31, Paul argued, "By the deeds of the law there shall no flesh be justified." For instance, if 
Abraham's security, wellness, protection, and honor were dependent on his works, then he had something to boast about, but not before God. In other words, such works would have given temporary honor to Abraham, but they would have dishonored God. Rather, Abraham chose to honor and be loyal to God. Then God honored and blessed Abraham with prosperity, wellness, security, and a better life.

Scripture gives new meaning to work. The Adventist message needs to reinterpret the meaning of work for Chinese immigrants. First, work is a gift of honor from God to human beings. People derive security and prosperity from God. Scripture says, "Both riches and honor come from You ... and it is of His own we give unto God" (1 Chr 29:12, 14). God uses work to honor and discipline the human family. However, the honor derived from work, such as face, fortune, respect, family wellness, and hope for a better life, are not inherent in the work. These face-honor qualities come from God. In $1 \mathrm{Chr}$ 29:15-17 (NIV), David acknowledges God to be the Source of these face-honor qualities:

We are foreigners and strangers in your sight, as were all our ancestors. Our days on earth are like a shadow, without hope. LORD our God, all this abundance that we have provided for building you a temple for your Holy Name comes from your hand, and all of it belongs to you. I know, my God, that you test the heart and are pleased with integrity. All these things I have given willingly and with honest intent. And now I have seen with joy how willingly your people who are here have given to you.

God gives these face-honor qualities to families to test their loyalty to Him. The Adventist message needs to interpret these qualities for the Chinese in the context of relationship. God honors families through work so that families will return glory and honor to Him. It is the obligation of families to be loyal to God. He is the Source of their protection, honor, family wellness, and better life.

Families are indebted to God. Sin broke families' relationships with God. Paul said families became "aliens, ... strangers, ... having no hope, without God in the 
world" (Eph 2:12). However, Jesus paid the debt that families could not pay. He reconciled them "unto God in one body by the cross" (v. 16). He "came and preached peace to you which were afar off, and to them that were nigh" (v. 17).

God honors families with work. He is the Source of all of the privileges that come from work. Therefore, Chinese immigrants are indebted to God. Since Jesus paid the debt that they could not pay, they are invited to respond by giving Him their loyalty, love, and lives.

\section{Care and Respect}

Chinese immigrants also link hard work to respect. Respect is viewed as a debt every child owes to parents, ancestors, employers, and the emperor. However, Chinese immigrants in Latin America are more concerned with respect as it relates to families and ancestors. Respect in Chinese culture is based on the principle of reciprocity. Kuang-Hui Yeh and Olwen Bedford (2004) contended that "reciprocal filial piety is based on the idea that children should repay their parents for their lives, and the expense and trouble of raising them. This fact can never be questioned, so the existence of the obligation is likewise unquestionable" (141). Because of the meaning given to the parent-child relationship in Chinese culture, children are obligated to respect parents and ancestors. Parents give birth to the child, care for the child, and educate the child. It is then the obligation of the child to reciprocate with respect, honor, and material support.

Scripture echoes this theme of children's obligation to their parents. Exodus 20:12 admonishes children to "honor thy father and thy mother: that thy days may be long." However, Paul suggested in Eph 5:4 that parents can be overbearing and demanding, thus putting unnecessary pressure on children to fulfill their expectations of respect and honor. 
$\mathrm{Wu}(2015,153)$ considered the demand of "reciprocal filial piety" as one of the "false gods" in Chinese culture. He suggested that children's obligations to their parents could become so overwhelming that parents usurp the respect due to God.

Scripture frames respect within a covenant motif. God said, "Thou shalt have no other gods before me" (Exod 20:3, KJV). He is "jealous" (v. 5). He is no "respecter of persons" (Acts 10:34, KJV). He admonished, "Call no man father" (Matt 23: 9, KJV), for "God alone is our Father" (v. 9). These verses imply that God alone deserves our allegiance. He created people with an innate yearning to love, respect, worship, honor, and be loyal to Him. He is our Creator. While Scripture commands worship of the Creator God, it forbids the worship of ancestors. This practice is incompatible with the teachings of Scripture.

The doctrine of natural immortality teaches consciousness in death. This form of spiritualism originates with Satan's first lie to Eve: "Ye shall not surely die" (Gen 3:4). For many, the divine sentence that "the soul that sinneth, it shall die" (Ezek 18:20) has been reversed to say, "The soul, even though it sins, shall live eternally." The doctrine of natural immortality contradicts the biblical principle of immortality (Schwisow 2010, $354)$.

The Bible declares that God alone is immortal. He is uncreated, self-existent, and has no beginning or end (1 Tim 6:16-17). The Bible does not teach that humans or their souls possess the quality of immortality. On the contrary, the Bible declares that God is immortal, but man is mortal (Job 14:2; Ps 78:38; Jas 4:14). This means that men and women are susceptible to death. In the Bible, death is described as a sleep. In other words, death is the cessation of life (1 Kgs 2:10, 11:43, 14:20; $2 \mathrm{Chr} 21: 1$; John 11:11). 
The Bible asserts that death is an unconscious state. In this state, there is cessation of thinking, feeling, and activity. The Bible says, "The dead know not anything" (Eccl 9:5), "his thoughts perish" (Ps 146:4), "there is no work . . in the grave" (Eccl 9:10), "their love, and their hated, and their envy, is now perished" (v. 6), and finally, "the dead praise not the LORD” (Ps 115:17).

The Bible does not sanction ancestor worship. However, the Bible admonishes that respect be given to persons in authority. For instance, Chinese respect for sages, emperors, hierarchy, and living relatives synchronizes with the biblical view of respect. First Peter 2:17 says, "Show proper respect to everyone, love the family of believers, fear God, honor the emperor." The Bible advocates respect for everyone. This research finding indicates that respect has unique meanings in Chinese culture. Within the framework of the covenant, contextualizers should use Scripture to reinforce respect for the living and change the relational bond Chinese immigrants tend to have for the deceased. Contextualizers should first seek to transfer the affection of Chinese immigrants to Jesus. Second, by illustrating what Jesus did to honor, protect, and prosper them and to restore their broken relationships with Him, Chinese immigrants may reciprocate to transfer their allegiance and affection to Jesus. Thus, the goal is to establish new relations of trust in the living Christ.

The biblical view of respect can also be contextualized within a covenant motif. God treats everyone with respect. He sends "rain on the just and on the unjust" (Matt 5:45). He is the Father of all families. Paul argued that faith in Christ makes humanity one family (Gal 3:28; Eph 2:15, 3:28). All families owe their respect first to God. Children's respect for their parents originates from their respect for God. God gives 
children honor, face, and dignity. The children shared this honor with their parents. Respect flows from a covenant relationship between the receiver and the giver. God's faithfulness to families evokes respect and honor from each family member.

Interpreting the Adventist message within a covenant father-child relationship may resonate with Chinese families. For Chinese immigrants, this contextualizes respect in ways that are culturally sensitive. They may begin to reformulate their beliefs about the meaning of respect (Matt 10:34-39). In addition, they might modify their understanding of respect for fathers and mothers (Matt 12:50; Mark 3:35). The covenant father-children paradigm teaches Chinese immigrants to reinterpret the meaning of allegiance and honor/respect in families. This reinterpretation may release children from excess anxiety and undue pressure. Chinese parents may also make adjustments in the demands they place on their children. Such changes may foster new perspectives on the meaning of harmony in Chinese culture.

\section{Harmony}

Harmony holds relationships together in Chinese culture. Chinese immigrants seek to maintain harmony with family members, local people, government officials, and nature. The respondents in this study interpreted harmony to mean "not causing trouble among the local people, fidelity in marriage, solidarity with government, and avoiding shame through hard work." The Chinese believe it is their responsibility to maintain harmony to avoid losing face with others. However, the Chinese meaning of harmony does not always synchronize with the biblical meaning of harmony.

Harmony is framed within the covenant and creation motifs. At the end of creation week, God declared that everything "was very good" (Gen 1:31). He made 
everything in perfect harmony. For instance, "the herb that yields seed according to its kind, and the tree that yields fruit ... according to its kind" (Gen 1:12, NKJV). The first family lived in harmony with their Creator. In addition, they lived in harmony with each other and with nature (Gen 1:27-28, 2:20-24).

Genesis 3:7-8 reveals that the first family lost face with God. Chaos entered into God's perfect creation. However, in verse 15, God announced His plan to restore honor and harmony to families. He further expanded this covenant promise in Gen 12:3: through Jesus "shall all families of the earth be blessed."

Jesus is the $f u$-he-zhe 復和者. He restores us to harmony with His Father, the Holy Spirit, and Himself. There is perfect harmony in the Trinity. Jesus declares, "I and my Father are one" (John 10:30). Harmony epitomizes who God is. He lives in harmony with Himself, His creatures, and all of His creation. Harmony is an attribute of the Trinity. The harmonious work of the Trinity is evident throughout Scripture such as at the creation of the first family and the baptism of Jesus. The Godhead worked in harmony to fulfill God's mission of redemption.

In contrast, Chinese immigrants foster harmony to avoid shame. The research data from the interviews revealed that Chinese immigrants are hesitant to speak against government officials or local people in the Dominican Republic. Wu $(2015,158)$ observed that the Chinese use reciprocal activities to maintain harmony in families. For example, they exchange gifts to keep family members indebted to each other. This sense of obligation to each other fosters harmony. It seems Chinese pursue harmony to avoid shame.

Harmony in Scripture is a coordinated strategy to restore the human family's 
relationship with the Godhead. Harmony in the Trinity is the basis for harmony in families. Scripture suggests that harmony in a family mirrors harmony in the Trinity. Biblical harmony fosters honor and reconciliation, rather that the avoidance of shame. Jesus explained the meaning of harmony: "My prayer . . that all of them may be one, Father, just as you are in me and I am in you" (John 17:21, NIV). Jesus prayed that families would live in harmony with God and with each other.

In the context of eschatology, the new heaven and the new earth illustrate the biblical view of harmony: "The lion shall play with the lamb. There shall be no disharmony in my entire holy mountain" (Isa 65:25, NIV).

Chinese immigrants need a holistic view of harmony. Harmony is more than avoiding shame. It is pursuing and maintaining a relationship with Shang Di - the God of heaven. This new meaning is framed in the context of creation, covenant, and eschatology. In this framework, Chinese immigrants may understand the harmonious working of the Trinity to restore families into a relationship with their Creator. God's work of harmony may clarify their perspectives of harmony and inspire them to live in harmony with Him. By living in harmony with God, immigrants will obtain a new identify.

\section{Dual Identity}

Chinese immigrants, as well as Dominican-born Chinese, are concerned about their state of liminality. Liminality is a state of having one's identity divided between two countries. Dominican-born Chinese want to be Dominican and Chinese at the same time. Dual identity is a cherished value for Dominican-born Chinese. Dual identity includes the ability to speak Spanish and Mandarin fluently. This bilingual skill enables Dominican 
born Chinese to enjoy the cultures and amenities of both countries.

This cultural theme of dual identity can also find its meaning in biblical eschatology. In the context of eschatology, persons with dual identities were included in the heritage of the Messiah. It appears that Ruth and Rahab were included to illustrate the Messiah's eschatological mission to redeem people from every nation, language, and culture. For instance, Ruth the Moabite left her homeland to become an Israelite. Her mother-in-law, Naomi, introduced Ruth to Boaz, whom she later married. Ruth gave birth to Obed. He became the father of Jesse, who was the father of David (Ruth 4:18-21). The Messiah came through the lineage of David. This means that Ruth is part of Jesus' ancestral line. People with dual identities are included in the heritage of the Messiah.

Matthew listed Rahab in his genealogy of Christ: "Salmon begot Boaz by Rahab" (Matt 1:5, NKJV). Ruth and Rahab had dual identities. It appears that Ruth and Rahab spoke Hebrew as well as their native languages. God worked through their bilingual proficiency to give eschatological meaning to their dual identities. In Heb 11:13-16, Paul expressed Ruth's and Rahab's eschatological vision for a "better country" where "God is not ashamed to be called their God: for he hath prepared for them a city." In Rev 7:9-12, NKJV, John described the culmination of this eschatological vision: "After these things I looked, and behold, a great multitude which no one could number, of all nations, tribes, peoples, and tongues, standing before the throne and before the Lamb, clothed with white robes." This great multitude consists of persons with multiple identities whom the Lamb redeemed. The Bible contextualizes dual identity within the framework of eschatology. This framework gives new meaning to dual identity. At conversion, immigrants become members of the body of Christ. Paul referred to this new identity as being "fellow citizens 
with God's people and also members of his household" (Eph 2:19, Phil 3:20-21 NIV).

This represents a new dual identity. By faith in Christ, Chinese immigrants become members of the body of Christ and of the coming kingdom. In Heb 11:13, Paul summarizes the biblical view of dual identity: "All these people were still living by faith when they died. They did not receive the things promised; they only saw them and welcomed them from a distance, admitting that they were foreigners and strangers on earth" (NIV). Chinese immigrants are likely to respond to this new meaning of dual identity that is biblically sound and culturally relevant.

\section{Finding 3: Culturally-Sensitive Teaching and Ministry Methods}

Storytelling and social needs relate positively to the Chinese immigrants' appreciation of the gospel and decisions for Christ. Chinese immigrants generally prefer listening to the gospel through stories. Storytelling synchronizes with the Chinese immigrants' collective pattern of thinking. Such thinking focuses on the holistic concept of a story. In this discussion, storytelling is framed in the context of creation. The gospel is a story. It began at creation and moves towards an eschatological end.

In addition, 66 percent of the Seventh-day Adventist Dominican Chinese in this study indicated that social activities contributed to their appreciation of the gospel.

Social needs are examined within the context of covenant. This biblical theme relates to the cultural theme of relationship. Social needs tend to be relational. Based on the data, these needs include parenting, health, education, and visitation.

Scripture puts storytelling and social needs into context. God is the source of the grand narrative of Scripture (Gen 1:1; John 1:1-3, Col 1:15-18; Heb 1:2-3). The content 
of the story comes from Him. Flemming noted, "Jews understood Logos to be the preexisting wisdom of God" $(2005,260)$. John used the word logos because it resonated with both Jewish and Hellenistic cultures. John considered the Logos to be the essence of who God is. He is "full of grace and truth," and "we beheld his glory" (John 1:14). He is the Image of the invisible God (Col 1:15). In Revelation, Jesus is "Alpha and Omega" (Rev 1:8), and is the "One who lives and was dead" (Rev 1:18). Jesus is Creator, Redeemer, and King. The story is first about who God is.

The story also describes what God has done. He created all things in six literal days (Gen 1:31). This included the creation of the first family in His image. He gave the first family dominion over all His creation. He honored the first family with His presence, marriage, and the Sabbath. The family dishonored themselves by violating His laws. This act of disobedience brought shame to the first family. They hid from the glory of their Creator. He went in search of the first family to announce His plan to restore "all families" (Gen 12:3) into relationship with Him. God has always been faithful to this covenant promise. In Exod 20:1 (NIV), God reminded Israel of His mighty acts: "I am the LORD your God, who brought you out." Exodus 15:4-7 (NIV) tells the story of God's deliverance:

Pharaoh's chariots and his army he has hurled into the sea. The best of Pharaoh's officers are drowned in the Red Sea. The deep waters have covered them; they sank to the depths like a stone. Your right hand, LORD, was majestic in power. Your right hand, LORD, shattered the enemy. "In the greatness of your majesty you threw down those who opposed you."

The story of God's acts of deliverance continues in the New Testament, which includes Jesus' acts of healing, compassion, and death on Calvary. He bore the shame of families to give them His honor and glory. The story will come to a climax at the coming 
of the King (Matt 9:36-38, 27:45-47; Rev 1:7). Jesus is the Source of the story. The Bible writers used various genres (see chapter 2) to communicate the grand narrative to their audiences. However, Jesus remained the central figure of the story. The narrative reveals who Jesus is and what He has done to restore families to a right relationship with Him.

The Bible frames social needs in the context of the covenant. The first family's disobedience led to a broken relationship. This separation from God resulted in shame, pain, loneliness, and sickness. God works through our social needs to bring glory to Himself and restore the dignity of families. Jesus interpreted Lazarus' death as an occasion to bring glory to God (John 11:40). He honored His brother by restoring Him to life. Matthew 9 explains what Jesus did in response to human needs. He went from village to village teaching, preaching, and healing the sick. He wanted everyone to know that He had the power to forgive sin and restore families to wholeness. Human needs convey human frailty and provide an opportunity for God to be glorified through human weakness. Human brokenness is measured in the context of God's glory. Paul emphasized this frailty by stating, "All have sinned, and come short of the glory of God" (Rom 3:23). The glory of God exposes our frailty. White said, "One ray of the glory of God, one gleam of the purity of Christ, penetrating the soul, makes every spot of defilement painfully distinct, and lays bare the deformity and defects of the human character" $(1846,30)$. The glory of God reminds us of who we are and of who God is God restores our frailty. Storytelling and meeting social needs demonstrate the holistic nature of the grand narrative. It communicates a dynamic interaction between the divine and human in the process of making us whole. This holistic view synchronizes with Chinese immigrants' appreciation of wholeness. 
Chinese missionaries have a tendency to view Chinese immigrants' social needs as a starting point to begin conversations. Others view social needs as issues to be solved to make Chinese immigrants receptive to the gospel. Both of these views have strengths. However, Scripture purports a more noble rationale for addressing Chinese immigrants' social needs. In John 9:3, Jesus indicated that His motive for healing the man was "that the works of God might be displayed in him." In addition, Jesus stated that Lazarus' sickness was "for God's glory so that God's son may be glorified" (John 11:4). Jesus healed the sick to bring glory to Himself and His father (Luke 13:13).

Chinese immigrants need to be exposed to God's glory. The glory of God exposes human limitations and flaws (Isa 6:1-6; Acts 9:1-6; Rev 1:12-17). Storytelling may be used to expose Chinese immigrants to God's glory, what He has done, why Jesus is important, and how Chinese immigrants may respond to Him. Telling the story in this sequence may help Chinese immigrants appreciate the gospel and make a decision based on who God is and what He has done.

Finding 4: Language and the Deeper Experience

Chinese immigrants respond favorably to the gospel delivered in their mother tongue. Data from participant observations at two Chinese churches confirm the significance of language to first-, second-, and even third-generation Chinese.

God created the first family with the ability to speak. It was a gift from God. However, the first family used the gift of language to dishonor the Creator (Gen 3:1-5). Wu (2015) argued that Gen 11:1-3 expresses the Chinese view of dishonor and shame. The verses tend to convey a collective act of disobedience against the God of heaven. 
Scripture tends to frame language in the context of eschatology and creation. It appears that the human family spoke one language at creation. Scripture states, "Now the whole earth had one language and one speech" (Gen 11:1, NKJV). Everyone spoke the same language. Gen 11 indicates that the people used their monolingual skill to rebel against God. They attempted to make a name for themselves by building a tower to reach to heaven. Their ability to understand each other focused their efforts in one place and on one project. God confused their language to prevent them from understanding each other, to stop the building project, and to scatter the people over the face of the earth. It appears that they were scattered over the face the earth according to their languages. Language propelled the migration movement with families having similar languages migrating together.

John uses the word logos to convey the idea that Jesus is the "Expression" of His Father. Jesus reflects the fact that His Father is "full of grace and truth" (John 1:14). Jesus is the authentic Language of the Father. He expresses the attributes, character, and thinking of His Father. Paul captures the theology of language: "In the past God spoke to our ancestors through the prophets at many times and in various ways, but in these last days he has spoken to us by his Son. ... The Son is the radiance of God's glory and the exact representation of his being" (Heb 1:1-3, NIV). Jesus is the Language through whom God speaks to the human family.

God used language to scatter people. He also used language to gather people. In Acts 2:4-7, Luke relates that the Holy Spirit gave bilingual abilities to the Apostles so that people residing in Jerusalem from "every nation under heaven" could have the good news in their own language. However, the Holy Spirit gave them the ability to 
communicate in the multiple languages of their listeners. Acts 2 resembles Gen 11. The devout men gathered in one place. In that place, all who listened heard in their own "tongues the wonderful works of God" (2:11). Each heard in his/her own language that "God hath made the same Jesus, whom ye have crucified, both Lord and Christ" (v. 36). In other words, Jesus bore their shame to give them His honor. He honored them with the indwelling power of the Holy Spirit. Therefore, all of the people present heard of God's works of honor in their own language. What God has done to honor the human family needs to be communicated in the language and perspective of the hearers.

God's acts of honor synchronize with the Chinese immigrants' cultural themes of shame and honor. The Adventist message needs to emphasize what God has done to honor the human family. Chinese immigrants will hear the message of honor from their cultural vantage point. Such a contextualized message may awaken reciprocal responses from them.

Sharing this message of honor in the mother tongue of Chinese immigrants may effect changes in their lives and culture. Honor is a contextualized message. However, the mother tongue is the culturally appropriate vehicle to deliver that message.

Finding 5: Pragmatism

A practical presentation of the gospel positively affects how Chinese immigrants respond to the gospel. The data indicate that ministries to Chinese immigrants need to offer tangible and short-term outcomes. The respondents used words such as "benefits," "values," and "practicality" in answering the question, "What motivates you to make a decision?" One respondent, a Chinese teacher, put it tersely: "Chinese are practical people. They want to see and feel the message. The message needs to have benefits to 
encourage them to listen." The Chinese are concerned with the benefits or the practicality of the message for themselves or their children.

The themes of creation and covenant provide a frame to discuss the cultural theme of pragmatism. Scripture illustrates the grand narrative with symbols, parables, and animals within a variety of literary genres. Some of these literary genres include metaphors, similes, and personification. Bible writers used these literary forms to make abstract concepts relevant and practical to the human family.

God's immanence reveals His pragmatism. He is near to His creation. However, His creation is not part of Him. He transcends His creation, yet He is close at hand (Sire 1988). The practical manifestation of His immanence is seen in the things He has done, is doing, and will do for the human family.

He provided for the first family before He created them. He gave them the Sabbath to experience spiritual and physical rest. He also blessed them with marriage to illustrate their covenant relationship with Him.

God used various metaphors to illustrate the practical nature of the plan of salvation. In Genesis, God called Abraham to offer his son as a sacrifice. Abraham grasped the full import of the true cost of salvation to God. He would give His Son to reconcile the human family unto Himself. The nature of salvation is made clearer through the ceremonial system. The various symbols (the lamb, bread, light, and altar) all pointed to the nature of Jesus' death through which the Israelites grasped the real cost of sin. Paul contended, "Without the shedding of blood there is no forgiveness" (Heb 9:22, NIV).

The incarnation illustrated God's immanent nature. He incarnated Himself among His people. Paul expressed the concrete significance of the incarnation: "But when the 
fullness of the time had come, God sent forth His Son, born of a woman, born under the law, to redeem those who were under the law, so that we might receive the adoption as sons" (Gal 4:4-5, NKJV). These verses described Jesus' immanence. He became fully human to illustrate the practical nature of salvation to the human family.

Paul described the influence of Jesus' immanence on human responses and decisions in Phil 2:1-7. He bore the shame of the human family, and then the Father exalted Him and gave Him a name (honor) above all other names. Paul skillfully integrated the themes of shame, honor, and immanence to evoke a human response- "at the name of Jesus every knee should bow" (v. 10). The Scripture gives new meaning to Chinese pragmatism.

Chinese immigrants tend to respond to the immanent nature of Christ. However, the transcendent nature of Christ should precede His immanence in the process of contextualizing the Adventist message to Chinese immigrants. Who Christ is, precedes what He has done. The glory of Christ can help immigrants comprehend their brokenness. Furthermore, what Christ has done creates an indebtedness to Jesus. For example, Christ honored the human family with His glory and immanence. The human family is indebted to Christ. They reciprocate with their loyalty to Christ, love for Christ, and firm decision to follow Christ. The immanence of God gives new meaning to Chinese immigrant pragmatism. Scripture interprets pragmatism to mean God's presence through the Holy Spirit to help families comprehend spiritual truth in practical and culturally relevant ways. The Holy Spirit teaches contextualizers how to use illustrations, idioms, symbols, and stories to present the Adventist message to Chinese immigrants that is biblically based and culturally sensitive. This kind of pragmatism gives clarity to the 
message, credibility to contextualizers, and may result in immigrants' understanding the message as they contemplate their decisions for Christ.

\section{Summary}

A new model of contextualization emerged from the discussion of the findings. The discussion was framed within biblical and cultural themes. The cultural themes are relationship, identity, and fortune. The research data indicate that these are common cultural themes among Chinese immigrants in the Dominican Republic. In contrast, the biblical themes are covenant, creation, and eschatology. These themes tend to frame the Adventist message within the grand narrative of Scripture. The themes are interrelated.

The creation motif relates to fortune, covenant relates to relationship, and eschatology links with identity. The biblical themes help to clarify, reinforce, or change the meanings of cultural themes. Scripture determines the appropriateness of cultural themes for contextualization. On the other hand, cultural themes help to illustrate the meaning of Scripture from the perspectives of the hearers.

For instance, the covenant theme is appropriate for contextualizing the Adventist message concerning family, reconciliation, respect, ancestors, honor, and shame for Chinese immigrants. Similarly, the creation theme helps to contextualize the Adventist message for Chinese immigrants with reference to hard work, fortune, language, and family. Finally, the eschatology motif helps to frame the Adventist message regarding identity, honor, glory, and language. Some cultural themes, such as family, fit into all three biblical themes. An analysis of the family within the framework of creation, covenant, and eschatology helps Chinese immigrants to understand the grand narrative of the family in Scripture. 
The Chinese find meaning in wholeness. People from a collectivist culture tend to comprehend the sum of the parts, rather than the distinctiveness between parts. Chinese immigrants in Latin America may grasp the wholeness of the Adventist message within the framework of covenant/relationship, creation/fortune, and eschatology/identity. The biblical themes place the cultural themes within the grand narrative of Scripture. The three cultural themes are identifiable in both Scripture and the Chinese culture. The contextualizer should use biblical exegeses to interpret these cultural themes appropriately. At the same time, cultural contextualization can be used to contextualize the Adventist message appropriately for Chinese immigrants in Latin America. Biblical themes can be integrated with cultural themes to communicate a holistic, culturally sensitive, and biblically-based Adventist message.

The Adventist message needs to answer four important questions to evoke appropriate responses from Chinese immigrants. First, who is God? The Adventist message needs to give preeminence to God's transcendence. In one of his prayers, Nehemiah referred to God's transcendence: "LORD, the God of heaven, the great and awesome God" (Neh 1:5, NKJV). Daniel expressed similar honor to God: "O Lord, righteousness belongs to you" (Dan 9:7, NKJV). The Adventist message is first about a Person. In Exod 15:11, Moses said that God was "glorious in holiness, fearful in praises." The glory and holiness of God come first. They are the standard of measurement. Chinese immigrants need to be exposed to who God is. The glory of God allows them to see their shame. Paul described this shame as falling "short of the glory of God" (Rom 3:23, NKJV).

Second, what has God done for the human family? This question needs to be 
answered in the context of creation and covenant. The Adventist message answers this question by demonstrating that God is the Source of all wealth. He honors the human family with wealth so they might give Him glory. This concept of wholeness tends to relate to the Chinese cyclical worldview. For instance, all wealth comes from God and it is of His own that we return to Him (1 Chr 29:14).

God also reconciled the human family unto Himself. In 2 Cor 5:19, 21 (NIV) Paul said, "That God was reconciling the world to himself in Christ, not counting people's sins against them. And He has committed to us the message of reconciliation ... God made him who had no sin to be sin for us, so that in him we might become the righteousness of God." God took the initiative to bear the shame of the human family. In exchange, the human family could receive the righteousness of God. The principle of reciprocity is explicit in these verses. What God has done for human families invites a reciprocal response to Him.

This brings us to the third question. Why is Jesus important? The human family is indebted to Jesus. He bore our shame and gave us His glory. This principle of reciprocity is prevalent in Chinese culture. The Chinese are sensitive to acts of kindness. The Adventist message needs to answer the first, second, and third questions. These answers provide the catalyst for appropriate responses (appreciation of the gospel, acceptance of its message, and decisions for Christ) from Chinese immigrants.

Finally, how should Chinese immigrants respond? They may respond by demonstrating their love for God, loyalty to God, appreciation for the Adventist message, a firm decision to begin a journey toward Christ, and a readiness to witness for Christ.

Three variables influence Chinese responses toward Christ. The first is biblical 
exegeses of cultural themes within the framework of creation, covenant, and eschatology. The second is a cultural contextualization that communicates the meaning of Scripture through appropriate cultural themes, such as relationship, identity, shame, honor, and fortune. The third is the methodology. Who is God? What has He done? Why is Jesus important? How should we respond? These variables tend to facilitate Chinese decision to begin their journey toward Christ.

Canary's and Spitzberg's (1987) conflict-competence-based theory influences the interrelations of the above variables. The contextualizer (agent) who uses integrative dialogue, biblical exegesis, and cultural contextualization to communicate the Adventist message in order to answer these four basic questions will be perceived as competent. Such perceptions of competence tend to promote trust, intimacy, and relational satisfaction between Chinese immigrants and the Adventist Church leaders in Latin America.

This new model of contextualization could give Adventist leaders relevant competences to contextualize the gospel to Chinese immigrants in the Dominican Republic and other countries in Latin America. I made fourteen recommendations to church leaders about how to implement this model of contextualization to facilitate relational satisfaction with Chinese immigrants and to help them make decisions to begin their journey toward Christ and His Church. 


\section{CHAPTER 6}

\section{RECOMMENDATIONS FOR INSTITUTIONS AND \\ SUGGESTIONS FOR FUTURE RESEARCH}

\section{Conclusions}

The field research and literature review revealed that there are differences in worldview between Hispanics and Chinese immigrants in the Dominican Republic. Those differences impede the rate at which Adventist church leaders are able to evangelize Chinese immigrants in that country. The Adventist traditional model of evangelizing Hispanics seems to be incongruent with the Chinese view of reality. The field research of this study indicates that a relevant model of evangelizing Chinese immigrants in the Dominican Republic should synchronize with their needs (e.g., language learning, orientation to local culture, and educational opportunities for their children, etc.), values, cognitive patterns, first or second language, and pragmatism. The traditional Adventist model of evangelization ignores those issues Chinese immigrants consider relevant to them.

This study suggests a biblically faithful and culturally sensitive model of contextualization. It synchronizes with the needs, cognitive patterns, and relevant values of Chinese immigrants. This model has the potential to foster relational satisfaction between Chinese immigrants' and the gospel to effect conversion to Christ. This model of contextualization also integrates biblical themes with cultural themes to give new meanings to the issues that concern Chinese immigrants. 
The research questions examined those issues in order to gain insights into how to present the gospel in more relevant ways to Chinese immigrants. The first question sought to determine factors that influence Chinese immigrants' appreciation and decision to begin their journey toward Christ. The second question examined relevant values that facilitate a Chinese understanding of the gospel. How to facilitate such understandings that may begin a steady journey toward Christ is the focus of question three.

Semi-structured interviews and participant observation provided answers to the research questions. These methods allowed me to listen, record, and observe Chinese immigrants' views of reality. Reoccurring themes, discrepancies, and nuances emerged from analysis of the data. The first cycle of analysis yielded approximately twenty-five themes. In the second cycle of analysis, sixteen themes emerged. The final analysis generated eight themes. These eight themes reflect the worldview of Chinese immigrants in the Dominican Republic. The themes or findings include cognitive crisis, hard work, respect, harmony, dual identity, storytelling, language, and pragmatism. In addition, the literature confirmed the validity and reliability of the findings. For instance, chapter 4 of the dissertation indicates how relevant literature validated the findings.

In chapter 5, I discussed the findings with a view to suggest a model of contextualization that addresses the needs, values, and cognitive processes of Chinese immigrants in their journey toward Christ and the Church. Based on Wu's (2015) hermeneutic theory of contextualization, the findings are integrated with biblical themes to determine the theological significance of each finding.

Biblical and cultural themes are integrated to develop a model of contextualization. For instance, the creation motif frames Chinese cultural themes of 
fortune, pragmatism, and hard work. This framework indicates these cultural themes are gifts from God, who honors us with these gifts. In addition, Chinese cultural themes of harmony and respect are framed within the covenant motif. Within this framework, relationship reflects God's faithfulness to all peoples and their loyalty to Him. Human relationships find their meaning in the faithfulness of God to us. Such faithfulness inspires love and honor for God. Honor rather than obligation should govern relationships among Chinese immigrants.

Finally, the issues of language and identity fit into an eschatological framework. The Bible tends to associate language and identify with mission expansion. For instance, Genesis 11 and Acts 2 illustrate the influence of languages on the global expansion of the gospel to all people groups. People appreciate hearing the gospel in their heart language. Language is connected to the experiences, values, and peoples' view of reality, so hearing the biblical in one's own language adds interest and value. Such communication fosters relational satisfaction in the process of contextualizing the gospel.

The Bible also implies that persons with dual identity have missional significant. They tend to live in anticipation of returning to their home countries, while appreciating the culture, values, and languages of their host countries. Many Bible characters, such as, Daniel, Joseph, Esther, Ruth, and others illustrate the missional significance of dual identity. The missional significant relates to a Messiah who took unto Himself dual identify to give glory to His Father and honor to humanity. The Messiah gives a new identity to all people who accept His gift of honor-salvation. They are citizens of their home countries or host countries but they also become citizens of the Messiah's eternal kingdom. 
The biblical themes clarify, reinforce, or change the meanings of cultural themes. On the other hand, cultural themes help to illustrate the meaning of Scripture from the perspective of Chinese immigrants' needs, values, and cognitive processes.

This model of contextualization fosters relational satisfaction. Canary's and Spitzberg's (1987) Conflict-Competence-based Theory explains how a model of contextualization can foster relational satisfaction. By integrating biblical themes (creation, covenant, and eschatology) with cultural themes (relationship, identify, and handwork) this model of contextualization promotes integrative dialogue that is culturally appropriate and biblically faithful. Chinese immigrants perceive persons who use integrative dialogue as competent and sensitive to their needs, values, and cognitive processes. This perception of competence engenders trust, intimacy, and relational satisfaction between Chinese immigrants and the contextualizers.

Integrative dialogue makes an integrative model of contextualization relevant to Chinese immigrants. A model without integrative dialogue tends to be abstract and disconnected from the personal needs and struggles of Chinese immigrants; however, when integrative dialogue is used to demonstrate the contextualizers' competence, a culture of trust, intimacy, and relational satisfaction make the contextualization of the gospel culturally relevant and biblically faithful to Chinese immigrants in Latin America.

\section{Recommendations for Institutions}

In this research, I provided answers to three research questions. The answers emerged from an analysis of data gathered from interviews, participant observations, review of the literature, and discussion of the findings. Based on the apparent validity of these answers as outlined in chapters 4 and 5, I make the following recommendations for 
implementation by various levels of the Seventh-day Adventist Church in the InterAmerican Division.

1. Church leaders should frame their message to Chinese immigrants who are experiencing crises by integrating the biblical themes of creation/covenant/eschatology with cultural themes of honor, shame, and relationship to make their message biblically authentic and culturally sensitive to Chinese immigrants.

2. Mission leaders should be equipped to manage the process of crisis resolution. James Loder's predictable theory explains the process of crisis resolution (Wright and Kuentzel 2004). The process includes cognitive dissonance, interlude struggle, insights, release or redirection, and verification. The research data and Scripture suggest that crisis events create a need for cognitive equilibrium. This need is satisfied through human supports, new insights, and renewal of one's relationship with God and family members. God appears to allow or create a crisis in the minds of Chinese immigrants to reconcile them unto Himself and give His church opportunities for ministry.

3. Adventist leaders should convene social events, business seminars, and joint business ventures to reinterpret the meaning of work to Chinese immigrants. God honors families through work so that they may return glory and honor to Him. He is the Source of their protection, honor, family wellness, and a better life. He is the Source of all the honors that come from work. The creation theme puts the Chinese notion of "hard work" into its proper perspective.

4. Adventist leaders should also convene culturally appropriate filial piety seminars 
for Chinese parents to discuss parent-child obligations. Leaders may frame the discussion within the biblical motif of covenant to reinterpret the meaning of filial piety. All families owe their respect first to God. The child's respect for his/her parent come from their respect for God. God gave the child honor, face, and dignity. The child shares this honor with his parents. Respect flows out a covenant relationship. God's faithfulness to families evokes respect and honor from each family member. The child's first obligation is to God. It is a response of love for God. God expects this love from the child; however, He does not demand it. The Adventist message in a covenant-father-child relationship may resonate with Chinese families. This contextualizes filial piety to Chinese immigrants in ways that are biblically relevant and culturally sensitive.

5. Church leaders should use drama and storytelling to communicate a biblical view of harmony to Chinese immigrants. For instance, a creation-covenanteschatological paradigm can reinterpret the Chinese immigrants' view of harmony. The Chinese tend to view harmony as a personal obligation to avoid shame. Harmony in the family, with locals, and with nature bring honor to the Chinese. However, the biblical paradigm of harmony indicates that it has its origin in the Trinity. Harmony in families is a reflection of harmony in the Trinity. This means that harmony in the family brings honor to God.

6. Church leaders should use the biblical theme of eschatology to give new meaning to the Chinese value of dual identity. This biblical framework will give new meaning to dual identity. At conversion, immigrants become members of the body of Christ. Paul refers to this new identity as being "fellow citizens with 
God's people and also members of his household" (Eph 2:19). This is a new dual identity. By faith in Christ, Chinese immigrants belong to a new family and the coming kingdom. Chinese immigrants are likely to respond positively to this new meaning of dual identity.

7. Mission leaders should develop a new policy to clarify their motive for social ministries. The goal should be to guide church leaders in developing a new culture of giving glory to God through various social ministries.

8. Chinese missionaries tend to view Chinese immigrants' social needs as a starting point to begin relationships. Others view social needs as opportunities to increase Chinese immigrants' receptivity to the gospel. These views are partially true; however, the Scripture suggests a more noble rational for social ministries. God is gloried through social ministries. He honors immigrants by removing their shame and brokenness. Immigrants may respond by giving glory to God. It appears that doers and recipients of social ministries need to clarify their motives for engaging in such ministries.

9. Mission leaders should use storytelling to communicate a holistic view of the gospel to Chinese immigrants. This method facilitates an explanation of who God is, what he has done, why Jesus is important, and how Chinese immigrants may respond to Him. For instance, Nehemiah used the story method to explain who God is (9:5), what He had done (vv. 6-15, 21-26), why God is important (vv. 27, 33), and how people should respond (v. 38). By telling the story in this sequence, Chinese the immigrants may appreciate the holistic nature of the gospel and made decisions based on their indebtedness to God 
10. Mission leaders should communicate the Adventist message to Chinese immigrants in their mother tongue. Immigrants respond more favorably to communication in their heart language. Mission leaders should attempt to dialogue with immigrants in the language that is appropriate to their culture.

11. Mission leaders should use drama, storytelling, and social activities to explain to Chinese immigrants their indebtedness to Christ. Who Christ is precedes what $\mathrm{He}$ has done. The glory of Christ helps immigrants become aware of their brokenness. Conversely, what Christ has done awakens the human response in immigrants. The immigrants could also base their response on the principle of reciprocity as immigrants acknowledge their indebtedness to Christ. They reciprocate with their loyalty and love for Christ and make a firm decision to follow Him.

12. Mission leaders should invite Chinese missionaries or Chinese pastors to work for three years or more in countries with large Chinese communities. The InterAmerican Division should initiate the recruiting and funding of Chinese missionaries in its territory. Chinese missionaries will have a dual role: first, to evangelize Chinese immigrants in their mother tongue, and second, to mentor a cadre of youth in appropriate cross-cultural mission strategies to Chinese immigrants.

13. The administrators should establish Chinese Cultural Centers to facilitate the Chinese missionaries' ministries to Chinese immigrants in their country. The ministries should include Chinese cultural activities, language learning, table tennis (ping-pong), Bible studies, and a library with Chinese literature and Bibles 
in the Cantonese and Mandarin languages. The Chinese Cultural Centers should also be places of training for young people who are involved in ministries to Chinese immigrants.

14. Church leaders should select persons with dual identity (e.g., Spanish/Chinese) who will learn the Mandarin or Cantonese languages to provide support and leadership in church planting projects among Chinese immigrants.

15. Church leaders should select Chinese converts to attend Adventist universities to become pastors of the emerging Chinese churches.

16. Adventist universities should offer continuing education credits in Chinese history, cultures, and languages (Mandarin and Cantonese) to conference and union presidents with large Chinese populations in their constituencies. The courses will give church leaders a greater appreciation of the history, cultures, and languages of Chinese immigrants.

17. Church leaders in the Dominican Republic should send some of their church planters and pastors to the China Theological Seminary for two years to learn and speak Mandarin. These workers will then return to the Dominican Republic to plant and lead new Chinese congregations.

18. Chinese missionaries invited to work in the Inter American Division should be given three months to learn the local language of their host countries before they begin their ministry to Chinese immigrants.

\section{Suggestions for Future Research}

Many immigrants experience severe hardships in repaying relatives for the cost of sponsorship to migrate to a new country. The issue of obligation is pervasive in Chinese 
culture. Future research may want to investigate the effects of social and economic obligations on Chinese immigrants in Latin America.

Local people tend to view Chinese immigrants with suspicion. As a result, firstgeneration Chinese immigrants tend to work for long hours to gain the respect and honor of the local people. Future research may want to investigate the missiological implications of China's global economic influence on Chinese immigrants in Latin American countries. 
APPENDIX A

INTERVIEW QUESTIONS 
English

\section{Category 1-Church Leaders of other Denominations Involved in Reaching Out to Chinese}

1. What helps Chinese listen to your message?

2. What are times Chinese seem receptive to your message?

3. Where have you observed Chinese giving favorable responses to your message?

4. What are some examples of Chinese favorable responses to your message?

5. What do Chinese appreciate about your message?

6. What do Chinese say about your message?

\section{Category 2-Chinese Immigrants within the ages 18-65}

1. In Duarte, what are some of the important values of Chinese people?

2. What are the meanings of each of these values?

3. What symbols communicate Chinese beliefs and values in Duarte?

4. What is the meaning of each symbol to migrant Chinese people in Duarte?

5. What are some favorite proverbs or sayings of Chinese people in Duarte?

6. What is the meaning of each proverb or saying?

7. What Chinese rituals are common among Chinese in Duarte?

8. What does each ritual mean to Chinese people in Duarte?

9. What does the death of a loved one mean to Chinese people in Duarte?

\section{Category 3-Chinese Adventists in the Dominican Republic}

1. As a Chinese Adventist, What does being an Adventist mean to you?

2. What helped you understanding the Adventist holistic message?

3. What do you like and appreciate about the Adventist message?

4. What makes the Adventist message relevant to your culture?

5. What helped you in making a decision to follow Christ?

6. Are there linkages between the Adventist holistic message and Chinese culture? If yes, what are those linkages?

\section{Category 4-Adventist Hispanic Leaders}

1. What are some of the barriers to communicating the gospel to the Chinese?

2. What causes Hispanics to respond to the gospel in the Dominican Republic?

3. How can the gospel be presented appropriately to the Chinese in the Dominican Republic?

4. What changes would you make in how Adventists present the Gospel to Chinese?

\section{Follow-up Questions}

Any further questions arising from the above initial questions and my observation of public behavior at funerals during burial ceremonies will strictly remain within the framework of the research approval granted by the IRB. 


\section{Mandarin Chinese}

(这六个子问题旨在收集数据来为问题\# 1 提供答案, 这些子问题要求向Duarte参与分享福音的六 个宗派领袖提问，这六个问题探讨促成华人对福音的回应）。

1.是什么有利于华人听你的信息?

2.在什么时间华人会接受你的信息?

3.你观察到华人在哪方面对你的信息给予有利的回应?

4.举例说明华人对信息的有利回应?

5.华人对你的信息中欣赏的方面?

6.华人对你的信息有什么看法?

（这些问题试图发现中国文化中可能用来说明复临信息的救赎类比。）

1. 在杜阿尔特, 华人的价值观是什么?

2.每个这些价值观有什么意义?

3.什么样的符号传达华人的信仰和价值观?

4. 每个符号对华移民的含义是什么?

5.华人最喜欢的浐语或古言是什么?

6. 每一句谛语含义是什么?

7.华人的仪式有哪些?

8.每种仪式对华人来说意味着什么?

9.心爱的人死亡对华人意味着什么?

这些子问题要求向六位华复临信徒成员提问。而且, 从问题\# 1 收集的数据可能与问题\# 3 的目标相 关）。

1. 作为华人复临信徒, 这对你意味着什么?

2. 什么能帮助你理解复临信徒的整体信息?

3.你对“复临信息”有什么喜爱和欣赏?

4.什么使复临信息与你的文化有关?

5.什么帮助你决定跟随基督?

6. 复临信徒的整体信息和中国文化之间有联系吗? 如果是的话, 这些联系是什么? 
APPENDIX B

GOVERNMENT INFORMATION FORM 


\begin{tabular}{|c|c|c|c|}
\hline \multicolumn{4}{|c|}{ Para ser Llenado por la Organización Llamante } \\
\hline $\begin{array}{l}\text { Nombre de la } \\
\text { Organización }\end{array}$ & \multicolumn{3}{|c|}{$\begin{array}{l}\text { UNION DE HONDURAS DE LOS ADVENTISTAS DEL } \\
\text { SEPTIMO DIA }\end{array}$} \\
\hline $\begin{array}{l}\text { Dirección de la } \\
\text { Organización }\end{array}$ & $\begin{array}{l}\text { Ciudad } \\
\text { Residencial Puerta } \\
\text { del Sol, Tegucigalpa }\end{array}$ & \begin{tabular}{|l|} 
Estado \\
Francisco \\
Morazán \\
\end{tabular} & $\begin{array}{l}\text { Pais } \\
\text { Honduras }\end{array}$ \\
\hline $\begin{array}{l}\text { ¿Dónde trabajarán } \\
\text { los misioneros? }\end{array}$ & Tegucigalpa & $\begin{array}{l}\text { Francisco } \\
\text { Morazán }\end{array}$ & Honduras \\
\hline \multicolumn{3}{|c|}{$\begin{array}{l}\text { ¿Cuál es el salario mensual básico aproximado para el misionero } \\
\text { en USD sin ninguna asignación? }\end{array}$} & $\begin{array}{l}\text { \$----- } \\
\text { 1. Las leyes de } \\
\text { Honduras requieren } \\
\text { el pago de } 14 \text { salarios } \\
\text { al año. 2. Los salarios } \\
\text { se pagarán en } \\
\text { moneda local y no } \\
\text { seran dolarizados. } \\
\text { Este cálculo se hizo } \\
\text { al tipo de cambio del } \\
\text { día. }\end{array}$ \\
\hline \multicolumn{4}{|c|}{ ¿Cuál es el factor salarial? } \\
\hline \multirow{2}{*}{\multicolumn{3}{|c|}{$\begin{array}{l}\text { ¿Se proporciona seguro médico? (Si no) } \\
\text { En caso afirmativo, ¿quién es responsable de pagar la prima? }\end{array}$}} & $\mathrm{Si}$ \\
\hline & & & $\begin{array}{l}\text { Unión de } \\
\text { Honduras }\end{array}$ \\
\hline \multicolumn{3}{|c|}{ ¿Se proporciona vivienda? (Si no) } & $\mathrm{Si}$ \\
\hline \multicolumn{3}{|c|}{ En caso afirmativo, ¿quién es responsable de pagar el alquiler? } & $\begin{array}{l}\text { Unión de } \\
\text { Honduras }\end{array}$ \\
\hline \multicolumn{3}{|c|}{$\begin{array}{l}\text { ¿Quién es responsable de pagar los servicios públicos } \\
\text { (electricidad, agua, etc.)? }\end{array}$} & \begin{tabular}{|l|} 
El misionero \\
pagará sus \\
servicios públicos
\end{tabular} \\
\hline \multicolumn{3}{|c|}{$\begin{array}{l}\text { ¿Se proporciona subsidio de transporte? (Si no) } \\
\text { En caso afirmativo, ¿cuánto por mes en USD? }\end{array}$} & $\begin{array}{l}\mathrm{Si} \\
\$----\end{array}$ \\
\hline
\end{tabular}




\begin{tabular}{|c|c|c|c|}
\hline \multicolumn{4}{|c|}{ To be Filled in by the Calling Organization } \\
\hline \multicolumn{4}{|l|}{$\begin{array}{l}\text { Name of } \\
\text { organization }\end{array}$} \\
\hline Address of the & City & State & Country \\
\hline \multicolumn{4}{|l|}{$\begin{array}{l}\text { Where will the } \\
\text { missionaries } \\
\text { work? }\end{array}$} \\
\hline \multicolumn{4}{|c|}{$\begin{array}{l}\text { What is the approximate basic monthly salary for the } \\
\text { missionary couple in USD without any allowances? }\end{array}$} \\
\hline \multicolumn{4}{|c|}{ What is the wage factor? } \\
\hline \multicolumn{4}{|c|}{ Is health insurance provided? (Yes/No) } \\
\hline \multicolumn{4}{|c|}{ If yes, who is responsible for paying the premium? } \\
\hline \multicolumn{4}{|c|}{ Is housing provided? (Yes/No) } \\
\hline \multicolumn{4}{|c|}{ If yes, who is responsible for paying the rent? } \\
\hline \multicolumn{4}{|c|}{$\begin{array}{l}\text { Who is responsible for paying the utilities (electricity, water and } \\
\text { etc.)? }\end{array}$} \\
\hline \multicolumn{4}{|c|}{ Is transportation allowance provided? (Yes/No) } \\
\hline \multicolumn{4}{|c|}{ If yes, how much per month in USD? } \\
\hline \multirow{2}{*}{\multicolumn{4}{|c|}{$\begin{array}{l}\text { Is there a church school for the children (below the age of 18) } \\
\text { of the missionaries? } \\
\text { If yes, is tuition subsidy provided? }\end{array}$}} \\
\hline & & & \\
\hline \multirow{2}{*}{\multicolumn{3}{|c|}{$\begin{array}{l}\text { Are the missionaries going to work at an existing Chinese } \\
\text { Adventist church? (Yes/No) } \\
\text { If yes, how many members are there in the congregation? }\end{array}$}} & \\
\hline & & & \\
\hline
\end{tabular}


APPENDIX C

ANDREWS UNIVERSITY IRB APPROVAL 

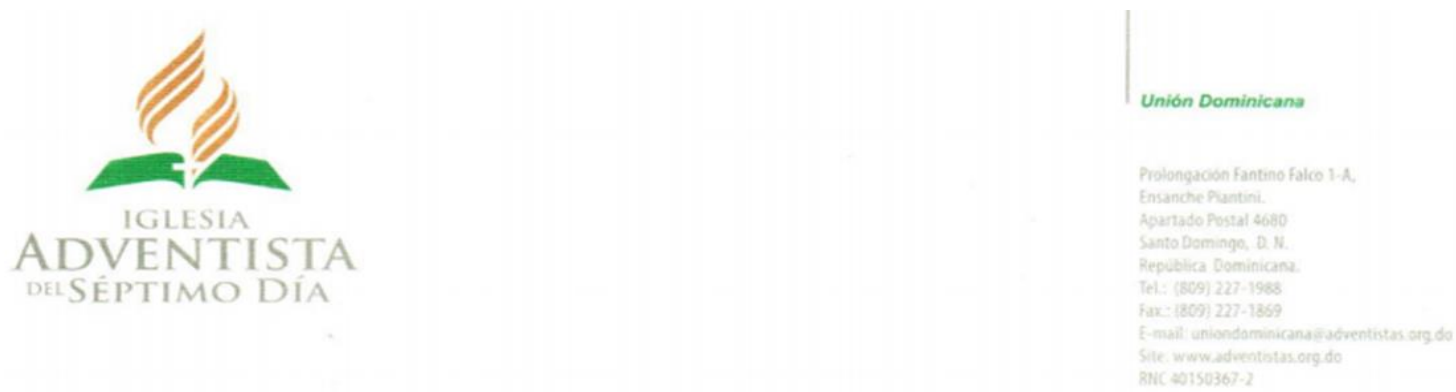

Santo Domingo, Dominican Republic.

October 30, 2017.-

\section{Institutional Review Board}

Andrews University

4150 Administrative Drive, Room 322

Berrien Springs, MI 49104-0355

Subject: Institutional Consent Letter

To Whom It May Concern:

The administration of the Dominican Union Conference of the Seventh-day Adventist Church writes to inform that Mr. Samuel Telemaque has been granted full permission to conduct his field research ("Towards a Theological and Missiological Model of Contextualization Among Chinese People in Duarte in Santo Domingo") in our territory towards the completion of his Doctor of Missiology degree at Andrews University.

Yours truly,

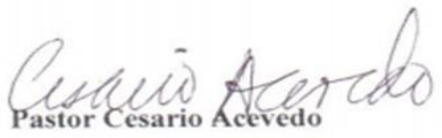

President of the Dominican Republic Union Conferentec.

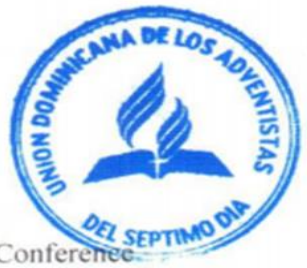

CC.: Mr. Samuel Telemaque 


\section{REFERENCE LIST}

Aragno, Anna and Peter. J. Schlachet. 1996. "Accessibility of Early Experience Through the Language of Origin: A Theoretical Integration." Psychoanalytic Psychology 13 , no. 1:23-34.

Bauer, Bruce L. 2005. "Avoiding Syncretism by Doing Critical Contextualization." Journal of Adventist Mission Studies 1, no. 2:18-33. https://digitalcommons .andrews.edu/jams/vol1/iss2/3/.

Bauer, Wolfgang. 1976. China and the Search for Happiness: Recurring Themes in Four Thousand Years of Chinese Cultural History. New York: Seabury Press.

Bevans, Stephen. 2002. Contextualization in World Mission: Models of Contextual Theology. Rev. and expanded ed. Maryknoll, NY: Orbis.

Bhaskar, Roy A. 2010. The Formation of Critical Realism: A Personal Perspective. New York: Routledge.

Bianchi, Suzanne M. 1984. "Children's Progress Through School: A Research Note." Sociology of Education 57, no. 3 (July): 184-92.

Bond, Michael H. 1992. Beyond the Chinese Face: Insights from Psychology. Hong Kong: Oxford University Press.

Burrus, Embry. 2013. “"Redemption-Acquisition': Marriage of Ruth as a Theological Commentary on Yahweh and Yahweh's People." Journal of Theological Interpretation 7, no. 2 (Fall): 257-73.

Canary, Daniel J., and Brian H. Spitzberg. 1987. "Appropriateness and Effectiveness Perceptions of Conflict Strategies.” Human Communication Research 14: 9-118. . 1989. "A Model of the Perceived Competence of Conflict Strategies." Human Communication Research 15, no. 4 (June): 630-649.

Checo, Jose C., and Mu-Kien Adriana Sang. 2009. Chinese Diaspora in the Dominican Republic. Accessed June 7, 2016. http://www.skyscrapercity.com/ showthread.php.

Chen, Edith Wen-Chu. 2008. "“You Are Like Us, You Eat Plátanos': Chinese Dominicans, Race, Ethnicity, and Identity." Afro-Hispanic Review 2, no. 1:23-40. 
Chinese Immigration to the United States. Accessed December 19, 2018. https://www .oakton .edu/ billtong/chinaclass/History/Chinese_Immigration.htm.

Ching, Julia. 1999. Chinese Religions. Maryknoll, NY: Orbis.

Chow, Christie Chui-Shan. 2013. "Guanxi and the Gospel: Conversion to Seventh-day Adventism in Contemporary China." Social Science and Mission 26:167-98.

Creswell, John W. 2013. Research Design. Los Angeles, CA: Sage.

Cronin, Mary M., and William E. Huntzicker. 2012. "Popular Chinese Image and the Coming Man of 1870.” Journalism History 38, no. 2:86-97.

de Bary, Theodore W., ed. 1999. Sources of Chinese Tradition. New York: Columbia University Press.

Doss, Gorden R. 2015. "Faithful Contextualization: Crossing Boundaries of Culture with the Eternal Gospel." Faculty Publications 29. https://digitalcommons.andrews .edu/cgi/viewcontent.cgi?article=1031\&context=world-mission-pubs.

Ellis, Robert E. 2012. "The Expanding Chinese Footprint in Latin America: New Challenges for China, and Dilemmas for the U.S." Asie.Visions 49. Paris, France: Institute Français des Relations Internationales.

Elwell, Walter.1996. Evangelical Dictionary of Biblical Theology. Grand Rapids, MI: Baker.

Fetterman, David F. 1998. Ethnography. 2nd ed. London, UK: Sage.

Fillmore, Wong L. 1991. "When Learning a Second Language Means Losing the First." Early Childhood Research Quarterly 6, no. 3 (September): 323-46.

Flemming, Dean. 2005. Contextualization in the New Testament. Downers Grove, IL: InterVarsity Press.

Gao, Ge, and Stella Ting-Toomey. 1998. Communicating Effectively with the Chinese. Thousand Oaks, CA: Sage.

Gudykunst, William B. 2003. Cross-cultural and Intercultural Communication. Thousand Oaks, CA: Sage.

Hall, Edward T. 1976. Beyond Culture. Garden City, NY: Doubleday. 1983. The Dance of Life. New York: Doubleday. 
Hesselgrave, David J. 1978. Communicating Christ Cross-Culturally. Grand Rapids, MI: Zondervan.

. 1984. "Contextualization and Revelational Epistemology." In Hermeneutic, Intimacy and the Bible, edited by Earl D. Radmacher and Robert D. Preus, 693738. Grand Rapids, MI: Zondervan.

. 1991. Communicating Christ Cross Culturally. 2nd ed. Grand Rapids, MI: Zondervan.

Hesselgrave, David, and Edward Rommen. 2000. Contextualization: Meanings, Methods and Model. Pasadena, CA: William Carey Library.

Hiebert, Paul. 1984a. "Contextualization and Revelational Epistemology." In Hermeneutics, Intimacy and the Bible, edited by Earl D. Radmacher and Robert D. Preus, 693-738. Grand Rapids, MI: Zondervan. . 1984b. "Critical Contextualization." Missiology 12, no. 3 (July): 287-96. . 2008. Transforming Worldviews: An Anthropological Understanding of How People Change. Grand Rapids, MI: Baker. . 2012. The Gospel in Human Contexts. Grand Rapids, MI: Baker.

Hiebert, Paul G., and Eloise Meneses M. 1995. Incarnational Ministry: Planting Churches in Band, Tribal, Peasant and Urban Societies. Grand Rapids, MI: Baker.

Hofstede, Geert. 1980. Culture's Consequences: International Differences in Work Related Values. Beverly Hills, CA: Sage.

Howard, David. 2001. Coloring the Nation: Race and Ethnicity in the Dominican Republic. Boulder, CO: Lynne Rienner.

Hsu, Francis L. K. 1981. Americans and Chinese: Passage to Differences. Honolulu: University of Hawaii Press.

Hui, Chen H., and Harry C. Triandis. 1986. "Individualism-Collectivism: A Study of Cross-Cultural Researchers." Journal of Cross-Cultural Psychology 17:225-248.

Ki-Kwan, Randy.1992 “A Cross-Cultural Study of the Collectivism and Individualism Paradigm: The Influence of Confucian Values on Conflict-Handling Behaviors of Male Graduate Business Students in Hong Kong and the United States." PhD diss., Andrews University. 
Knight, George R. 2000. A Search for Identity: The Development of Seventh-day Adventist Beliefs. Hagerstown, MD: Review and Herald

Kraft, Charles H. 1996. Anthropology for Christian Witness. Maryknoll, NY: Orbis.

Kung, Hans, and Julia Ching. 1989. Christianity and Chinese Religions. New York: Doubleday.

LaFromboise, Teresa., Hardin L. K. Coleman, and Jennifer Gerton.1993. "Psychological Impact of Biculturalism: Evidence and Theory." Psychological Bulletin 114, no. 3 (November): 395-412.

Lakos, William. 2010. Chinese Ancestor Worship: A Practice and Ritual of Oriented Approach to Understanding Chinese Culture. Newcastle, UK: Cambridge Scholars.

Lau, Peter H.W., and Gregory Goswell. 2016. Unceasing Kindness: A Biblical Theology of Ruth. Downers Grove, IL: InterVarsity Press.

Legge, James, trans. 1861. The Chinese Classics. Vol. 1, Confucian Analects. London, UK: Trübner.

Li, Yuan. 2015. Dominican Republic, China Exchange, Trade and Investment. Santo Domingo, DR: GFDD-Funglobe.

Lundius, Jan, and Mats Lundahl. 2000. Peasants and Religion: A Socioeconomic Study of Dios Olivorio and the Palma Sola Movement in the Dominican Republic. London, UK: Routledge.

Mah, Yeow Beng. 2004. "Critical Contextualization of Chinese Folk Beliefs and Practices: Feng Shui as a Case Study.” DMin diss., Asbury Theological Seminary.

Misadi, John. "What Languages Are Spoken in The Dominican Republic?” World Atlas. Accessed March 2, 2020. https://www.worldatlas.com/articles/what-languagesare-spoken-in-the-dominican-republic.html.

Moreau, Scott. 2012. Contextualization in World Missions: Mapping and Assessing Evangelic Model. Grand Rapids, MI: Kregel.

Neil, Anderson and Goodwin. 1972. "Concise Dictionary of the Christian World Mission." Philippine Studies vol. 20, no. 2, 580

Neill, Stephen. 1964. A History of Christian Missions. New York: Penguin.

Newell, Marvin J. 2016. Crossing Cultures in Scripture: Biblical Principles for Mission Practice. Downers Grove, IL: InterVarsity Press. 
Ng Báez, Rosa. 2016. El Barrio Chino de Santo Domingo. Santo Domingo, DR: Diseno y Diagramacion.

Ng, Gan-Theow. 1991. "Religion, Culture, and Modernity: Some Missiological Implications of the Process of Secularization in East Asia." PhD diss., Andrews University.

Noss, David. 2003. A History of the World Religions. Upper Saddle River, NJ: Prentice Hall.

Plummer, Kenneth. 1983. Documents of Life: An Introduction to the Problems and Literature of a Humanistic Method. London, UK: Unwin Hyman.

Robb, D. John. 1994. Focus: The Power of People Group Thinking: A Practical Manual for Planning Effective Strategies to Reach the Unreached. 2nd ed. Monrovia, CA: MARC.

Rogers, Glenn. 2004. The Bible Culturally Speaking: Understanding the Role of Culture in the Production, Presentation and Interpretation of God's Word. Bedford, TX: Mission and Ministries Resources.

Rubin, Herbert J., and Irene S. Rubin. 2005. Qualitative Interviewing: The Art of Hearing the Data. London, UK: Sage.

Rumbaut, R. G. 1991. Migration, Adaptation, and Mental Health in Refugee Policy: Canada and United States. Edited by H. Adelman. Toronto: York Lanes Press.

Sauer, Erich. 1972. From Eternity to Eternity: An Outline of Divine Purposes. Grand Rapids, MI: Eerdmans.

Schreiter, Robert J. 1985. Contextualizing Local Theologies. London, UK: SCM Press.

Schwisow, Edwin A. 2010. Seventh-day Adventists 28 Fundamental Beliefs. Gladstone, OR: Jack Sequeira Ministries.

Silvestre, Teofilo. 2017. The Secretariat of the Dominican Republic Union Conference. Santo Domingo, DR: The Office of the Secretariat.

Sire, James W. 1988. The Universe Next Door. Downers Grove, IL: InterVarsity Press.

Skeldon, Ronald. 1996. "Migration from China." Journal of International Affairs 49, no. 2 (Winter): 434-55.

South, Scott, Kyle Crowder, and Jeremy Pais. 2008. "Inter-Neighborhood Migration and Spatial Assimilation in a Multi-Ethnic World: Comparing Latinos, Blacks, and Anglos." Social Forces 87, no. 1:415-43. 
Thomassen, B. 2009. “The Uses and Meanings of Liminality.” International Political Anthropology 2, no. 1:5-27.

Thompson, Marianne Meye. 1992. "John Gospel of" Dictionary of Jesus and the Gospel. Edited by Joel B. Green, Scot Mc Knight, and Howard Marshall. Downers Grove IL: InterVarsity Press. 368.

Ting-Toomey, Stella. 1999. Communicating across Cultures. New York: Guilford Press. . 2005. "The Matrix of Face: An Updated Face-Negotiation Theory." In Theorizing About Intercultural Communication, edited by W. B. Gudykunst, 7192. Thousand Oaks, CA: Sage.

Ting-Toomey, S., and J. Oetzel. 2001. Managing Intercultural Conflict Effectively. Thousand Oaks, CA: Sage.

Tippet, Allan. 1987. Introduction to Missiology. Pasadena, CA: William Carey.

Toppelberg, Claudio O., and Brian A. Collins. 2010. "Language, Culture, and Adaptation in Immigrant Children." Child and Adolescent Psychiatric Clinics of North America 19, no. 4 (October): 697-717.

Turits, Richard Lee. 2003. Foundations of Despotism: Peasants, the Trujillo Regime, and Modernity in Dominican History. Stanford, CA: Stanford University Press.

Turner, Victor. 1967. The Forest of Symbols: Aspects of Ndembu Ritual. Ithaca, NY: Cornell University Press.

Van Gennep, Arnold. 1960. The Rite of Passage. Chicago, IL: University of Chicago Press.

Vivian, Louie. 2006. "Growing Up Ethnic in Transnational Worlds: Identities Among Second-Generation Chinese and Dominicans." Global Studies in Culture and Power 13, no. 3:363-94.

Wallace, Anthony. 1956. "Revitalization Movements." American Anthropology 58, no. 2 (April): 264-81.

Wan, Enoch. 2003a. "Jesus Christ for the Chinese: A Contextual Reflection." Global Missiology 1, no. 1 (October): 1-12. http://ojs.globalmissiology.org. . 2003b. "Practical Contextualization: A Case Study of Evangelizing Contemporary Chinese." Global Missiology 1, no. 1 (October): 1-9. http://ojs.globalmissiology.org. 
, ed. 2011. Diaspora Missiology. Theory, Methodology and Practice. Portland, OR: Institute Diaspora Studies.

White, Ellen G. 1905. The Ministry of Healing. Mountain View, CA: Pacific Press. . 1846. Steps to Christ. Mountain View, CA: Pacific Press. . 1990. The Desire of Ages. Silver Spring, MD. Better Living.

Wikipedia. 2019. "Chinese Community in Latin America." November 11. http://en.wikipedia.org/Chinese_community_in_Latin_America.

Wright, Arthur F. 1965. Buddhism in Chinese History. Stanford, CA: Stanford University Press.

Wright, Dana R., and John D. Kuentzel, eds. 2004. Redemptive Transformation in Practical Theology: Essays in Honor of James E. Loder Jr. Grand Rapids, MI: Eerdmans. polanyisociety.org.

Wu, Jackson. 2015. One Gospel for All Nations: A Practical Approach to Biblical Contextualization. Pasadena, CA: William Carey Library.

Xiang, Biao. 2006. "A New Mobility Regime in the Making: What Does a Mobile China Mean to the World?" Paper presented at Development Assistance and Emerging Countries Workshop, Seminaire Regulier, 1-19.

Xie, Xiaolin, Yan Xia, and Zhi Zhou. 2014. Strengths and Challenges in Chinese Immigrant Families. DeKalb, IL: Northern Illinois University.

Yao, Xinzhong. 2000. An Introduction to Confucianism. New York: Cambridge University Press.

Ybarrola, Steven. 2012. "Anthropology, Diasporas, and Mission." Mission Studies 29, no. 1 (January): 79-94.

Yeh, Kuang-Hui, and Olwen Bedford. 2004. "Filial Belief and Parent-Child Conflict." International Journal of Psychology 39, no. 2 (April): 132-144. https://www.researchgate.net.

Zhang, Q. 2015. "A U.S.-China Investigation of the Effects of Perceived Partner Conflict Styles on Outcome Satisfaction: The Mediating Role of Perceived Partner Conflict Competence." Communication Quarterly 63, no.1:1-22.

Zinzius, B. 2005. Chinese America, Stereotype and Reality: History, Present, and Future of the Chinese Americans. New York: Peter Long. 
VITA 
VITA

Name: $\quad$ Samuel Telemaque

Birthdate: April 5

Wife: Elvetha Gloria Derrick Telemaque

\section{Education:}

2015-2020

Doctor in Missiology (Emphasis: Diaspora Missiology), Andrews University Seventh-day Adventist Theological Seminary

2002-2006

Masters in Inter Cultural Studies (Emphasis in Leadership) Fuller Theological Seminary

1993-1997 Masters in Religion, Andrews University Seventh-day Adventist Theological Seminary

1981-1985 BA in Theology, Caribbean Union College

\section{Ordained:}

1991

East Caribbean Conference

\section{Experience:}

$2015-2020$

Director of Sabbath School, Inter-American Division

2010-2020

Director of Special Needs Ministries, Inter-American Division

2010-2020

Director of Adventist Mission, Inter-American Division

2010-2015

Associate Director of Sabbath School and Personal Ministries Director, Inter American Division.

$1996-2010$

Director of Personal Ministries/Sabbath School, Caribbean Union Conference

$1991-1996$

Director Stewardship/Personal Ministries/Sabbath School, East Caribbean Union Conference

$1987-1991$

District Pastor, East Caribbean Conference

$1985-1987$

Associate Publishing Director, East Caribbean Conference 